\title{
The Discursive Enactment of Edward Snowden
}

\author{
By
}

Alessandro R. Marcon

A thesis submitted to the Faculty of Graduate and Postdoctoral Affairs in partial fulfillment of the requirements for the degree of

Master of Arts in Applied Linguistics and Discourse Studies with a Specialization in Digital Humanities

Carleton University

Ottawa, Ontario

(C) 2015, Alessandro R. Marcon 


\begin{abstract}
Edward Snowden's whistleblowing on the National Security Agency (NSA) has resulted in widespread discursive battles on popular and social media. The purpose of this study was to theoretically and empirically explore how various participants discursively engaged the debate with digital media. It sought to identify and analyze the discursive forces at play, investigating how 'storylines' and 'antagonisms' are enacted, reinforced, and contested. Performing a type of 'online ethnography', the digital realms were analyzed on a macro-level before 22 articles were selected for in-depth analysis. Additionally, a corpus of nearly 40,000 YouTube comments was built then analyzed, and five interviews with Snowden were taken into consideration. Analysis reveals how and why the terms 'hero', 'patriot', 'traitor' and 'villain' come to be used for many whistleblowers, including Snowden. Furthermore, the study offers explanations for the roles that these 'terms' played when taken up and resisted by diverse participants.
\end{abstract}




\section{Acknowledgements}

To Mom, Dad, and Heidi, thanks for all the unwavering love and support. I love you.

To my supervisors, Graham and Jaffer, thanks for guiding me towards the bastion of structure that these ideas needed to be housed in. Your patience, support and enthusiasm for this project have been invaluable.

Additional thanks to all my professors at Carleton who contributed to this project directly or indirectly, in particular: Natasha Artemeva, Marc Furstenau, and Richard Darville.

A big shout-out to all my friends and classmates especially: Anne, Plooch, Jordon, Sara Doody, Janna 'bud' PK, and Mike Ham. Your support and friendship, especially your patient and benevolent toleration of my rambling-maelstroms has been greatly appreciated.

A special thanks goes out to Philip 'der Zauberer' Klostermann for collaborating in the construction of the corpus. This project is indebted to your creative and hard work. 


\section{Table of Contents}

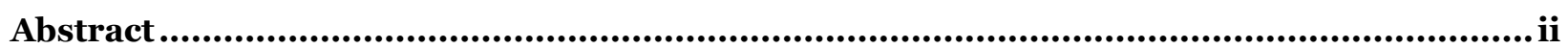

Acknowledgements .................................................................................................ii

Table of Contents......................................................................................................... iv

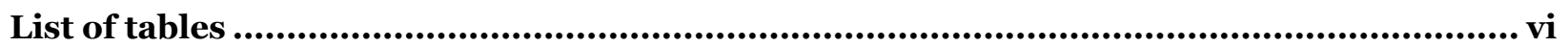

Chapter 1: Introduction .................................................................................................. 7

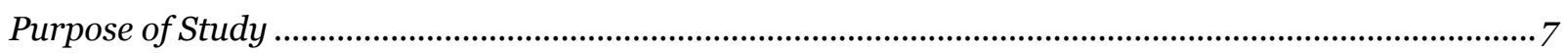

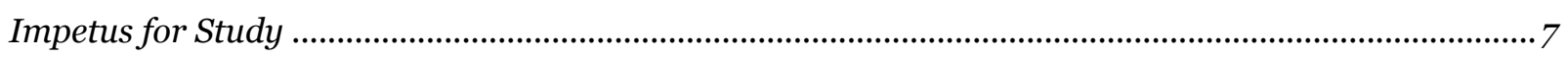

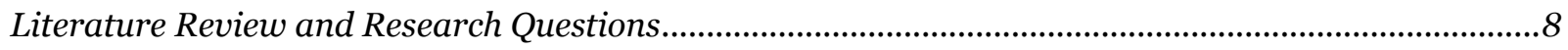

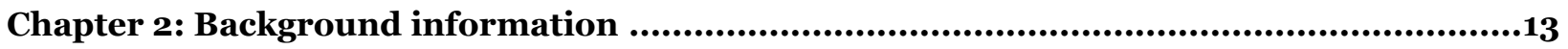

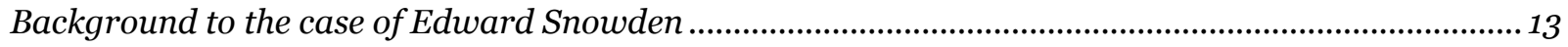

The Case of Daniel Ellsberg ..................................................................................................................... 13

The Case of Thomas Drake/ William Binney...................................................................................... 15

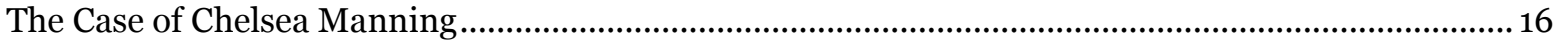

The Whistleblowing Case of Edward Snowden .................................................................................... 17

Chapter 3: Theoretical Perspectives ............................................................................ 23

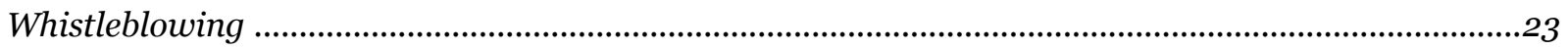

Heroes, Villains, Traitors and Patriots as Socio-Discursive Constructs .................................................26

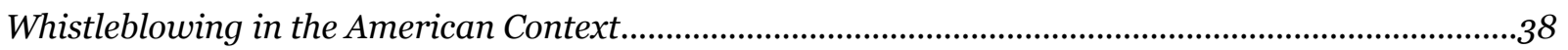

Conceptions of Discourse ........................................................................................................................4

Chapter 4: Method....................................................................................................... 55

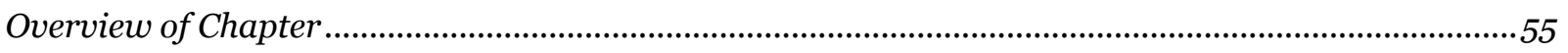

Theoretical Underpinning of Methodological Practices ..............................................................................5

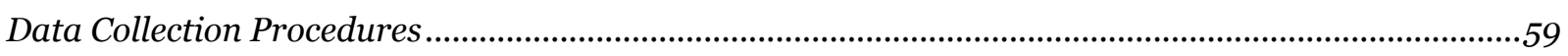

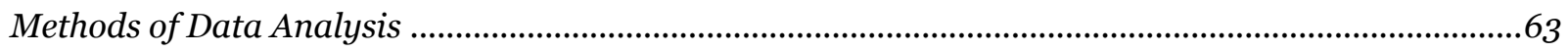

Chapter 5: Findings, Analysis and Discussion ..........................................................65 65

Chapter Road Map ........................................................................................................................65

Macro-level Findings: Mapping out the Discursive Spheres ...............................................................66

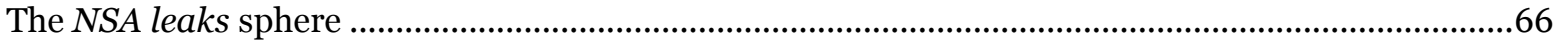

The Edward Snowden Sphere.........................................................................................................69

General Summary of the two spheres ..................................................................................................... 71

Findings and Analysis of the Spheres....................................................................................................

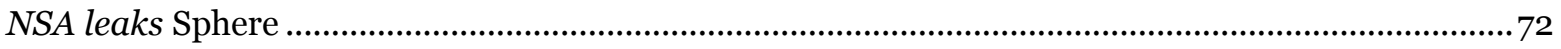

Analysis of the 'Snowden effect' storyline .............................................................................................. 75 
Edward Snowden Sphere .76

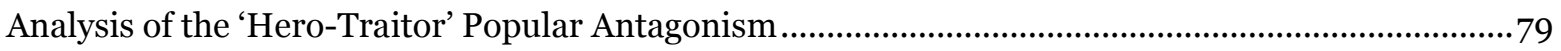

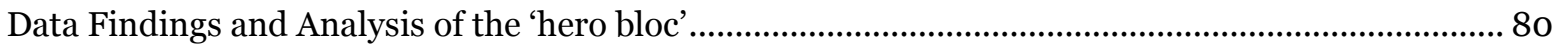

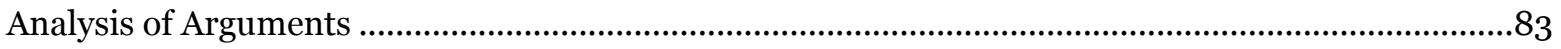

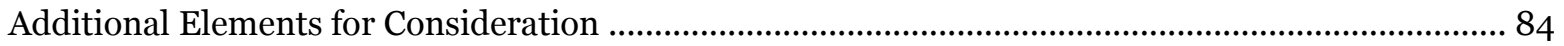

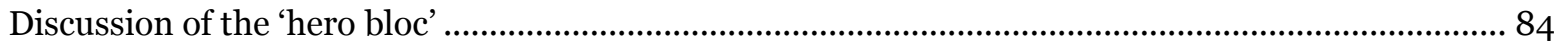

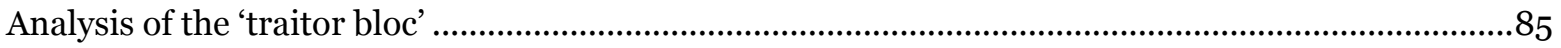

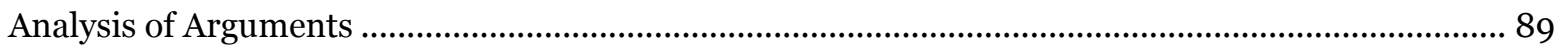

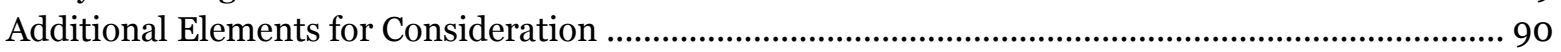

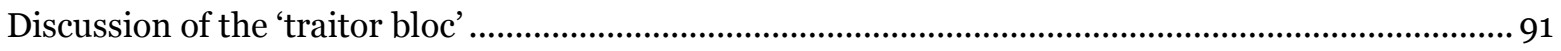

Discussion of 'Public Intellectuals in both the 'Hero' and 'Traitor' Blocs ..............................................93

Data Findings, Analysis and Discussion in YouTube comments ............................................................94

Data Findings in YouTube comments: Word Frequency ....................................................................94

Analysis of the YouTube comments: Word Frequency ..........................................................................96

Data Findings and Analysis of YouTube Comment: 'likes' and 'replies' ................................................97

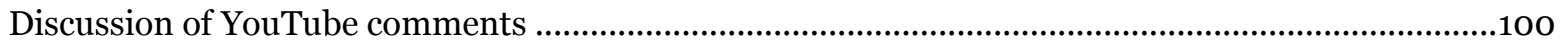

The Contestation of/Resistance to the Popular Antagonism ....................................................................102

Findings, Analysis and Discussion ...............................................................................................102

Chapter 6: Conclusions and Implications of Study ....................................................111

References............................................................................................................. 117

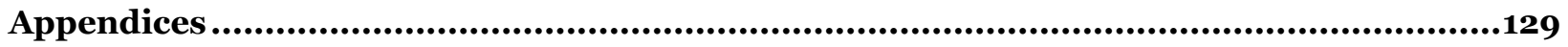

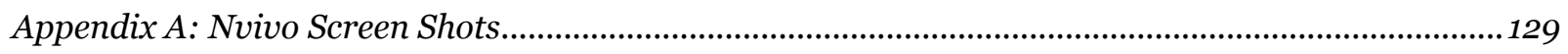

Appendix B: Table of Snowden-Interview videos ............................................................................130

Appendix C: Top-40 word frequency table + 'patriot' using 'Exact' setting on Nvivo...........................131

Appendix D: Top-40 word frequency table + 'patriot' using 'Exact+ 1' setting on Nvivo.......................132

Appendix E: top-10 YouTube comments ranked by the most-replies (capped at 11)............................133

Appendix F: top-10 YouTube comments ranked by number of 'likes' (capped at 12)............................ 135

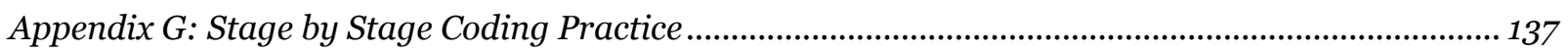

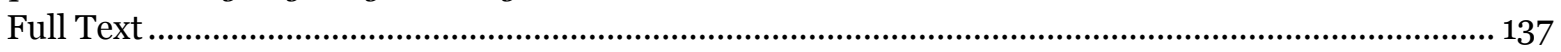

Coding Stage 1: Identifying arguments in bold ............................................................................... 139

Coding Stage 2: Labelling arguments ............................................................................................... 142

Coding Stage 3: Separating arguments from text to compare with others ........................................... 144

Appendix H: Screenshots of Edward Snowden action figure ................................................................. 145 


\section{List of tables}

Table 1: Discourse Acts in the 'hero bloc' ........................................................................80

Table 2: Types of Arguments and the Discourse Acts that use them .........................................81

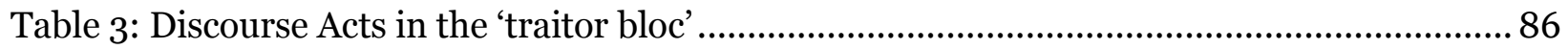

Table 4: Types of Arguments and the Discourse Acts that use them ...................................... 87

Table 5: Condensed table of 'Exact' words ......................................................................... 95

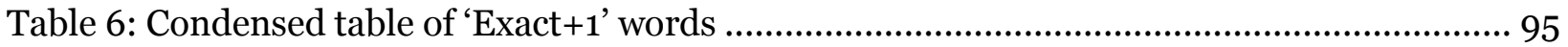




\section{Chapter 1: Introduction}

\section{Purpose of Study}

The purpose of this study is to illuminate how Edward Snowden's whistleblowing on the National Security Agency (NSA) has been taken up on the internet by a wide range of participants. While Snowden's actions have sparked intense social and political debates about whether or not his whistleblowing should be seen as 'heroic' or 'traitorous', the objective of this study is not to argue for either side of the argument. Rather, by analyzing articles, interviews, and social media, the efforts expended here strive to illustrate and analyze the socio-discursive forces at play, and the manner in which participants use language to engage the antagonistic and sociopolitical milieu, to collaborate with one another, and to contest others. Facing a digital realm teeming with ever-changing, intermingling discursive forces, a realm which resists all efforts to totalize, the task becomes one of engaging the forces, reading into their diverse meanings, and providing interpretations concerning their multifarious social functions and effects.

\section{Impetus for Study}

As the internet and digital technologies have surged inside our world with everincreasing pervasiveness, their social presence and force have become fascinating, mind-boggling and, at times, alarming - alarming in the sense that individuals and societies are not always cognizant of the diverse implications that these technologies educe in social environments and social practices. When Edward Snowden blew the whistle on the National Security Agency's (NSA) practices in early June 2103, he revealed not only some of the hidden essences of these technologies, but also the manner in which democratically elected governments, as well as corporations, were surreptitiously employing them. In turn, Snowden's whistleblowing, whether one 
politically or philosophically agrees with it or not, will likely come to be regarded as a socio-historical milestone in terms of highlighting the complex nature of our generation's relationships with, and dependence on, the technologies that structure our realities. As these technologies and their social roles continue to change, certain individuals - of which there are many - ask of us to take a step back, to assess whether or not the world we are creating with our technologies is the world we want. For this reason, I became greatly interested in the information Snowden wanted to share, and also, in turn, how he and his story were being taken up with language on the internet. A decision was made to conduct an analysis on the discursive enactment of Edward Snowden. Although I do not share all of Snowden's opinions, I feel somewhat indebted to what I believe were his courageous actions, and I hope my project does his actions at least some form of justice.

\section{Literature Review and Research Questions}

Engaging contentious social issues by means of discourse analysis is a rich and diverse avenue of inquiry. An abundance of studies have been conducted in which discourse theorists and analysts assess not only how societies make sense of pressing issues, but also how individuals and collectives engage the topics with certain objectives: in cases to propagate particular social, political, or philosophical perspectives. Evident are numerous studies carrying out this work. Studies have analyzed the socio-discursive debates over climate change (Smart, 2011; Currie, 2013), representations of the homeless in the United States (Huckin, 2002), and the rhetoric used in political speeches and public discourse by political leaders (Oddo, 2011; Fairclough, 2000, 2005). Additional studies have looked at the role that digital technologies and the internet have played in linguistic minorities shaping cultural identities in shifting geopolitical landscapes (Sheyholislami, 2010, 2012). This study is very much embedded in this academic tradition, broadly referred to as 'discourse studies'. Acting as "discourse theorists", researchers "are concerned with how, under what conditions, and for what reasons, discourses are constructed, contested and change. They seek, therefore to describe, understand and explain particular historical events and processes...” 
(Howarth, 2000, p. 131). As Snowden's story has sparked national and international debates and discussions in popular media, it has also attracted the attention of various discourse analysts the world over; so far, in 2015, there have at least three studies taking up these endeavours.

Two such studies, by Branum and Charteris-Black (2015), and by Wu, W.K. Ma, and W.L. Chan (2015), share similar objectives. The former analyzes the reporting styles of three UK newspapers' coverage of the Snowden story: The Guardian, The Daily Mail, and The Sun, arguing that as a result of language choices, distinct ideologies can be found in each of the respective newspapers. The latter study examines the portrayal and characterization of whistleblowers, specifically Snowden, across three different newspapers: The Guardian, The Washington Post and The South China Morning Post. Assessing keywords through digital corpuses, the study demonstrates how different newspapers portray Snowden in diverse manners and for diverse objectives.

Furthermore, this later study demonstrates how the portrayal of Snowden has changed over time, and argues that 'keyword analysis' is a viable and valuable analytical tool.

While these studies essentially argue that Snowden comes to be represented by different newspapers 'neutrally', 'positively' or 'negatively', their means of doing so focus solely on powerful news institution, and therefore does not take into account discourse produced by the public at large on social media websites. As such, these studies do not look at how the discourse created by news situations is taken up or contested by the public at large. Furthermore, the conclusions of the two studies, while illuminating specific linguistic characteristics pertaining to each newspaper, essentially argue that different news institutions have different rhetorical means of taking up a similar story - conclusions which demonstrate already established notions of the news creation and dissemination practices undertaken by popular media institutions, albeit in a new historical context.

In contrast with the two aforementioned studies, Qin (2015) carries out a project similar to mine by investigating how the portrayal of Snowden differs in the discourse created by news institutions when compared with that on the social media site Twitter. Qin (2015) effectively demonstrates, using 'framing' theory, and applying 'word selection' and 'word salience' methods to big data corpora, that there is a difference between the 
two discourses: Snowden is commonly portrayed as a 'hero' on Twitter, and as a 'traitor' on legacy news. Qin (2015), however, does not provide extensive analysis of how the terms 'hero' and 'traitor' are socio-discursive diachronic constructions existing apart from whistleblowing or information-leaking contexts, and how the arguments and portrayals of Snowden have come to be aligned with these very socio-discursive terms.

Furthermore, Qin's (2015) analysis does not shed elaborate light on the relationship between the two sets of discourses in terms of: 1) how the discourses are taken up or contested, and 2) how the discourse produced in social media moves, or interacted with, in its respective socio-digital realm. By building a YouTube corpus which includes not only the comments, but also data showing which comments were the most 'liked' and which comments were the most replied to, the participants' discursive interactions were able to be assessed in the analysis of my project. As such, my study begins shedding light not merely on the language used in the comments, but also on the movements and interactions between the comments. It also begins to illuminate the relationship between the discourses in social media and those produced by popular media institutions and companies. This analysis of comment boards on social media websites contributes to the growing body of studies which have taken up the topic from both socio-linguistic and computer studies perspectives (Hughey \& Daniels, 2013; Dinakar, Reinchart \& Liberman, 2011; Sierdorfer, Chelaru, Nejdl \& San Pedro, 2010; Walther, Deandrea, Kim \& Anthony, 2010;).

In addition, the previously mentioned discourse-analysis studies on Snowden do not take into account the discourse produced by Snowden himself. By incorporating the discourse produced by Snowden, as well as by reflecting on the manner in which all discourses can be considered at least partial enactments of individuals shaping and modifying their personal identities, my study foregrounds the social aspect of the discursively-intermingling relationships on both theoretical and empirical grounds. Because of these points, my study sheds new and unique light on what I am calling the 'discursive enactment' of Edward Snowden.

Ultimately, the goal of this project is not to reduce all inquiry to a singular, easilyidentifiable hypothesis which can be succinctly and objectively proven or disproven. 
Rather, this study takes on the more subjective and pluralistic notion of truth, striving to provide viable interpretations which reveal particular aspects of the ever-changing discursive enactment of Snowden. For this reason, although some strong conclusions have been reached in this study, even more questions have been raised. It is hoped that these questions, these fissures left vacant, will invigorate desires for further studies. Engaging with the story of Edward Snowden and his whistleblowing actions, I sought to answer the following questions:

1) How does Edward Snowden's story emerge in the digital realm of the internet?

2) In the discursive enactments of Edward Snowden, why have the terms, 'hero', 'patriot', 'traitor' emerged? Who is using these 'terms'? How and why are they doing so?

3) How are these discursive enactments being taken up and resisted in both media institutions as well as by the public at large? What interpretations can shed light on these zones of both collaboration and resistance?

At first, I sought answers to the following broad question: What is the discursive construction of Edward Snowden? But recognizing that the term 'construction' implies some kind of mechanical creation, whereby the identities of those engaged in the acts are cast (in degrees) to the peripheries, I sought to foreground the social beings whose identities are intertwined with the discursive acts making up these 'constructions'. For this reason, I decided that exploring the notion of a 'discursive enactment of Edward Snowden' would be more suitable to reflect these conceptualizations of discourse. And so, I ask:

What is the discursive enactment of Edward Snowden?

My project is organized in the following manner. First, to conclude this introductory chapter, a socio-historical overview of Snowden's whistleblowing is provided in order to properly contextualize the study. Next, in Chapter 2, a theoretical examination of whistleblowing generally, as well as in the American context, is undertaken, and a theoretical overview of the socio-discursive terms: 'hero', 'patriot', 'traitor' and 'villain' is expounded. Rounding out Chapter 2, an understanding of discourse is posited. Chapter 3 outlines the methodology used in the study, first by situating the practices in a 
theoretical framework, then by presenting the data and data collection procedures, and lastly by describing the practices undertaken to analyze the data. Chapter 4 illustrates the data findings, and also provides analysis and discursion of those findings. Chapter 5 covers the conclusions and implications of the study. Lastly, appendices are added, in which screen shots, complete data tables, a textual example of a discursive act, and an example of coding practices, are displayed. 


\section{Chapter 2: Background information}

\section{Background to the case of Edward Snowden}

Edward Snowden blew the whistle on the National Security Agency's (NSA) activities beginning with press releases through The Guardian and Washington Post newspapers in early June, 2013. For his actions, Snowden was charged with crimes by the United States, two of which fall under the Espionage Act of 1917. Originally drafted in the midst of WWI, the Espionage act is used to condemn speech which "runs counter to the needs and actions of a government; said speech is deemed non-protected and in violation of sedition, libel and obscene" (Open Websites, 2015). The Espionage Act allowed Woodrow Wilson's government to decree all social dissent against the war (WWI) potential criminal activity, by which, if one were to be charged and prosecuted, sentences of life imprisonment or even the death penalty could be administered (Greenwald, 2014) . Thus, in the current day, anyone who allegedly undermines governmental power regarding national defense - including the spreading of confidential, classified information - is liable to be charged under the Espionage Act. Snowden is not the first person to blow the whistle on the NSA, nor is he the first whistleblower to be charged under the Espionage Act ${ }^{1}$. To properly situate Snowden's actions in the history of whistleblowing - a task which is integral to making sense of the discursive enactment of Snowden - three cases need first to be briefly summarized: Daniel Ellsberg, Thomas Drake/ William Binney, and Chelsea Manning. Although many more than these three cases tie into and shed light on the whistleblowing act of Edward Snowden, these three cases provide the rudimentary, though sufficient, basis required to understand Edward Snowden's context, which the discursive enactment of Edward Snowden presupposes.

\section{The Case of Daniel Ellsberg}

\footnotetext{
${ }^{1}$ Eight whistleblowers have been charged under the Espionage Act by the Obama Administration. The Obama Administration has charged more individuals under the Espionage Act than all other American administrations combined.
} 
Ellsberg has become a well-known figure in the American cultural landscape, particularly concerning issues of government fraud and human rights violations, and his case has significant bearing on that of Edward Snowden's. Ellsberg was initially lambasted for leaking classified government documents. He was derided as a traitor by both government and the public at large. Over time, however, he has come to be seen by many (arguably by the majority of the American population) as a courageous hero, especially as the Vietnam War fell out of favour with the vast majority of Americans. He has now come to stand as perhaps not the first but arguably the archetypal American whistleblower.

Daniel Ellsberg, piano player, military officer/commander, scholar, and inner-circle Vietnam-war strategist shocked the nation, most notably his colleagues in government, when he leaked the now famous 'Pentagon Papers', documents containing evidence that numerous successive U.S. governments had consciously and willingly misled the public regarding American involvement in Vietnam and the Vietnam War. Ellsberg himself called the document "evidence of a quarter century of aggression, broken treaties, deceptions, stolen elections, lies and murder" (Biography, 2015). Stuck in a muddle of moral introspection, Ellsberg drew inspiration from a fellow Harvard-graduate Randy Kehler, a man imprisoned for failing to comply with military draft orders, as well as from the writings of Thoreau, Gandhi, and Dr. Martin Luther King before taking the decision to blow the whistle. After leaking copies of the Pentagon Papers, which he had photocopied at home, page by page with the help of his children and which were subsequently published by the New York Times, Ellsberg, once discovered to be the leaker, was aggressively subjected to an ardent campaign by Nixon and Kissinger that strove to discredit him (The SimpleTruth2/BBC four, 2011). Although initially charged with crimes including violations of the Espionage Act, his case was tossed out when the government-ordered wiretappings of his phone and break-ins of his home were deemed illegal (Biography, 2015).

All understanding of whistleblowing in the American context must make at least some reference to the case of Ellsberg. Not only does his name continually appear in the discourse concerning Snowden, but Ellsberg himself weighs in extensively on modern whistleblowing enactments, including that of Snowden's. In short, he has become a 
principle figure in shaping the discourse of Snowden, the man, as well as Snowden's whistleblowing activities.

\section{The Case of Thomas Drake/ William Binney}

The stories of both Thomas Drake and William Binney are important in contextualizing the case of Edward Snowden simply because both men had blown the whistle on the NSA prior to Snowden. Both Drake and Binney were NSA employees, the former a senior-executive, the latter a director of a military-analysis reporting group and senior encrypto-mathematician. Drake worked for the agency for almost seven years, Binney for almost forty. Both men were deeply distraught by what they deemed to be significant overstepping of NSA activities, which, in brief, consisted of spying on American citizens in violation of constitutional rights of privacy and using exorbitant funds to do so. Both men tried unsuccessfully to raise their concerns through internal avenues before publicly blowing the whistle. Binney, unlike Drake, resigned from the NSA before doing so. For their actions, both men have been subjected to severe retaliation from government authorities (Wise, 2011; R.M., 2011; Democracy Now!, 2013).

Although never formally charged (all prosecution efforts were sullied with improper evidence gathering efforts), Binney and his family were affronted by 12 FBI agents who stormed their home with shotguns drawn. Binney was ripped from his shower at gunpoint and interrogated on his back porch (Democracy Now!, 2013). Drake was charged with ten felony court indictments, including five counts under the Espionage Act. He was facing a maximum jail sentence of 35 years. When the case against him had significantly collapsed, Drake pled guilty to a misdemeanor for 'exceeding authorized use of a computer' and received a sentence of one year's probation and 240 hours of community service (Wise, 2011; R.M., 2011).

What is telling about the cases of these two men with respect to Snowden is that, from a perspective of context, working inside of the system to address wrongdoing and to evoke change, cannot only prove ineffective, but can also result in becoming a target for internal investigations. It partially explains why Snowden fled the U.S. to blow the whistle. Not only can it be argued that he sought to escape charges, but the case can also be made that had Snowden not fled the country, he would have been unable to 
participate in the creation of the wide-spread, ongoing debates that have taken place. Chelsea Manning, for example, having been charged under the Espionage Act, and in turn, detained, was unable to make a significant public defense on her own behalf. The public has heard very little from Manning.

Furthermore, on reflecting on the manner in which the U.S. government deals with whistleblowers, Drake, on receiving the Ridenhour Prize for truth-telling in 2011, stated that the government's prosecution, in his case, was intent "not on serving justice, but on meting out retaliation, reprisal and retribution for the purpose of relentlessly punishing a whistleblower" (Ridenhour, 2011). Drake also added that in modern times "dissent has become the mark of a traitor" (Wise, 2011). Thus, the arguments made by Drake claim that the government's prosecution of whistleblowers is not merely an effort to punish actions but serves as a means to intimidate prospective whistleblowers; the punitive measures serve as pre-emptive muzzling. Cognisant of Drake's case, Snowden most likely realized that staying in the United States would greatly, if not entirely, diminish his capabilities to engage the topics and issues which were certain to arise.

Lastly, a question arises as to why Snowden's leaks have garnered considerably more attention than those of Drake and Binney's. Although a concrete answer to this question is difficult to obtain with certainty, it should be noted that while Drake and Binney have spoken at length about perceived NSA malpractices with journalists, neither man could provide the sheer abundance of hard evidence, that is, actual documents of the NSA's questionable practices ,which the Snowden's leaks have.

\section{The Case of Chelsea Manning}

Like Drake and Snowden, Manning was also charged under the Espionage act for publishing more than 250,000 U.S. diplomatic cables and 500,000 military reports, now commonly-known as the "Iraq War Logs" and "Afghanistan War Logs" on Julian Assange's webpage, Wikileaks, in early 2010 (Shantz \& Tomblin, 2014). Manning's leak has often been equated with that of Snowden's and yet, with regard to the manner of leaking information, the two cases are strikingly dissimilar. Manning obtained an abundance of documents and 'dumped' them, all of them, onto the internet. Snowden, in contrast, worked with reporters, Glenn Greenwald and Ewan MacAskill from The 
Guardian, as well as with Laura Poitras and Barton Gellman, therefore handing over responsibility of what should be leaked, when, and how (Greenwald, 2014). Snowden, in all of his interviews, stresses this point: that which gets disclosed to the public through the press has been determined as suitable for public consumption by journalists, and in turn, their respective media enterprises. For his actions, Manning, who, it should be noted, also received the Sam Adams award in 2014, was tried at NSA headquarters in Fort Meade and was found guilty of offenses under the Espionage Act. He is currently serving a sentence of 35 years imprisonment. It is not difficult to speculate, as many have done on public media, that if Snowden were ever to return home and face trial, he would surely face a similar fate.

The last essential point that bears relevance to the case of Chelsea Manning with respect to Snowden is that when an individual is charged under the Espionage Act, they are forbidden to make a public defense of their actions - both inside and outside of a court of law (Greenwald, 2014). Thus, in fleeing the United States and escaping prosecution not only has Snowden granted himself freedom from the law, but this very act has made possible the discursive presence of Snowden's integral and socially-significant contributions to the wide-range of debates taking place. In short, where Manning's prosecution effectively resulted in muzzling his perspective, Snowden's fleeing has granted him discursive potentialities via internet technologies. The internet is not, therefore, merely an appendage to Snowden's story, but has provided the very technological means for it to have presence in social realms.

\section{The Whistleblowing Case of Edward Snowden}

Despite dropping out of high school in his sophomore year, Edward Snowden, a highlyintelligent individual with a penchant for technology and computer systems, managed to work his way into the upper echelons of government intelligent agencies. Born in 1983 in North Carolina, Edward Snowden was born into a family who for generations had worked for the civil service: in the Coast Guard, in the military, as law-enforcements officers, and as government lawyers (Burrough, Andrews \& Ellison, 2014; Bamford, 2014). Snowden spent an extensive period of his adolescence on the internet actively engaging in discussions on the technology website, Ars Technica, where he often 
"referred to Newton and Goethe and mused on the nature of freedom. 'It is the confidence of purpose,' he noted, 'that allows you to be truly free"” (Burrough et al., 2014, p. 156). As an unemployed twenty-year old, the events of 9/11 had a 'deep effect' on him, and he joined the army to serve his country. Speaking with Bamford (2014) for Wired, Snowden reflected on this period of his life,

I still very strongly believed that the government wouldn't lie to us, that our government had noble intent, and that the war in Iraq was going to be what they said it was, which was a limited, targeted effort to free the oppressed. I wanted to do my part. (Section 3)

The situation changed quickly. He left the army shortly after breaking both of his legs in a training exercise and after becoming disillusioned with the attitudes of his fellow recruits (Burrough et al., 2014; Greenwald, 2014). A year and a half later, in mid-2006, he landed a job with the Central Intelligence Agency (CIA) as a computer engineer.

The early 2000's were an era in which American intelligence agencies were experiencing a resurgence of purpose. Following the collapse of the Soviet Union, and the end of the Cold War period, intelligence agencies were, generally speaking, deemed somewhat unnecessary; there were no pressing external threats and in turn, intelligence agencies' budgets were slashed. In the wake of 9/11, however, intelligence agencies' efforts, including those of the CIA, were once again fervently, perhaps even manically, imbued with importance (Burrough et al., 2014). But seeing as the agencies had aged - had found themselves scrambling to make sense of the technological advances that had transformed the global landscape - they desperately sought new recruits. An instance of such can be seen in the case where Keith Alexander, the head of the NSA at that time, appeared at Def Con hackers' conference clad in jeans and a t-shirt, and pleaded to the attendees to help bolster the agency's initiatives with their abundance of technological knowledge and computer-system skills. Snowden was one of those hired to help (Burrough et al., 2014).

Working with the CIA, Snowden found himself transferred to Geneva, where he was paid handsomely to provide security for different systems' networks. Snowden says that he was "drawn to the CIA by a sense of duty, a desire to contribute" (Burrough et al., 
2014, p. 158). However, he became disillusioned with how the government was functioning and the negative impact it having on the world at large (Burrough et al., 2014,). Snowden reflects, "This was the Bush period, when the war on terror had gotten really dark...we were torturing people; we had warrantless wiretapping” (Bamford, 2014, Section 4). He also tried bringing up the issue of ethical breaches to his superiors, but they were almost always rebuffed (Greenwald, 2014). Ironically, it was during this work stint, in early 2009, only weeks before Obama would take over office, that Snowden lashed out against the New York Times, which had ran stories based on internal disclosures of the Bush administration's plans to sabotage an Iranian nuclear facility. He was disgusted with the disclosures, writing on Ars Technica that those disclosing the information should be "shot in the balls", that classified information is "classified for a reason" (Burrough et al., 2014, p. 158-159). Though highly skeptical of practices in which he was involved, Snowden thought that a change in administration would result in a change of practices, but this, in his view, would not be the case. In Snowden's words:

I think even Obama's critics were impressed and optimistic about the values that he represented... he said that we're not going to sacrifice our rights. We're not going to change who we are just to catch some small percentage more terrorists. ...not only did they not fulfill those promises, but they entirely repudiated them... they went in the other direction. What does that mean for a society, for a democracy, when the people that you elect on the basis of promises can basically suborn the will of the electorate? (Bamford, 2014, Section 4).

Shortly after resigning from the CIA, Snowden got a job with Dell in Tokyo, where he worked with top officials and military officers, helping them defend their networks from Chinese hackers. It was 2010, and Dell, it turned out, had a very important and very secretive client, the U.S. government's NSA (Burrough et al., 2014).

The NSA is the worlds' largest and most sophisticated eavesdropping agency, staffed with over 35,000 employees. Where the CIA focuses on "gathering intelligence involving human beings... the NSA is the code-breaking, code-making, machine and computer outfit, specializing in what is known as signals intelligence or 'SIGNIT"' (Burrough et al., 2014, p.159). More mathematicians work at the NSA than anywhere else in the country. 
Intensely-focused individuals make up its headquarters; a place where, according to a former top NSA officer, "an extrovert is someone who looks at your shoes when he talks to you" (Burrough et al., 2014, p. 159). Involved with tracking all kinds of activities, including those of government officials, everyday citizens, and international populations, much of what the NSA did remained secretive, even to those working in congress. Early NSA whistleblowers like William Binney, alongside Kirk Wiebe, tried to raise concerns about the NSA's activities with congress, the Department of Defense, and even the Supreme Court, but could not manage to obtain any significant traction. Around this time, Snowden, first as an employee of Dell and later with Booz Allen Hamilton, secured a position as a high-level systems administrator at an NSA facility in Hawaii. His girlfriend relocated, joining him there (Burrough et al., 2014).

Over time, and by proving himself with exceptional skills, Snowden moved into the section of the NSA that dealt with 'cyber-security' (Burrough et al., 2014). He was receiving a six-figure salary, and had what he claims as close to full access of internal information as someone could have. Here, like Binney and Drake before him, Snowden became deeply alarmed and concerned with the activities of the NSA. Over the years, he had seen CIA drones "turn people into body parts", and watched as the NSA monitored the pornography-viewing habits of political radicals, which could later be used to tarnish their reputations if they sought to aggressively criticize the government (Bamford, 2014, Section 4). He witnessed and participated in the construction and maintenance of programs which monitored and stored vast amount of communication between 'everyday' American citizens (Bamford, 2014).Continuing to struggle ethically with the activities in which he was engaged, Snowden began downloading classified documents, rock-solid evidence of what he thought were breaches of America's administrative and public trust. James Clapper's outright lie to a Senate committee on March 13, 2013, stating that the NSA does "not willingly" collect information on millions of Americans, significantly spurred Snowden towards action (Bamford, 2014; Greenwald, 2014). He began sending out feelers to journalists, such as Laura Poitras and Barton Gellman, exploring how it might be possible to disclose the inner workings of the NSA to the public (Burrough et al., 2014). 
On May $18^{\text {th }}$ of the same year, thumb drives loaded with a staggering number of NSA documents, Snowden went to the Honolulu airport and flew to Hong Kong. One day previous, his girlfriend had left on a one-week sailing trip with friends. He had told her he was going on a business trip and would most likely not be home by the time she returned. In Hong Kong, his hopes that Gellman would publish leaks on the NSA fizzled out, and so he reached out to Laura Poitras and Glenn Greenwald. He had been following Greenwald's journalist work for a considerable time, which had included an unflinching defense of Chelsea Manning's leaks, and hoped that he, alongside Poitras, would take on his story. On May $31^{\text {st }}$, Poitras and Greenwald boarded a plane with Ewan MacAskill, the senior journalist who The Guardian newspaper had obligated Greenwald to bring along, and arrived in Hong Kong. After spending days with Snowden, verifying his information, and legitimizing his character (Burrough et al., 2014; Greenwald, 2014; Poitras, 2014), the first disclosures of NSA programs ran on June $6^{\text {th }}$, starting with those related with Verizon. On the morning of June $9^{\text {th }}$, the leaks were still flowing. By now, the NSA had strong suspicions that Snowden was the leaker, and so, after consulting with Greenwald and discussing the best manner in which to proceed (Poitras, 2014), on June $10^{\text {th }}$, Snowden disclosed his identity to the world. Fearing for his life as well as extradition to the United States, Snowden, working with a pseudo-lawyer of Julian Assange's entourage, decided to make his way to Latin American via Russia then Cuba (Burrough et al., 2014). After arriving in Russia on June 22 ${ }^{\text {nd }}$, the US government deactivated his passport, trapping him in Russia. In addition, they had, one day previous, indicted him on charges of Espionage. At this point Snowden carried none of the stolen documents; he had given them all to Greenwald, Poitras, MacAskill, and Gellman. Exactly how many documents they possessed, one could not know for sure (Burrough et al., 2014; Bamford, 2014; Greenwald, 2014). In short, Snowden was never allowed to leave Russia. Though pressured by the American government to extradite him, the Russian government granted Snowden asylum, which has since been extended for three more years. Snowden currently resides in Moscow. He girlfriend has joined him. Snowden on numerous occasions has expressed his desire to return home. He has stated that he is willing to face trial, but only if that trial is one considered fair, that is, a trial in which he is granted the right to make a public defense - a stipulation which 
Snowden, as well as his lawyers, has suggested is very unlikely to come to fruition (Burrough et al., 2014).

This is the context of Edward Snowden's whistleblowing actions. Despite a few examples to the contrary, the information provided here strives to avoid expounding how Snowden or others interpret his actions and motives. To discuss those matters is to begin the discussion of how it is the Snowden is discursively enacted. But before any such discussion can commence, what is first required is a theoretical examination of both whistleblowing and a conceptualization of discourse. 


\section{Chapter 3: Theoretical Perspectives}

\section{Whistleblowing}

Whistleblowing is a rupture. Regardless of context, to perform any act of whistleblowing is to breach the trust, laws, and/or structure of an established organization. In minor cases, it is an accusatory finger, pointing out flaws, judging and reprimanding. When the case is severe, it is a thunderous axe, hacking the support beams of an organization's edifice. And yet, for all the 'damage' that whistleblowing inflicts, any putative act of whistleblowing occurs as a result of and response to injurious and inappropriate actions, whether purported or justified, festering inside a given organization. As such, whistleblowing strives for justice and improvement. It raises concerns of ethical practices. It discloses wrongdoing. It argues that things are amiss and that things can be better. Because not everyone will agree that 'things are amiss', that malpractice is evident, whistleblowing acts, especially as viewed by those whose activities have been critically questioned, often create intense polemic contestations, in which both the whistleblower's personae and decisions, as well as his or her whistleblowing actions, face feverish scrutiny.

Miceli and Near (1992) map out what they believe to be the four-stage process of an individual's decision to blow the whistle. First, an individual recognizes malpractice, which then leads to a period of assessment whereby one decides if the wrongdoing requires a response. Next, a whistleblower has to determine if they are able to take action ('if they are responsible'), and lastly, to decide what kind of action to take whether it be a form whistleblowing or perhaps an alternative action. Perhaps this sequential mapping out of how whistleblowing occurs is overly logical and rational. Perhaps in practice the act involves a much greater degree of spontaneity and emotion. Regardless, a roadmap or code which whistleblowers may or may not choose to follow, plays a central role not only in either legitimatizing or undermining a whistleblower's 
actions but also in determining the power or influence that the whistleblowing can have (Sagar, 2013).

The decision-making process that eventually leads to whistleblowing straddles the realms of both chaos and structure. In terms of the whistleblowers themselves, they "are often characterized as principled individuals with strong moral convictions, high levels of moral development, universal standards of justice and self-efficacy and high levels of internal control" (Hersch, 2002, p. 248). Whistleblowers often act based on selfdetermined tenets of morality, and, contrary to commonly-held assumptions, whistleblowers' actions have not been seen as stemming from feelings of subordination or self-righteousness; whistleblowers do not typically act on the basis of seeking revenge (Hersch, 2002). On an emotional level, whistleblowers often act because not doing so is causing inner turmoil. FBI whistleblower, Coleen Rowley stated that she simply could not "hold the words inside anymore" (Ripley \& Sieger, 2013), and WorldCom whistleblower Cynthia Cooper explained in an interview,

I certainly knew it was possible that I would lose my job. I told my husband that I am going to the [WorldCom board's] audit committee what I need to report. I even cleared some things out of my office. But the fear of losing my job was secondary to the obligation I felt. (Time, 2002-2003)

Generally speaking, studies have shown that more often than not, a decision to blow the whistle is highly correlated with the potential success it is deemed to possess (Hersch, 2002), which in turn suggests that whistleblowers, though acting emotionally, also exhibit some elements of rational decision-making. Whistleblowers, therefore, while typically charged with emotions, are also able to make decisions in a manner which will evoke the type of social or institutional impact they believe the actions have the potential to educe.

When a decision to act is made, when the whistle screams and the ensuing chaos rages, life for the whistleblowers often changes dramatically, and often for the worse. In addition to weeks, months, or even years of harassment from institution or government officials, whistleblowers often lose their jobs, or, in the most extreme cases, do time in jail. Whistleblowers often suffer physical and emotional injuries as well; Hersh (2002) 
summarizing (Miethe, 1999) notes whistleblowers suffer both physically and financially: approximately 50\% end up facing bankruptcy, and more than 80\% experience 'severe' depression and anxiety (p.253). Enron whistleblower Sherron Watkins notes, "The scary thing is the amount of resistance we met. People I thought were my friends and I thought would support me backed away. They said, 'Sherron, you're on your own on this"'(Time, 2002-2003, p. 59). Jesselyn Radack, a lawyer for Edward Snowden and the national-security-and-human-rights director at the Government Accountability Project (GAP), states that whistleblowers, "underestimate the sheer force of the executive branch raining down... It's this weird nether world, very lonely and isolated” (Burrough et al., 2014, p. 201). The severity with which whistleblowers are punished varies case to case, as does the relative successes or contributions that whistleblowing has been able to have in society.

Paraphrasing the studies of (Gunsalus, 1998) and (Bowie, 1982), Hersch (2002) explains that whistleblowers need to diligently comprehend the observed and suspected wrongdoing and collect substantial evidence to buttress whichever claims they intent to make. Whistleblowers must be prepared to disclose their personal intentions and motivations, and also must be able to demonstrate that 'all available internal procedures' were sufficiently exhausted before making a disclosure public. This notion of first attempting to resolve alleged wrongdoings internally, is one of the core tenets that defines the concept of 'whistleblowing', and in turn, a central argumentative point in the hegemonic battle when framing a whistleblower whose actions have caused significant political and/or social strife (Sagar, 2013). Being labelled a whistleblower, therefore, depends on the degree to which one has been perceived to have followed the required code of what constitutes the act. This very code, however, is subject to debate, and discussions might ensue whereby a whistleblowers claim to the title is argued to be contentious.

Once a whistleblower's actions are publicly disclosed, their persona revealed to the public at large, a discursive battle most typically ensues whereby, on one side of the spectrum, the whistleblower might be lauded, praised for their actions, and labelled a 'hero', or, if the case pertains to the national level, a 'patriot'. Conversely, they might be ridiculed and chastised, labeled a 'traitor.' These terms 'hero', 'traitor' and 'patriot' have 
come to be used with great frequency when discussing whistleblowers, especially in the American context. ${ }^{2}$ In addition, it is these very terms which have been used extensively in the whistleblowing case of Edward Snowden. Because these terms are broad, rippling outwards with numerous connotations, they require extensive unpacking; they are, as will be described in much greater detail, 'discursive constructs'.

\section{Heroes, Villains, Traitors and Patriots as Socio-Discursive Constructs}

While Hook (1945) and Alsford (2006) employ diverse means for determining the constituents that make up a 'hero', both thinkers stress that a 'hero' is not an inherent objective essence in the material world, but rather a concept which is socially constructed and construed. Hook, writing in a pre-internet world where the power of the press was highly-concentrated in the hands of a few, states, "Today, more than ever before, belief in 'the hero' is a synthetic product. Whoever controls the microphones and printing press can make or unmake belief overnight" (p. 10). Similarly, reflecting on the social construction of the 'hero', Alsford (2006) notes that the manner in which people are defined as heroes of traitors provides insight into a respective society's values.

Alsford (2006), in turn, draws on an abundance of cultural constructions of the hero as portrayed in literature, television, cinema, and comic books, in combination with philosophical principles to elucidate what constitutes the 'hero' in Western societies. In contrast, Hook (1945) takes up the task by examining what society has historically understood to be 'great' individuals such as the prodigious thinkers and political leaders who significantly affected their historical periods with their decisions and actions.

In assessing the potentialities and limits that an individual has in any given era, Hook (1945) argues that 'great' individuals were 'great' because they managed to influence their social environments in profound ways. While Hook (1945) agrees with the notions posited by thinkers like Carlyle and James that the hero is one with 'distinct' and potent individual talents, one who is able to 'exert influence on followers', he problematizes

\footnotetext{
${ }^{2}$ Included in Time's 2002 persons of the year edition in which the three aforementioned whistleblowers were named person of the year, a 'Time/CNN Poll' was included in the report, which asked over 1,000 adult Americans: "In general, do you think whistle-blowers are heroes who help uncover crimes or traitors who betray their company or government department?" $59 \%$ responded 'heroes', 18\% responded 'traitors', 9\% responded 'neither', and 14\% responded 'not sure (Time, 2002-2003, p. 60).
} 
their notions, stressing that the 'great individual' is always embedded in, and a product of, the social world of her epoch. Her characteristics of greatness, therefore, can never be attributed solely to her as if she existed and acted in an isolated bubble. As a result of such considerations, Hook finds himself confronted with Hegel's notion that exceptional individuals were 'spiritually-infused' beings, socially-determined from the 'great' eras in which they lived. Paraphrasing Hegel, Hook (1945) writes that under this conception "the great man can do only what his culture permits... but the culture permits of only one direction of development. There are no genuine alternatives" (p. 65). In turn it is argued that the 'great man' is merely cast as a 'symbol', 'instrument', or 'expression' of historical and social forces "on whose currents he rides to renown and victory... the source and reason of his greatness, his biography or purely personal traits are relatively unimportant" (p. 66).

Hook (1945) argues that this conceptualization is problematic, that there must be at least some agency that an individual possesses regardless of the fact that a society needs to be 'ripe' or already predisposed to change in the ways it does. In doing so, Hook (1945) takes up Dewey's notion of man as an "accultured organism": one who is "dependent for his intellectual power not only upon his biological capacities but upon the society that sets the framework of interest and attention within which doubt and inquiry arise, and that supplies the very words which both inspire and limit the ideas that germinate within him" (p. 104). Because history cannot develop in any arbitrary way - the past does have significant and necessary influence on the manner in which the present and future unfold- Hook's (1945) notion of the heroic action is one which, when taken, forces society, or at the very least a significantly powerful realm of society, onto a path that would not have transpired if the action had not been taken.

Based on this notion, Hook (1945) distinguishes between an 'eventful' individual and an 'event-making' hero. The former acts in a way that alters the course of history, but does so without any special or unique skills, talent, or intelligence. It is the case of one merely being in the right place at the right time, and once situated thus, performing an action which any other individual had the capacity to perform. Not only might this individual be unaware of the repercussions of his actions, he also, most likely, would not be considered the driving force propelling this event or issue into emergence. In contrast, 
the event-making hero "is an eventful man whose actions are the consequences of outstanding capacities of intelligence, will, and character rather than of accidents of position... a hero is not merely in virtue of what he does but in virtue of what he is" (p.154). This 'hero' does not merely come across a 'fork in the historical road' but "helps to create it...by virtue of the extraordinary qualities he brings to bear to realize it" (p. 157). Under this conceptualization, a hero is a person not simply of her time, nor a person with keen insight into her time, but one so consciously enmeshed in the ethos of her particular era that she is able, with her remarkable capacities, to unleash the kinds of forces that actualize a unique historical change of which only she would be capable to produce.

Alsford's (2006) conception of the hero, similar to that of Hook's, strives to make sense of the powerful and skillful individual acting inside of the collective social realm. Differing from Hook, Alsford (2006) argues that the hero, based on heroic prototypes from the Western cultural tradition, serves as a social model to be lauded and emulated in that he or she does not use special capacities to distance oneself from society by dominating others. Conversely, they further immerse themselves in the realm of social, reinforcing connections between other humans, with 'the other' in general.

Drawing on Campbell's (1949) Jungian inspired notions, Alsford writes that "the myth of the hero confronts us with the challenge of transformation, the call to develop, to grow up by freeing ourselves from the limitations of infancy" (2006, p.3). These heroes, though often feeling detached and isolated from their respective social worlds, demonstrate how one can engage the world through their special abilities and sense of 'coadunacy' "a heightened experience of the necessary interconnectedness and interdependency of humanity" (p.7). Furthermore, heroes recognize that to affect the world in remarkable ways, one cannot simply follow established formulaic procedures but must reimagine and transcend them. Snowden's 'stealing' and leaking of classified documents are clear examples of resisting and working against established codes and norms of conduct. As such, a large part of being hero consists in "being in the world in a certain way" (p. 22), in a way that 'transcends' the norm - and yet herein lies the paradox. By enacting the role of one with the might, courage, and ability to transcend, the hero often takes on the characteristics of an omnipotent, God-like figure, one who is 
necessarily differentiated and distanced from fellow humans. It is the continual desire to reintegrate oneself with the concerns and dilemmas of others, to empower others, and to fight for others regardless if failure is inevitable, which marks the hero as something unique, special and praiseworthy (Alsford, 2006).

Underpinning Alsford's (2006) notions is the Kantian 'postulate of practical reason', in which freedom or free will is equated with ethical action based on the fact that one possesses the ability to determine what one should do, not merely what one can do, in any given situation. Humans, therefore, can consider themselves 'the makers' of a universal law which is based on no cause other than that of the 'rational will': it is the very potential of determining the correct action that provides one with the rational will, and in turn establishes "all rational beings as ends in themselves" (p. 27). Because all humans are interconnected in the possible enactment of rational behaviour, interacting with 'others' cannot be understood as means to an end, but stands as the end itself. This is argued on the basis that inflicting one's free will on another can force the potential of the other's free will to be occluded. As such, the task becomes one for individuals to conduct their lives through a notion of free will which acknowledges that all others also possess this potentiality. For Kant, an individual can become a member in the 'Kingdom of Ends' when they act in adherence to the very laws they strive to establish (Alsford, 2006) 3 .

By making use of Kant's notion of the 'postulate of practical reason', what Alsford (2006) demonstrates is that heroic prototypes from popular culture, despite possessing an abundance of power, refuse to use others as a means of achieving some kind of social or personal betterment. As such, superheroes like Superman, Buffy the Vampire Slayer, Spiderman, Luke Skywalker or Captain America refuse to sacrifice innocent lives, and will never use their powers for personal gains. Their ongoing struggle is to remain enmeshed in a world structured by the ethical code through which all human should

\footnotetext{
3 "Ernst Cassier, writing on Kant, echoes this notion: "all rational beings stand under the law so that in constituting their personhood, they are in relation with the moral individuality of all others, and so, that they also demand the fundamental worth which they thus grant themselves from every other subject and acknowledge it in all other subjects" (Alsford, 2006, p. 28).
} 
live. Thus, it is by continually and empathetically giving oneself over to the others in the name of justice and humanity, and by spreading the possibilities for others to reach happiness and well-being, that heroes become constituted as such.

In many ways, Viroli's (1995) conception of the 'patriot' is strikingly similar. Like that of the 'hero', the concept of the 'patriot' or of 'patriotism', Viroli argues, is also a discursive construct. With the objective of demarcating the discursive constructions of 'Nationalism' and 'Patriotism', which Viroli (1995) argues are often mistakenly used synonymously, "the language of Patriotism" he writes,

aims at resuscitating, strengthening, and directing the passions of a particular people with a specific cultural and historical identity...it endeavours to reinforce bonds, such love of the common liberty of the people, which are as particularistic as the love of, or pride in, the cultural tradition or the shared destiny of a people. (p. 8)

Because citizens are born into a country which has provided them with the social conditions under and through which they were able to achieve whatever personal achievements or well-being they've obtained, a morally-charged patriot should feel indebted to this country and must therefore serve to protect the interests of the country including, necessarily, all of its citizens "against anyone who attempts to impose a particular interest over the common good" (p.9). One must fight to oppose the forces of discrimination and exclusion not by seeking to impose "cultural, ethnic, or religious homogeneity", as Viroli argues is the case with nationalistic discourse, but to "stand up for the defense of common liberty and rights" (1995, p. 9-10). Because common liberty and rights are upheld and enacted through collective institutions and political participation, the language of patriotism has the power to act as an 'intellectual tool' striving to instil in a populace not only an interest in the republic nor a love of the common good but rather respect and love for common good as a force superior to that of oppression and discrimination. As such, Viroli (1995) argues, "Patriotism makes citizens demanding toward their country and themselves. It urges them to find in the history of their country inspiration and reasons to strengthen a commitment to liberty" (p.164).

Under Viroli's conceptualization, a patriot recognizes that the citizenship of one's country is inherently pluralistic. If one intends on defending the common liberty of all, 
on working towards love and compassion for all humanity, this notion of patriotism should been seen as forming "the foundation of a healthy, open, liberal society" (1995, p. 168) which strives towards the highest degrees of citizen participation in the creation of civil and political equality. This is considered to be the core tenet of patriotism shared by supposedly open and democratic societies. Here, citizens feel that the republic is something created through their participatory actions. In the American context, political philosopher, Alex de Tocqueville stood as a key figure in promulgating this notion of patriotism as public participation in democratic processes. For de Tocqueville, the patriotism specific to the American context was one in which a rational application of communal law intertwines with personal interest. A citizen, in de Tocqueville's terms, cannot merely exist in a community, but must actively participate in that community, including its governing practices. Thus, the general prosperity of the nation comes to be understood as one's own common good. Despite the fact that American patriotism is grounded on notions of pride, a sense of duty, and perhaps even greed, it is also based on affection for the republic achieved only through rational laws of governance and a public's willingness to participate in both the very creation and administration of these laws (Viroli, 1995).

Rounding out his project, Viroli (1995) makes a clear connection between a 'hero' and a 'patriot', when he states that a heroic patriot is one who sacrifices everything for his or her republic. Imbued with an ardent love for one's country, this kind of citizen practices "civic virtue as a completion of private life and private interest" (p. 185). It is not the case that a patriot simply loves her country and desires the proliferation of its strength and prosperity, but rather that, like Alsford's (2006) conceptualization of the 'hero', she actively and passionately defends fellow citizens who have become victims of injustice, crime and corruption. It is a sense of extending justice beyond oneself and into the communal. As such, like the 'hero' in Alsford's terms, Viroli's patriot establishes and enforces connections between others, 'others' who may differ from her politically, religiously, racially, or culturally, but with whom she is irrevocably linked not only by nationhood, but by a shared humanity.

An understanding of patriotism as such, however, paints an uncomplicated portrait of a complex and diversely-interpreted concept. Contrary to Viroli (1995), Kateb (2006) 
argues that notions of patriotism are more detrimental than beneficial to an individual in that by adhering to 'sacrificial' patriotism, committed to establishing oneself as necessarily part of the collective body of others, one enacts an 'abjection of self'. Furthermore, he argues that love for a country is not really love, but an 'imitation of love' in that a country is actually a 'false object'. One, in turn, using terminology from Augustine, ends up loving 'dream substances' and 'mock realities' (Kateb, 2006). Kateb adds, "Patriotism is a kind of vicariousness, a living outside oneself and through something else that one partly imposes on oneself, while pretending that one has no choice but to lend or give oneself to it" (2006, p. 16).

Furthermore, Kateb (2006) argues there is an inherent paradox in notions of patriotism in that a nation's government protects and preserves itself by treating people 'morally', but does so through the creation of adversaries which at times need to be attacked or whose actions need rebuking, with, in instances, actions which might be considered 'immoral but necessary'. The discourse of patriotism thus fails to acknowledge the morally-contradictory positions one must assume in faithful adherence to a countries' actions. In turn, propagating patriotism ends up resulting in a misguided love or worship of self, or an all-too-willing abjection of the self in favour of something external, 'other' and ultimately contradictory. Principally, however, Kateb (2006) argues that notions of the patriot result in a dangerous idolatry, whereby the self is always striving to move outside of itself, loving something by which it might be influenced but is inherently not. For a thinker like Levinas, however, any sense that one might have of living solely by oneself, or living based on steadfast notions of the individualistic self apart from others, cannot be entertained. For Levinas, the self is inherently and inextricably enmeshed in the others; it gains its very sense and value through them (Alsford, 2006).

Harking back to what was aforementioned regarding Alsford's (2006) notion of the 'hero' as well as Viroli's (1995) conception of the 'patriot', it is the very ability of individuals to recognize the self as necessarily indebted to the other, and that it is through actions which strive to maintain an enforce this interconnectivity, where 'heroes' and 'patriots' are made. This is not to say, however, that the issues of 'idolatry' raised by Kateb (2006) are unfounded, especially when heroic or patriotic actions are 
considered in democratic societies, where the any exertion of power, especially that seen in opposition to democratically elected officials, often becomes a contentious issue. As such, when whistleblowers like Snowden act against democratically elected individuals and bodies, questions arise as to whether or not they have the democratic or ethical right to do so. It might be argued that they are undemocratically subjecting others to their personal ethical code, and thus, that societal change should come not from individuals, such as whistleblowers, but from democratically-founded institutions and their respective systems (Sagar, 2013). Thus, can whistleblowing be considered an act of heroism, and if so, on what grounds?

It has been illustrated that the conceptualization of the 'hero', and also the 'patriot', is based on one's ability, decision, and power to affect their social environments in the aforementioned manners of serving the humanity of others. Heroic actions, therefore, can be seen as the exertion of power and force which often transcend typical norms and power structures, and can be seen as characteristically exceptional to the daily actions in everyday life. This was precisely the conceptualization of the übermensch (superman/ higher person/ overman) as promulgated in the philosophical writings of Friedrich Nietzsche.

Nietzsche decreed morality as "the herd instinct in the individual" (Alsford, 2006, p.104), in which one slavishly follows the ethical or religious dogmas instilled in society by powerful institutions or collective bodies. It is the übermensch who strives and succeeds to break free from conventional values or moral customs, to question their existence, and to determine on one's own ground the manner in which to live one's own life. As noted by Nietzschean scholar, Ernest Nolte, "To create means for Nietzsche primarily to give 'meaning' and define values. The superman not only provides peoples and times with their tables and values: he creates 'meaning' for the earth and for all aeons to come" (Alsford, 2006, p.104). Nietzsche, therefore, valorises "the anonymous individual, and sees in it the most heroic manifestation of humanity - a humanity free to revel in self-definition and to exercise the will to power" (Alsford, 2006, p.104). To access this 'will', humans need to release the strong animalistic instinct within (the lion); they must act like lightening, powerfully charged (Nietzsche, 1967). For Nietzsche, it was this struggle to reconceptualise the given norms that made one 'super' 
or 'heroic', but it is also on this very basis, that a society, in response to such defiance, might view such actions not only as reckless, barbaric, and heinous, but also, from the perspective of those in, or willing to adhere to, the power structures on national or institutional levels, as treasonous or traitorous. What should be made lucid at this point, is that whistleblowing actions like those undertaken by Snowden, are forceful transcending acts of not merely social norms, but national and institutional laws. These actions therefore are not solely emblematic of ardent social contestations but are the causal force behind their emergence in social debates.

The etymological roots of 'traitor', generally meaning one who 'betrays a trust or duty' stems from the Old French 'traitre' meaning 'traitor, villain or deceiver' and from the Latin 'traditor' meaning 'betrayer', or, more specifically, 'one who delivers', an explicit reference to the actions of delivery performed by Judas Iscariot (Harper, 2014). Under Alsford's (2006) conceptualization of the hero, the villain also possesses a similar potency of force to affect their environments. The difference lies in the kinds of actions they choose to take, and their reasons for doing so.

Whereas the hero strives to enforce the interconnectivity of all humans in the social realm in which she voluntarily subjects herself, the 'villain', in contrast, "revels in the power to control, to manipulate and ultimately to create a world in their own image" (Alsford, 2006, p. 38-39). It is not merely the case that the villain's objective is to create a world for herself but that her goal becomes one of 'world domination', whereby the newly-established laws serve the whims of the omnipotent leader. While the hero embeds himself in a social world governed by ethics, continually strive to align himself with others, the villain, in contrast, "deepens the gulf" between himself and others, seeking instead the domination of the other (p.29).

As previously mentioned the hero chooses to suffer alongside humanity and will not use other humans or nefarious methods to bring forth social justice. The villain, however, as can be seen in the example of Sauron from The Lord of Rings, willingly uses the evil powers, in this case, a ring, to achieve omnipotence and to fulfil his own self-serving desires of destruction. The villain, like Darth Vader in Star Wars, or the Joker in Batman, takes no issue with using others as objects, as weapons; she is more than 
willing to subsume whatever is available, including previously-established allies, as pure resource (Alsford, 2006). It is the central objective of the villain to foist rules, order and control over others as a means of creating the empire of their desires, an empire in which it is the villain who becomes more and more powerful, more and more disconnected from those over whom he rules. Alsford expands on these notions, drawing connections to institutions, as he (2006) writes,

It is little wonder that multinational corporations, bureaucracies and political parties of all kinds are often viewed with suspicion and cast in the role of the villain as they become increasingly disengaged from ordinary lives. Faceless corporations and other powerful organizations appear to care little for the lives of actual human beings concerning themselves rather with abstractions, apparently for the sake of greater efficiency and objectivity. (p.120)

When Snowden, therefore, discloses what he has understood to be institutional malpractices in the NSA, he might not necessarily endorse a nefarious framing of all NSA activities, but it becomes possible for society to view the institution as an 'evil' entity that needs to be reckoned with. All whistleblowers, however, by making use of their special capacities and situational power to transcend the norms, usurping previously-established bodies of power, especially for what might be perceived as selfbenefit, have the potential to be deemed villainous, and in turn labelled as 'traitors' by the powerful bodies which granted them power.

A 'traitor' is understood to have committed some form of betrayal to any social group to which he belongs: his family, friends, ethnic group, team, religion, social class, political party or nation. Hoffman (1997) notes that "traitor is a harsh word, belonging to a set class of vile epithets" and "applies far beyond the arcane universe of those who trade in state secrets" (p. 30). Hoffman (1997) observes that in many cases a populace might envy or cherish a traitor's rebellious, free spirit in that by setting and living by their own rules, they harness and convey a somewhat romantic aura. In reality, however, a traitor's life often ends up riddled with controversy and derision - especially when the traitor's actions are taken against one's state, when treason is committed (Hoffman, 1997). 
Treason is defined in Oran's Dictionary of the Law (1983), as a "citizen's actions to help a foreign government overthrow, make law against, or seriously injure" the nation of one's belonging (Pantana Sr., 2007, p. 121). When treason is committed, the word 'traitor' is commonly used to describe the actions of these individuals. In attempting to make sense of the psychological motives underpinning acts of treason, Carlton (1998) argues that the concept of treason escapes eludes simple, straightforward definitions. Complicating the notions in (Pincher, 1987), Carlton (1998) states that "traitors can be ambitious, unscrupulous, and ruthless, but they can also be suave and charming, and...can often be both kinds of people at the same time" (p. 240). Thus, while it might be possible to view 'personality defects' as the driving force behind a person's treachery, as Pincher (1987) had done, Carlton (1998) argues that there is no concrete evidence for causal connections of this kind. Rather, for Carlton (1998), any definition of treason ultimately depends on the context and circumstances in which that action had taken place. "It is precisely this point, this inherently grey zone of interpretive possibilities, that leads West (1995) to state, 'one man's traitor is another man's patriot'” (as quoted in (Carlton, 1998), p.1).

Alsford (2006) also takes up this complex realm of interpretive possibilities regarding heroes, patriots and traitors. With a clearly-defined enemy, it becomes rather easy to establish for what it is that superheroes are fighting: Superman, Wonder Woman and Captain America are all comic book heroes that were constructed as figures devoted to combatting the evil forces of Fascism on America's behalf (Alsford, 2006). There are other superheroes, however, such as Batman, dedicated to fighting a more enigmatic enemy, an enemy which others might not perceive to be an enemy at all. Contrary to the aforementioned superheroes, who always act in adherence with the system and its laws, superhero vigilantes like Batman strive to serve and protect the general populace from dominating, and corrupt bureaucratic powers. Their efforts in fighting for justice are much more personal, more emotionally-infused. Alsford's (2006) analysis demonstrates that often times both mythological heroes and villains are suffering emotional strife accrued from antecedent events in their childhoods. How individuals act on these emotions often sets them on diverse paths. 
In the example of Star Wars, Yoda teaches young Luke Skywalker that the dark side of the force is rife with anger, fear and aggression, forces which needs to be constantly resisted. In the case of Batman, Bruce Wayne's alter ego, the impetus for his vigilante actions is not simply overarching ideals but rather deeply-conflictive emotions (his parents were murdered by governing powers [the typical revenge plot]). Alsford (2006) argues that for this reason there is a 'sheer humanness' to Batman; we can associate with his pain, his carnal anger spurred by injustice. Batman, however, strives to protect others from experiencing the pain he has suffered but in doing so becomes a conflicted hero. One on hand, he wants to help society. On another, he wants revenge. It is this very conflict, and the manner in which he deals with it, which makes him, according to Alsford, "more human than superhuman" (p.54). Alsford (2006) writes,

The Judeo-Christian tradition speaks of vengeance being the prerogative of God and this provides us with something of an insight into the popularity of heroic figures such as the Batman... [he] is more the Nietzschean superman than is his red, white and blue counterpart who actually bears the name. While Superman is very much part of the establishment and thus never truly free to judge it, the Batman is the other, the vigilante who stands outside established laws and conventions, free to set his own agenda to watch the watchmen as it were. (p. 55)

Paraphrasing Skoble, Alsford (2006) adds that the crime-fighting vigilante stops at next to nothing to attain his or her notions of what constitute social justice. What surely appears obvious, however, is that any clearly definable notion of the 'objective right' does not exist. The central issue becomes, therefore, a problem which has been touched on throughout this theoretical overview of 'heroes', 'traitors', 'patriots' and 'villains', one that might best be summarized in the following question: Does the forceful exertion of one's own ideals over democratically-instilled processes not stand in opposition to the democratic ethos, regardless if the taken actions are deemed 'heroic' or 'patriotic' under the humane, pluralistic, and interconnectivity-creating tenets of Alsford and Viroli? It is this very question which plays a substantial role in constituting the debate which Edward Snowden's whistleblowing has evoked.

Hook (1945) is cautious about the valor of heroic actions in democratic societies, writing that if a hero is understood as acting individually in a manner that re-determines the 
path of history for others, that democratic societies should not only be weary of him or her, but should be "on guard against him" (p.229). In acting against the powers of a ruling majority elected through democratic processes, the 'potential hero' must be one who "sees what others do not. His will to action is stronger. His knowledge of what must be done to realize what he sees is surer" (p.232). Thus, because the 'hero' often finds himself in the minority, "His sense of vocation impels him to fight for his insight. His loyalty to the democratic ideal compels him to make this insight the common faith of the majority" (p.232-233). As a consequence, notes Hook (1945), the task becomes one of educating the majority on his actions with the efforts of winning over the majority's approval. In short, a battle begins in the public sphere; a battle of ideas, beliefs, and astute persuasive tactics; a battle in which powerful figures and the public at large defend their positions, and attack their adversaries; a battle in which rhetoric is wielded like shields and swords, missiles and mustard gas.

It is precisely this discursive battle which comes to presence in the discursive enactment of Edward Snowden. With various actors taking up various positions, joining together, at times, into political camps, a war wages that strives to dominate and shape the public's understanding of Snowden and his whistleblowing. Before detailing the theoretical principles which outline how discursive enactments take place in highlypoliticized milieus, a theoretical history of whistleblowing in the American context will be provided. Whistleblowing is not unique to the United States, but understanding how and why whistleblowing occurs in the American context illustrates why Snowden's actions have gained such a high degree of social relevance.

\section{Whistleblowing in the American Context}

Johnson (2002) notes that "during the last three decades, whistleblowing has become a prominent part of U.S. vocabulary, culture, organizational life" (p.2). This declaration, however, may have more to do with the widespread use of the term 'whistleblowing' than the act of publicly disclosing the malpractices occurring in profit or non-profit organizations; antecedent events show the practice's roots deeply embedded in American history. 
In the latter half of the 1800's, during the American Civil War, it was discovered that defense contractors were selling deficient, fraudulent and hazardous war products to the Union Army.4 Responding to this malpractice, the False Claims Act of 1863, which still exists today, encouraged citizens to disclose said malpractices, which resulted in sullying the brand's reputation and in turn hindering their ability to move products. Furthering this initiative of encouraging disclosures, President Lincoln included a 'qui tam' provision, whereby citizens unaffiliated with the government could file claims against these corporations on the government's behalf. As such, citizens were able to receive not only compensation for incurred legal fees but also financial rewards in the range of 15 to $25 \%$ in cases which resulted in conviction (Shantz \& Tomblin, 2014). Some 50 years later, the Lloyd-La Follete Act (1912) recognized the importance and need for employees to publicly disclose malpractice in the civil service by offering legal protection for employees who decided to take action. Previous to this act, the dismissal of employees needed not be substantiated with due process (Shantz \& Tomblin, 2014).5 Thus, the need for common or ordinary individuals to willingly transcend the confines of regulated, organizational power structures for the betterment of society can be evidenced as a central tenet of social and organizational justice in America. Hannah Ardent (1972) touches on this notion, writing, "Ever since the Mayflower Compact was signed under a different kind of emergency, voluntary associations have been the specifically American remedy for the failure of institutions, the unreliability of men, and the uncertain nature of the future" (p. 102).

It was in 1960's when these acts of disclosure formally acquired the name 'whistleblowing'. Hersch (2002) traces the first use of the term to 1963, where Otta Otopeka's act of giving classified documents to the chief counsel of the Senate Subcommittee on Internal Security picked up the 'whistleblowing' moniker; a term which derived, it has been argued, from the image of an English policeman blowing his whistle to alert the public and other police officers of criminal activity. In this period, the coining of 'whistleblower' served the purpose of distinguishing these particular 'dissenters' or 'info informants', like Otopeka, from informants ('rats', 'snitches', or

\footnotetext{
${ }^{4}$ Examples of such products included: weak and malnourished horses, malfunctioning rifles, and gunpowder salted with sawdust (Shantz \& Tomblin, 2014) citing (Lahman, 2005).

${ }^{5}$ Paraphrased from (Smith \& Gebale, 1974).
} 
'name namers') "who provided evidence against the Mafia, or former communists... for the FBI and assorted congressional committees.” (Johnson, 2002, p. 4)

Teo and Caspersz (2011) as well as Johnson (2002) pinpoint a conference (and subsequent publication) organized by Ralph Nader in the early 70's whereby a formal definition of whistleblowing was legitimized as the following: "an act of a man or woman who, believing that the public interest overrides the interest of the organisation he [sic] serves, blows the whistle that the organization is involved in corrupt, illegal, fraudulent or harmful activity" (p. 237). Because whistleblowing is so firmly engrained in the American cultural landscape, evident in an abundance of films addressing the topic (Serpico, Silkwood, Marie, The Insider, Erin Brockovich, North Country, Michael Clayton, The Whistleblower, CitizenFour), television shows such as 60 minutes which are devoted to documenting in-depth exposures, as well as the fact that in 2002 Time magazine's person of the year were three whistleblowers: Cynthia Cooper (WorldCom); Coleen Rowley (FBI), and Sherron Watkins (Enron), questions arise as to why whistleblowing permeates with the vigor it does through American society.

Johnson (2002) claims there are four main reasons why whistleblowing is enacted in America with such great frequency. First, numerous changes have taken place in American bureaucratic practices. Increased levels of education have resulted in professionals who not only hold their work and their work environments to high standards but are less likely to compromise these standards when professional codes of ethics are broken or bent. Furthermore, studies have shown that institutions holding onto outdated ideas of organizational methods become more vulnerable to whistleblowing, a dynamic intensified through the advent and use of new technologies, such as the internet, which radically alter organizational practices.

Second, there are a wide range of laws in the United States which encourage whistleblowing and protect whistleblowers. In addition to the 'Ethics in Government Act (1978), the previously-discussed 'False Claims Act', and the 'Code of Ethics for Government Service (PL 96-303)' there are federal hotlines for each agency which encourage people to report on instances of government fraud and waste. Also, although monetary gains rewarded under the False Claim Act might not be the central motivation 
for all whistleblowers, they certainly play a motivational role in some circumstances. Laws such as the 'Uniform Health and Safety Whistleblower Protection Act', and, more importantly the 'Whistleblower Protection Act' of 1978 which was strengthened in 1989 and 1994, provide some means for legally protecting those who decide to blow the whistle (Johnson, 2002). Additionally, the Sarbanes-Oxley Act of 2002 strives to protect whistleblowers in American corporations (Shantz \& Tomblin, 2014; Teo \& Caspersz, 2011). Important to note, however, is the relative ease with which government seems to bypass or bend whistleblower laws to persecute whistleblowers as they see fit, as was the case with - to give one example - Chelsea Manning (Shantz \& Tomblin, 2014).

A third reason why whistleblowing occurs in the United States with such frequency is that institutional support for whistleblowers is extensive. As whistleblowers need to make claims of credibility and legitimacy, national and public media are more than willing to assist in telling their stories. Additionally, organizations such as PEER (Public Employees for Environmental Responsibility), AAAS (American Association for Advancement of Science) offer support, financial or otherwise, to whistleblowers. As does the National Whistleblower Centre, formed in the mid 90's, and the very reputable, and financially-strong Government Accountability Project (GAP). Acts of dissent, including those in the form of whistleblowing, are often falsely interpreted as a solely individual endeavours but the overarching community of support should not be disregarded (Arendt, 1972).

Fourth and lastly, American society, as a culture, values whistleblowing. Although exposed agencies may frame whistleblowers as disloyal, characterizing their actions as malicious or treasonous, the media and congress often embrace whistleblowers, lauding their actions, portraying them, as aforementioned, as heroes (Johnson, 2002). This was certainly the case with Jeffrey Wigand, "the insider", who blew the whistle on Brown and Williamson Tobacco, exposing the manner in which the company had misled the public concerning tobacco's addictive qualities. On one hand, Wigand was blasted by the tobacco industry, which labelled him a traitor. Popular media, however, propped him up as a 'hero' (Johnson, 2002). Wigand's actions, like those taken by many whistleblowers, strike a chord with the American ethos of individualism, a seemingly paradoxical notion in which a notion of individualism is embraced collectively, where one's courage to act 
in the face of corruption closely aligns with the deeply-rooted American tradition of civil disobedience.

Quoting (Rubin, 2000), Johnson (2002) writes that "Jeffery Wigand believed that the fundamental message of his story was that 'an individual can take a stand and make a difference' (p. 16). As such, while acting in a courageous yet bellicose, individual manner, whistleblowers simultaneously stand up for the general public, addressing health and safety, or ethical issues about which people are personally concerned. It is the sense of saving people, or looking out for the masses which plays a role in labelling the actions of whistleblowers as heroic. This can certainly be applied to the fields of health or engineering where malpractice can have vital, life-and-death consequences (Johnson, 2002; Hersch, 2002). It is a case of numerous individuals, working collectively, to uphold the rights of individuals. Lastly, there are major awards that are given to whistleblowers or 'truth-tellers', the two most famous of which being: The Sam Adams Award, and the Ridenhour prize. It should be noted that Edward Snowden, as well as Thomas Drake, has won both of these awards.

Since 9/11, the interest in and enactment of whistleblowing has increased substantially; the GAP's whistleblowing intake has tripled (Johnson, 2002). Fueled by an aura of fear and suspicion, for many whistleblowing has become a patriotic duty. The internet has also played a significant role in the heightened practice and interest in whistleblowing activities in the modern age as the mediums for disclosing information are now lesscentralized, less-regulated, more communal and more accessible. The now well-known case of Wikileaks, the not-for-profit website created in 2006 by Australian hackeractivist, Julian Assange, demonstrates how an enormous amount of valuable and polemical information can be made accessible to anyone in possession of a computer equipped with an unrestricted internet connection.

The role of the internet and digital technologies is central to the whistleblowing case of Edward Snowden. Not only is it on, and through the internet, where Snowden's story primarily takes place, but his whistleblowing itself discloses issues of malpractice concerning the NSA's activities regarding the internet. As such this study's analysis of the discursive enactment of Edward Snowden focuses, almost exclusively, on the 
discursive enactment of Snowden in the digital realm of the internet. In order to adequately and diligently shed light on this discursive enactment, what is required is a conceptualization of discourse deemed applicable to assess the highly-politicised and ardently-antagonistic social milieu that Snowden's leaks have created. It is towards this conceptualization of discourse where this study now turns.

\section{Conceptions of Discourse}

Although Laclau and Mouffe's conceptualization of discourse has been criticized on various grounds, as seen in (Butler, 1997) and Geras (1990), one particularly pointed criticism of their notions is that they subsume all notions of discourse in the realm of the political (Torfing, 1999). While this might in fact prove problematic for all assessments of discourse, in the case of Edward Snowden's whistleblowing, the discursive sphere is not only political, but ardently so. As such, Laclau and Mouffe's theories prove useful in providing an analytic framework through which one can elucidate the discursive enactment of Edward Snowden. In order to briefly summarize Laclau and Mouffe's complex conceptualization of discourse, a very short summary of Marxist thinker Antonio Gramsci is necessary, not only because his theories directly inform those of Laclau and Mouffe's, but also because his concept of 'public intellectuals' informs the discussion. In addition, Maarten Hajer's terminology will be introduced and defined as it proves helpful in establishing Laclau and Mouffe's theories in practical terms. Lastly, because the enacting of discourse is partially contingent on the technological means, or material objects, that allow such discourses to take place, a basic overview of Actor Network Theory (ANT) will be provided.

Gramsci occupies an influential position in the advancement of social thought (particularly social thought working inside of the Marxist tradition) in that he problematized the Marxist binary distinction between base and superstructure, arguing that it was not merely the economic base which determined social identities but rather the materialization of 'Ideology' propagated by the powerful social forces, embedded in particular socio-historical epochs. 'Ideology' in Gramsci's (2000) terms is not, however, a nefarious force inflicted upon unwilling subjects, but rather a means through which people organize themselves sociologically into camps of social power imbued with 
political desires. Gramsci (2000) uses the term 'hegemony' to describe the process in which these camps form.

In order for hegemony to take place, all subjects play an active role. It is not the case that the political elite force or coerce citizens to take up certain positions, but rather that they seek to win them over by consent. What occurs is that a ruling class provides 'intellectual and moral leadership' not simply 'political leadership'. If they are able to win over the consent of civil society through discursive practices in private affiliations, public institutions, and culture in general, they manage to construct a 'collective will' in the citizenship; they manage to create 'hegemony'. However, because hegemony is a temporally-bound unification of social powers, different hegemonic blocks can rise up and seize power, capsizing the hegemonic blocks that were previously established. What exists in society, therefore, is a perpetual sea of social forces which gain social potency through contributions and amalgamation. This hegemonic creation of a populace's 'collective will', which contributes to the creation of an 'historic bloc' (a social unification of both structural and superstructural elements), is partially dependent on the efforts made by 'public intellectuals', and partially dependent on the public at large.

'Public intellectuals' are not necessarily 'intellectuals' with regards to any academic or esoteric knowledge, but rather, in Gramsci's (2000) terms, figures who can use rhetoric to construct ideas and arguments through which people come to align, and to enact, their socio-political identities. The public might not be able to re-articulate the arguments and ideas they experience with any degree of eloquence, let alone articulate them at all, but do become affected by their force, and in turn become affiliated emotionally, psychologically, materially (through actions) with certain socio-political camps. As such, the actions of the public at large are integral and instrumental in the construction of the hegemonic blocs. The result of such processes is that hegemonic activities create an imbrication of social groups in which social actors possess a wide variety of affiliations; one could not distinctly demarcate one from the other. This last aspect, which concerns the practical consequences of hegemony, is developed by Laclau and Mouffe, whose conceptualization of discourse borrows heavily from these notions of hegemony posited by Gramsci. 
For Laclau and Mouffe, the notion of discourse presupposes an understanding of the social in which everything is text (discourse). This notion does not deny or negate the existence of an objective material world but rather posits that when that external world is brought into the realm of the social, it necessarily possesses the potentiality to be read (interpreted) and written (re-interpreted for oneself or for others). They (1985) write,

the fact that every object is constituted as an object of discourse has nothing to do with whether there is a world external to thought, or with that realism/ idealism opposition.... What is denied is not that such objects exist externally to thought, but the rather different assertion that they could constitute themselves as objects outside any discursive conditions of emergence. (p. 94)

As such, although Edward Snowden is not what we would typically call an 'object', he is certainly a material entity existing in the 'real' world. He is, therefore, without doubt, a corporeal being that lives and affects the material world. Any efforts to render his being through language, or text, however, necessarily entail the enactment of him, discursively.

In turn, under Laclau and Mouffe's notions, any instance of discourse and discursive enactments involves mediation between parties in the realm of the social (Torfing, 1999). Where one's physiological engaging of the world might best be understood through phenomenological understandings of one's being in relation to the external world - a world through which even one's senses are mediated by the meanings one's world have ascribed to it - a notion of discourse implies the necessarily relational mediation of meanings between subjects engaged in shared communicative practices. Paraphrasing and quoting Laclau (1998), Carpentier and Spinoy (2008) write that "all social phenomena and objects obtain meaning through discourse, which is defined as 'a structure in which meaning is constantly negotiated and constructed”" (p. 4). Furthermore, for Laclau and Mouffe, discourse, or the perpetually mediated and negotiated construction (or enactment) of meanings, is materially-bound and inherently antagonistic (Torfing, 1999; Howarth, 2000; Carpentier \& Spinoy, 2008). Laclau and Mouffe (1985) write, 
Antagonism, far from being an objective relation, is a relation wherein the limits of everyday objectivity are shown - in the sense in which Wittgenstein used to say that what cannot be said can be shown... but if... the social only exists as a partial effort of constructing society... 'Antagonism' is the experience of the limit of society... the impossibility of fully constituting itself. (p. 112)

Constituting the structure of the antagonistic social sphere in which discourse is enacted are the processes of articulation which Laclau and Mouffe (1985) define as "any practice establishing a relation among elements such that their identity is modified as a result of the articulatory practice" (p. 91). A subject, in turn, when engaging in discourse, can make use of a wide range of 'differential positions', 'elements' in Laclau and Mouffe's terms, which are discursive possibilities not yet brought into discursive presence. When these positions are actualized in discourse through articulation, they become 'moments'. Whenever 'elements' become articulated in 'moments', one's social identity is irrevocably intertwined in the enactment, and, in turn, necessarily modified through them (in various degrees). While this notion of discursive functionality applies to all cases of language communication, it takes on a particular role in politicized speech, which is of central concern for Laclau and Mouffe.

Although Laclau and Mouffe's description of articulation is quite similar to Althusser's concept of interpellation, (individuals being made into subjects through societies' structural forces acting upon them) it does not adhere to Althusser's notions of a rigid economic or social determinism (Torfing, 1999). Rather, their concept of articulation hinges on the Derridian notion of the 'play of differences' in which no fixed identity of the subject can ever be achieved (Torfing, 1999). Forever circulating in the nebulous sphere of meaning-making, all 'moments' of articulation cannot provide society or social agents with any fixed essence because the 'moments', and in turn the social agents bringing them forth, are only temporarily fixed in specific discursive acts in specific contexts. When contexts change, when new social agents are introduced, the previous articulations continually need to be re-enacted and reinvigorated in order to gain any established presence. They never reach a stage of fixity or utter completion. As such, Carpentier \& Spinoy (2008) write, 
the impossibility of the multiplicity of identities to fill the constitutive lack of the subject prevents [the subjects'] full and complete constitution because of an inevitable distance between the obtained identity and the subject, and because of the (always possible) subversion of that identity by other identities. (p. 7)

What occurs is a subject, whose very essence consists, in Zizek's (1989) terms, as a 'lack' (Torfing, 1999). Because subjects are deemed to be 'empty voids' who strive towards, but never manage to succeed in, reaching 'full identity', it is this very contingency of all identity that "creates the space for subjectivity, agency, freedom and the particularity of human behaviour" (Carpentier \& Spinoy, 2008, p. 7). The subject, however, can achieve partially-fixed identities, and can do so by enacting a process of self-determined identification with various aspects of the social realm.

Even though the social is always 'overdetermined' (a realm overflowing with meanings which cannot be totalized and in which identities can never manage to fully fixed), and discourses therefore can never reach any final closure, (in Derrida's terms, the play of difference is always at play [Howarth, 2000]), discourses do possess the capacity to be at least partially fixed; a discourse incapable of generating any stable meanings would be utterly 'psychotic' (Laclau \& Mouffe, 1985). The points, or discursive blocks, that partially lock in meanings into discourse are called, using Lacanian terminology, 'points de capiton' or 'nodal points' (Torfing, 1999). Similar to the Derridian concept of 'traces' (Howarth, 2000), nodal points are "privileged signifiers that fix meaning of a signifying chain" (Laclau \& Mouffe, 1985, p. 99). Where nodal points can essentially be seen as activating specific language in specific contexts, the concept of the 'floating signifier' refers to the fact that the 'specific language' only gains its social force through its articulation on the 'signifying chain'. For example, a 'floating signifier' like 'justice' or 'hero' only takes on meaning when it becomes (re)applied to a specific social context. As such, 'floating signifiers' come to be taken up in a variety of diverse contexts and discourses taking on different meanings. When for example, a subject discursively enacts oneself as, say, a 'baker', he or she necessarily adheres to what is required for that subject position to take form (that is, one who bakes and knows about baking), but that self is played against all of the diverse positions of which the baker is not; it is the negation of the 'non-baker', the outside, which, as noted by Derrida, constitutes the very 
identity of the inside terms ('the baker') (Howarth, 2000). The subject-positioning that takes place when one discursively becomes a 'baker', however, does not possess -as can be assumed - the same kind of ardent antagonisms which do occur when the subject positions take on a political nature.

When subjects take on the role of affiliations with various political factions such as: NDP, Left-Wing, Libertarian, Democrat, Republican, Conservative, Liberal, whistleblower, etc., their subjects naturally become more ardently antagonistic; to become a 'democrat' necessarily involves partial or complete denial and refusal not only of the discursive positions which constitute the 'republican', but also the hegemonic social objectives inherent in that term. In the inherently communal process that engages the material, social realm, Carpentier and Spinoy (2008) quote Howarth (1998) writing that "hegemonic practices are an exemplary form of political articulation which involves linking together different identities into a common project" (p. 8). In turn, as noted by Mouffe (2005) the hegemony necessary to constitute one's political identity is always susceptible to the challenge of the hegemonic practices running counter to it, striving to achieve their own respective desired hegemony (Carpentier \& Spinoy, 2008). Succinctly summarizing the play of forces in the social sphere, Torfing (1999, p. 109) paraphrasing Laclau and Mouffe (1985) defines hegemony as "an articulatory practice instituting nodal points that partially fix the meaning of the social in an organized system of differences."

To reiterate, the notion of discourse posited by Laclau and Mouffe is "a relational totality of sequences, in and through which the identity of subjects, objects and social actions are shaped and reshaped" (Torfing, 1999, p. 214) and where, for Laclau (1990), "the constitution of social identity is an act of power and that identity as such is power" (Torfing, 1999, p. 214). The manner in which this shaping and reshaping occurs, the social realm in which the power of identity is gained and lost, relies on notions of constructing signification through 'chains of equivalence' and 'chains of difference' (Laclau \& Mouffe, 1985). The chains of equivalence refer to the blocking in of nodal points of recognizable 'sameness' whereby different identities become linked together against a common enemy or antagonist. Although these identities might continue to differ in some or many respects, they temporality unite through their discursive actions 
in order to solidify particular social positions. In contrast, the chains of difference weaken or chip away at existing antagonisms, striving to reduce their social prominence and relevance. These chains of difference emerge as disjoined and somewhat unaligned discursive particularities linked only to other discursive elements by their differences. As such, "the logic of difference does not presuppose the drawing of a [clearly defined] antagonistic frontier [my addition]" (Carpentier \& Spinoy, 2008, p. 11). The terminology of Maarten Hajer helps to explain these complex conceptual notions in practical terms. Both Hajer's and Laclau and Mouffe's terminology will be used, and used interchangeably, to analyze/interpret the discursive enactment of Edward Snowden. Maarten Hajer has a very similar conceptualization of discourse to Laclau and Mouffe, which he defines as:

....an ensemble of ideas, concepts, and categories through which meaning is given to social and physical phenomena, and which is produced and reproduced through an identifiable set of practices...discourse refers to a set of concepts that structures the contributions of participants to a discussion. (Hajer, 2015, FAQ)

In mapping out the discursive sphere in which Edward Snowden is discursively enacted, one must identify the formations of 'chains of equivalence', constructed through the use of shared language or metaphors. Hajer (2015) uses the term 'storylines' to define these 'chains of equivalence' writing that they "refer to a condensed form of narrative in which metaphors are employed" that "bring people to actually do something" about a particular issue and do not simply "refer to a problem with a fixed identity" (FAQ). These 'chains of equivalence' or 'storylines' are constructed and become imbued with social power as multiple practitioners align their political efforts and socio-political identities to them. Hajer (2015) coins the term 'discourse-coalitions' to refer to that "group of actors that, in the context of an identifiable set of practices shares the usage of a particular set of story lines over a particular period of time" (FAQ). Because these 'discourse-coalitions' are contested by opposing 'discourse-coalitions'- one necessarily requires the other in order for its identity to be constituted as such - the task of shedding light on the discursive enactment(s) of Edward Snowden requires an elaborate mapping out of the various 'storylines' and 'discursive coalitions'. Also, an analysis is 
required of how and why their respective 'chains of equivalence' have come to be used by various contributors. In addition, the 'chains of difference' must also be identified as they work to oppose the 'chains of equivalence'. Central to the conceptualization of 'chains of equivalence' is the fact that they are hegemonic constructions.

Core instrumental tools used in hegemonic constructions are myths, which are defined by Laclau (1990) as "a principle of reading a given situation" (Carpentier \& Spinoy, 2008, p. 9). As noted by Alsford (2006), myths are imaginative responses to existential questions concerning meaning which become discursively constructed through "prototypes representing the extremes of human response to boundary situations (p. 10). The seemingly 'real' discursively-constructed objects are understood to be myths because as Torfing (1999) summarizing (Zizek, 1989) explains, the objects are necessarily a 'void' only substantiated by articulation practices which cannot reach fixity. As such, we might sense that we know what a 'hero' means, but efforts to concretely define it continually fail to totalize its essence. Objects and concepts, therefore, are precisely that which can never be completely and utterly conceptualized, and in turn, only come to presence as socio-political constructions. It is the failure to obtain concrete fixity, which is for Zizek (1989) the "unrepresentable kernel of the Lacanian real" (p. 50).

Subjects, therefore, claiming to enact the 'real', are only involved in the creation of mythological or discursive constructions of that 'real'. In turn, the subject is always split, "trying to establish itself as a fully achieved identity through acts of identification"; "the negation invoked by the antagonistic force is always the negation of a negation" (Torfing, 1999, p. 52). Subjects enacting their identities through discourse can sense the threatening obstacles (counter-discourses) which preclude the full-closure of their social identities. In some extreme cases, these obstacles are viewed (in the terms of Carl Schmitt) as enemies which need to be 'destroyed' (Carpentier \& Spinoy, 2008). In other cases, the negation of one's identity can result in self-blame or self-denial, whereby one becomes traumatically resigned to the impossibility of uniting all into one's particular discursive efforts (Torfing, 1999). Because the social antagonism is constitutive of social identities enacted through discursive responses to the social order's inherent dislocation, "our political actions [are] guided by the illusion that the annihilation of the 
antagonistic force will permit us to become the fully constituted 'we' that we have always sought to be [my addition]" (Torfing, 1999).

Linguistically speaking, the 'nodal points' or 'floating signifiers' used by subjects to enact identities through the construction of chains of equivalence rely on words or phrases that are bursting with an abundance of connotations (are thus widely-interpreted), and which, in turn, can be accessed, or taken up by a wide-range of participants seeking to align themselves with particular social positions. In chains of difference 'metaphor and metonymy' are markedly absent. These chains of difference can be disrupted by the forces of equivalence which produce 'metonymical relations of contiguity'. When the chains of equivalence begin to take on a paradigmatic sameness of 'contiguous elements' what becomes evident, as previously stated by Hajer (2015), is the construction of metaphors. Here, politically-charged objects and concepts come to be constructed not through a widely expansive sea of unique, individual metaphors, but rather easily identifiable blocks of metaphors shared by a wide-range of diverse social subjects. In short, large groups of society come to take up issues using similar discursive metaphoric structures. Once again, these constructions are not 'real' (the real has already been posited as an unobtainable 'lack' or impossibility of full presence) but rather, social imaginations or myths that strive to constitute a stable objectivity (Torfing, 1999). It is for exactly this reason that ideology, in Zizek's terms, "constructs the real world in terms of fully constituted essence and tends to deny that these essences are contingent results of political decisions taken in an undecidable terrain" (Torfing, 1999, p. 116). For Zizek, as paraphrased by Torfing (1999), although many people possess the capacity to recognize the constructed nature of 'ideological truth', and therefore do not become fully invested in their knowledge (don't take them seriously), society as a whole still 'acts', generally speaking, according to these representations. Zizek (1989) calls this the ideological fantasy in that what people 'mis-recognize' is the illusion structuring reality, and, in turn, their 'real social activities'. Zizek argues that there is some pleasure or enjoyment involved in enacting the ideological fantasy (Torfing, 1999). 
In terms of identifying the social antagonisms evident in discursive practices, Laclau and Mouffe (1985) state that there are typically two kinds: the popular and the democratic. In case of popular antagonisms, the social space becomes simplified whereby a plethora of voices amalgamate into one 'predominant chain' or one 'major social antagonism' in which two distinct, combative camps ('coalitions') are formed. This is precisely what can be found in the discursive enactment of Edward Snowden. In contrast, in democratic antagonisms, everything is more complex and diverse. There are all kinds of diverse social spaces, all kinds of different battlegrounds where voices are unified in a plethora of diverse camps. Laclau and Mouffe note that in situations of increased individualization where societies might be disjointed or unified, the possibility of organizing popular struggles becomes increasingly diminished and it becomes increasingly difficult for people to unify in collective action (Torfing, 1999).

Lastly, the distinction between what is defined as the discursive vs the non-discourse requires attention. While this distinction remained ambiguous and problematic in the notions of discourse posited by Foucault (1972), and while Laclau and Mouffe have taken up the distinction on a philosophical level (arguing that all objects are necessarily subsumed socially through mediated discourse), Actor Network Theories (ANT) describe the relationship between subjects and objects from a sociological perspective which proves useful for empirical studies.

Actor Network Theories (ANT) emphasize the role, or agency, that non-human actors (tools, for instance) have in the construction of social worlds and social practices. In ANT, humans and technologies are seen as 'working together'; as noted by one of ANT's leading theorists, Jim Johnson (1988) ${ }^{6}$, who, after illustrating how objects become 'delegates' when humans delegate roles to them, writes, "Knowledge, morality, craft, force, sociability are not properties of humans but of humans accompanied by their retinue of delegated characters. Since each of these delegates ties together part of our social world...studying social relations without the nonhumans is impossible" (p.310). In addition, Latour (2005) states, "There exists no relation whatsoever between the 'material' and 'the social world' because it is this very distinction which is a complete

\footnotetext{
${ }^{6} \mathrm{Jim}$ Johnson was a pseudonym used by Bruno Latour
} 
artifact" (p. 75). Objects have social roles to play alongside humans, and therefore have varying degrees of agency.

In laying out ANT's objectives and practices, John Law (2009) states that ANT is an empirically-based, descriptive practice more so than a theory; it seeks to unveil processes and the relations that constitute processes by asking how these relations assemble. As such, it describes, or 'traces', webs of activity in which neither the material nor the human are posited as the principal, dominant force, but rather interlocking potentiality-creating zones through which other networks or webs are connected (Law, 2009). There is not one specific methodology of which one undertaking ANT makes use, but the overall objective is one in which the 'social as a fluid' is made partially 'visible' an act which occurs when "new associations are being made" (Latour, 2005, p.79). As such, with regards to discourse, as objects and subjects discursively come to presence an act in which discursive meanings are transferred, absorbed, contested and resisted through material objects- some attention needs to be paid to these very material objects as they significantly contribute to the construction of the discursive realms in which meaning takes place. The discursive enactment of Edward Snowden in this study takes place on the digital realm of the internet, and some attention therefore needs to be paid to the kind of particular discursive spheres that the medium of internet creates.

With regards to the notion of how identities are enacted on the internet, because Laclau and Mouffe have stated that any instance of discursive articulation necessarily involves the modification of a subject's identity, what occurs on the digital discursive realm of the internet are instances where subjects take on a polyphony of multifarious identities. At times individuals engage the discursive sphere using their 'real names', but in other instances, individuals use (multiple) monikers and pseudonyms depending on personal motivations, which might include desires to remain anonymous, or desires to play out various conceptualizations of self. As noted by Poster (1990), like media-theorist Marshal McLuhan, the "mode of communication 'reconfigures the subject and its relation to the world' (Torfing, 1999, p.221). As such, paraphrasing Poster (1990), Torfing (1999) notes that the mediated communication in electronic domains such as the internet lends itself to the potentiality of the subject to construct and reconstruct his or her identity with, and through, a wide-range of discourses. In turn, the subject is 
perpetually involved in the practice of constituting the self through reading and writing practices that emphasize 'multivocality'. Individuals, therefore, become 'nomadic and multiple selves', and in turn, with regards to this project, a question arises as to how these diverse multiple selves become unified or aligned into shared hegemonic practices.

It is under this conceptualization of discourse, in which individuals enacting multifarious and ultimately unfixable identities in digital politically-charged realms construct and align themselves with hegemonic blocs, which outlines how an understanding of the discursive enactment of Edward Snowden can be ascertained. 


\section{Chapter 4: Method}

\section{Overview of Chapter}

This chapter outlines how the digital realm of the internet was engaged in order to map out and make sense of the discursive enactment of Edward Snowden. First, the theoretical underpinnings of the methodological practices will be described. Next, the data obtained for analysis will be provided, including the methodological procedures undertaken to collect the data. Detailed here will be the basic principles of how online search engines function, as well as how and why a corpus was built from YouTube comments. Lastly, the methods used for analyzing the data will be provided.

\section{Theoretical Underpinning of Methodological Practices}

The overarching investigative principles employed in this project are those which pertain, as previously mentioned, to the broad and diverse field referred to as discourse analysis. Based on the notions of language posited by Wittgenstein (2009), who writes that "language is part of an activity, or a form of life"(p. 15), Quine (1964, p. ix) who states that "language is social art", and Strawson (1954) who argued that to grasp the meaning of language is to grasp "a procedure - a way of acting" and thus, that language meaning equates to "use" (Stainton, 1996 p.151), all discourse analysis works inside the paradigmatic understanding that language is an active force contributing to the creation and modification of social realities. As such, discourse analysis, argues Hajer (2015), "is a method to analyse what language, the politics of meaning that take place, the way in which it affects perceptions and cognitions, the way in which it distributes power to some and less to others" (FAQ). Furthermore, discourse analysts work off the notion that there are patterns, typified forms, or generic structures and occurrences embedded in uses of language which can be analyzed to demonstrate how these uses affect and create diverse social environments. Because, as aforementioned, this project works on language enacted in politically-charged social realms by politically-invested participants, the goal becomes one of not simply analyzing patterns, typified themes, or structures in political arguments but more about "analysing politics as a play of positioning at particular sites of discursive production", which (Hajer, 2015, FAQ) refers 
to as Argumentative Discourse Analysis (ADA). In these kinds of investigations, the discourse theorist plays a distinct role.

The conception of a discourse theorist's methodological practices used in this project aligns closely with notions outlined in (Howarth, 2000) in that, while I view my investigative efforts as both theoretically and empirically rigorous, I am not able to remove myself from the processes through which my work takes place. Not only are my subjective biases inherent in each of the work's processes, and necessarily so (I can't not bring myself to the table of inquiry), but these very biases are also shaped by the sociohistorical era in which I live. In short, because I see all language meaning and knowledge-making practices as not only socially-imbued, but subject to, using Kuhnian (1962) terminology, 'paradigmatic shifts', that is, subject to knowledge-making rules, guidelines and social practices that change over time, I strive to make sense of social practices by interpreting their meanings in specific socio-historical contexts. I do so on the basis that whatever 'truths' are derived from study can only be determined as valid, false, flawed, or otherwise, by the 'community of scholars' with whom I'm communicating and with whom I share some overarching conceptual understandings of knowledge-making practices. As there is not one specific approach, or methodology, reigning supreme over others in terms of conducting discourse analysis, my approach takes up and interacts with the methodologies pertaining to Grounded Theory, Online Ethnography and Corpus Linguistics.

With regards to Grounded Theory, my project can be understood as interacting in the space between what Breckenridge (2012) defines as 'Classic Grounded Theory' and 'Constructivist Grounded Theory'. On one hand, I work in the 'Constructivist' realm in that, following Charmaz (2003, p. 250) as cited and quoted in (Breckenridge, 2012), I take up notions that assume "the relativism of multiple social realities", acknowledging "the mutual creation of knowledge by the viewer and viewed, and aim toward and interpretive understanding of subjects' meaning” (p.64-65). I acknowledge that my reality and that of the participants is a shared one. I do not, however, explicitly 'give voice to my participants' by interviewing or conducting surveys with those whose discourses I analyze. This is a core component of the 'Constructivist' methodology (Breckenridge, 2012). As such, I partially work in the realm of the 'Classic' in that my 
findings are solely focused on the "patterns of behaviour in which people engage" (Breckenridge, 2012), in this case, individuals' online discursive acts with respect to Snowden and his NSA disclosures. This is not to say, however, that I do not value or wish to consider the perspectives of those I am studying. To the contrary, I view the discursive acts embedded in specific instances of discursive activity as representative of their perspectives.

Furthermore, while my perspective does not strive towards, as previously-stated, the goal of pure 'objectivity', nor does it merely apply an a priori theoretical framework of analysis to the Snowden situation, traits which are typical of 'Classic Grounded Theory' (Breckenridge, 2012). In contrast, it is the way the data has emerged which informs and guides the kind of theoretical approach of which I made use. It is the discursive participants and their discursive acts which have continually forced me to adapt, to reassess and to reconsider new perspectives and theoretical lenses.

Lastly, my methodological practices might be argued to be more aligned with the 'Classic' camp in that I do focus primarily, though not exclusively, on a 'core category' or 'one main concern'. As noted by Breckenridge (2012), "it is the focus on one core category that enables the classic grounded theorist to present an integrated, parsimonious, theoretical product", which is, however, "transient [and] open to modification as it is exposed to new data" (p.68). Paraphrasing Glaser (2014), Breckenridge (2012) explains how the interpretations of the specific study move upwards towards the conceptual level thus enabling those case-specific understandings to be applied to different settings, and to be modified or reinterpreted as deemed necessary.

Ultimately, my methodological position combines tenets of both 'Classic' and 'Constructivist' Grounded Theory. While I certainly possessed a theoretical understanding of language use and discourse before engaging with the discursive enactment of Snowden, it was the discourses themselves which played a role in shaping the theoretical and methodological practices I would take up for the project. From the onset, the principle practice in which I was involved was that of performing what I have called a form of 'online ethnography.' 
My practice of 'online ethnography' embodies some of Androutsopoulos' (2008) practice of 'Discourse-Centred Online Ethnography' (DCOE) yet does not include 'moving offline' and thus, as already stated, engaging the participants through interviews or surveys. In outlining his methods for DCOE, Androutsopoulus (2008) highlights that DOCE research-practices focus on the communicative patterns and social relationships between communities and groups based on their language practices online. He then compliments these efforts by engaging online participants, offline. Androutsopoulus (2008) notes that doing this kind of ethnography works not solely as a tool for research but as a means of connecting various methodological and conceptual practices from a range of various traditions.

Regarding the analysis of interactions online, I share Androutsopoulus (2008)'s practice of 'systematic observation', which involves, "the continuous monitoring of given sites of discourse" which, in turn provides "insights into discourse practices and patterns of language use on these sites" (no page). Furthermore, 'systemic observation' "aims at charting the complex architecture of [spaces] and understanding the various relations among [their] components" [my addition] (no page). In turn, the questions that are asked of these spaces focus on the "activities unfolding in these environments", "their pace or rate of change", as well as "their main actors" and the manner in which they "interact or interrelate". These questions are expanded to the manner in which they interact with other online sites, and their respective participants, semiotic and linguistic features, and applications of genre. Ultimately, the goal is to engage with all the material on sites, including hyperlinks, into order to get a "feel" for the shape of the "discourses, emblems and language styles" (Androutsopoulus, 2008, no page). It is of upmost importance that websites are monitored regularly and for a long period of time, paying careful attention to changes or updates in previously-established trends and themes. Androutsopoulus (2008) notes that a researcher may make use of popularity statistics in forums in terms of tracking the kinds of movement patterns taking place in interactive spaces like comment forums. This approach to 'systematic observation' is precisely the kind of practices in which I was engaged with respect to the Snowden story, enacting what I had labelled as my own process of 'online ethnography'. 
Lastly, my methodological practices touch on those which pertain to corpus linguistics, or more specifically, to corpus-assisted discourse studies (CADS). Generally speaking, corpus linguistics is a kind of linguistic analysis pertaining to a large body of texts compiled in a corpus. The principle reasons for conducting most kinds corpuslinguistics is that the data set is: 1) far too large to analyze using manual procedures without the assistance of computer-based technologies, and 2) these computertechnologies provide researchers with the tools to reveal "broad discursive patterns through frequency, statistical significance, and language patterning alignment techniques (Freake, 2011, p.23). Partington (2008), in turn, writes that CADS "is the investigation, and comparison of features of particular discourse types, integrating into the analysis appropriate techniques and tools developed within corpus linguistics" (p.96). A CADS approach, therefore, works towards revealing "non-obvious" meaning, ('not readily available to naked-eye perusal') by combining a more quantitative approach, in some cases using statistical analysis (counting tokens and types and drawing out relationships) with the more qualitative approach of doing close and detailed textual analysis (Partington, 2008). For my particular study, the use of corpus linguistics is not taken up to identify specific linguistic patterns but rather as a means of revealing contextual elements that have been deemed relevant.

\section{Data Collection Procedures}

Engaging in the aforementioned processes of 'systematic observation', I began to map out what I will call 'discursive spheres'. I have detailed, as will be described in findings, what makes each sphere unique and particular. Androutsopoulus (2008) notes that 'systematic observation' establishes a backdrop, whereby the main themes of - in my case a 'sphere' - become evident, which, in turn, determines which text samples can be chosen for more specific linguistic or thematic analysis. Because the discursive spheres had demonstrated highly-politicized combative debates, Laclau and Mouffe's, as well as Hajer's conceptualizations of discourse proved applicable to provide an overarching analytic framework. Thus, I began analyzing the ascertained spheres for the possible instances where Hajer's (2015) concept of 'storyline', as well as Laclau and Mouffe's 
concepts of 'chains of equivalence', 'chains of difference', 'popular antagonism' and ‘democratic antagonism' could be seen as evident (Torfing, 1999).

Based on my immersion in the discursive fields concerning Snowden and his NSA disclosures, I noticed the emergence and prevalence of a discursive debate in which Snowden was being labelled a 'hero', 'a patriot' and conversely, a 'traitor'. Because I realized that the terms 'hero' and 'patriot' were being used almost synonymously, and in many cases interchangeably, and because I realized that the use of term 'hero' was more predominant that that of 'traitor' - an observation confirmed with the manner in which society at large in YouTube comments was taking up the debate - I decided to focus on discursive acts where Snowden was labelled a 'hero'. In turn, the goal became one of making sense of the kinds of arguments used to discursively enact Snowden as a 'hero' and a 'traitor'. The objective was to ascertain the kinds of arguments that were being used and whether these 'hero'/'traitor' arguments portrayed him in the same way in which the aforementioned studies outlined the socio-discursive constructions of the terms: 'hero' and 'traitor'. I decided to select an equal number of discursive acts with respect to each portrayal (11), which resulted in 22 in total. The number of discursive acts chosen was determined based on the relevance that the Google's search engine algorithm has ascribed them. That is, the 22 discursive acts chosen were those that appeared on the first three pages of Google's search results when "Snowden hero" and "Snowden traitor" were inputted during research.

Based on the principles of how popular search engines function, of which Google is understood to be the most popular in the world, the articles that appear on the first pages of search results are those which have gained a fairly high degree of sociodiscursive relevance at a particular time. Although the exact science of how Google's algorithm functions cannot be obtained (Google does not disclose the precise innerworkings of their systems for the reason of protecting their market assets [their products]), what essentially results in a page obtaining 'relevance' (appearing on the first pages of search results) amounts to what the technology website Moz (2015) defines as Page Authority (PA). In basic terms, a page gains 'authority' based initially on the correlation it has with the words/word combinations that were searched for, followed by: the amount of connections, or 'links' that the specific page has with other web pages; 
the duration of time that that website hosting that page has been to linked to (its longevity as a website); the number of times that a website and the specific page get liked, shared or commented on, either on its own website or on social media sites that include, for example: Facebook, twitter, Instagram, reddit (Moz, 2015, http://moz.com/search-ranking-factors). As such, while other 'Snowden Hero' or 'Snowden Traitor' discursive acts can be found on the internet, it is those appearing on the first two pages, which have arguably received the a substantial amount of social engagement. For this reason, they were selected for analysis.

Also important to note is that there were numerous discursive acts taking up the "herotraitor' Snowden debate but doing so in a less overtly argumentative manner. These included instances where a question would be asked such as: 'Snowden: Hero or Traitor?' or 'Is Edward Snowden a hero or a traitor' or 'Is Snowden a hero?' While these discursive acts also possess the potential for analysis, a decision was made to analyze the discursive acts that were overtly argumentative with regards to Snowden, that is, discursive acts which stated: 'Snowden is a hero', 'Snowden is not a hero' or 'Snowden is a traitor'. It was determined that these discursive acts would be sufficient to gain some understanding as to the manner in which Snowden was being discursively enacted as a 'hero' and 'traitor'.

In addition, the goal of this study was to make sense of discursive enactment of Snowden undertaken by established media institutions via 'public intellectuals' as well as the public at large. If Snowden's whistleblowing was to be seen as a socio-discursive enactment involving many participants, it was determined that not only institutional media should be analyzed but also the discourse pertaining to the public at large. For this reason, a corpus was built from YouTube comments in order to illuminate whether or not the 'hero-traitor' debate was taking place exclusively on established media company websites or whether that same debate was being taking up the public at large in public discussions on digital comment boards. Because YouTube is one of the world's most popular websites7, I selected the YouTube video of Edward Snowden which had the

\footnotetext{
7 "Recent studies have shown that traffic to/from this site accounts for over $20 \%$ of the web total and $10 \%$ of the whole internet and comprises $60 \%$ of the videos watched online. YouTube provides several social tools for community interaction, including the possibility to comment [on] published videos and, in addition, to provide
} 
most views and the most comments. This video, 'NSA whistleblower Edward Snowden: 'I don't want to live in a society that does these sort of things' ${ }^{8}$, which was a video of the first Snowden interview initially published on the Guardian website, had been viewed over 3,000,000 times and had received nearly 40,000 comments (at the time of writing). Working with a computer programmer, Philip Klostermann, I was able to 'scrape' the 39,373 comments into a corpus which could be then be analyzed using the program Nvivo. Obtaining a program to scrape the comments was complicated. Following failed efforts to use Nvivo's 'capture bar' (it could only capture 100 comments) and Statistica's software (outdated and too complex for a general practitioner to use), Philip advised me on how we could go about capturing the comments. A video has been made documenting this procedure and will be shared with the SLALS and Digital Humanities departments at Carleton. The video will be copyrighted using creative commons and will be able to be shared with any other Carleton students. In terms of analysis, the basic applications of Nvivo allow a user to determine word frequency in the corpus and to rank comments based on the information or characteristics ascribed to them (refer to Appendix A for screenshots of Nvivo).

The YouTube corpus consisted of comments, but also included the following characteristics: the user IDs (all of which have not been disclosed in this study in order to respect the privacy of the users); the date which the comment was published; the number of times the comment was liked; the number of times the comment was replied to; and to which comment a comment replied to if it happened to be the case. The objective was to determine how the texts in that social space were being taken up, or interacted with, by other participants. This corpus, albeit large, can only be understood as representing the discursive enactments of the public at large on a very small scale and in a very particular social-digital realm. Thus, no claims are made that this one corpus represents the entire discursive enactment of Snowden pertaining to the public at large.

rating about these comment by other users. These meta ratings serve the purpose of helping the community to filter relevant opinions more efficiently" (Siersdorfer, Chelaru, Nejdl, \& San Pedro, 2010).

8 https://www.youtube.com/watch?v=5yB3ngfu-rM 
The last data set selected for analysis was made up of the four Edward Snowden interview videos most-viewed on YouTube (one of which includes the video already mentioned), and the video interview with Brian Williams of the National Broadcasting Corporation (NBC). The interview with Williams was the first time that Snowden had appeared on National public television and for that reason was deemed to be high importance and relevance. The other four videos were selected simply based on the fact that there were the most viewed (see Appendix B for the table of videos).

\section{Methods of Data Analysis}

With regards to the 22 selected discursive acts from popular news media, analysis was conducted in terms of identifying the kinds of arguments made by 'public intellectuals' in discursively enacting Snowden as either a hero or traitor. I performed this analysis first by highlighting all of the arguments made. I then began the process of 'coding' (Dörnyei, 2007), which involved giving each of the arguments a short categorical description. After the initial stage of coding, I looked for repetitions in the coding, which is to say, cases where arguments made in different discursive acts could be seen as arguing on similar grounds. Throughout this process, I revised the descriptions of coding in order to give an accurate description of the kinds of arguments used (see Appendix $\mathrm{G}$ for an example of the coding practices over stages). The task then became one of identifying on which argumentative grounds Snowden had been discursively enacted as either a hero or a traitor, and whether those arguments could be seen as adhering to the theoretical conceptualizations of 'the hero' and 'the traitor' outlined at the outset of this paper.

With regards to the corpus, the objective was to first determine, quite simply, whether or not the terms 'hero', 'patriot' or 'traitor' appeared in the language that people were using to comment on the Snowden interview. Secondly, I analysed which comments had gotten the most likes. I made the decision to assess the top-10 most-liked comments on the basis that some limit, had to be drawn, in this case: 10. It was determined that the top-10 would provide a data set that would be manageable to work with. Because some 
of the 'liked' comments had the same number of likes, I capped the list at 12 and determined that this would provide a sufficient amount of data to determine, broadly, if any trends could be evident with regards to the kinds of comments which were 'liked' more than others. Another objective was to determine what role, if any, the 'hero-traitor' debate played in terms of a comment getting 'likes'. If the top-liked comments did not pertain to the 'hero-traitor' debate, I assessed on what basis a comment was 'liked' based on any overall trends or patterns in the data set.

Third, I made the decision to assess the most-replied-to comments. Because I wanted to keep this data set approximately the same size as the 'liked-comments' data set, I decided to analyze all comments which had been replied to more than 20 times. This resulted in a data set of 11 comments. Just as was conducted with regards to the 'liked' comments, the objective was to determine what kinds of comments created not 'likes' but discussions. Based on the argument that a comment which was 'replied to' created discussions and thus enlarged the discursive sphere in which Snowden's situation was being enacted, I sought to identify trends or patterns in the comments in order to assess why certain comments got more replies than others. Additionally, like the analysis of the data set of 'liked comments', an objective was to determine what role, if any, the 'herotraitor' debate played in terms of creating replies. Because neither of these data sets was assessed for statistical significance, the conclusions drawn from these kinds of analytic procedures are somewhat speculative and conjectural, and are explicitly presented as such.

Lastly, with regards to the Snowden interviews, a general analysis was performed in which I looked, first and generally, for the topic and themes which Snowden discussed regarding his life, his actions, and the NSA leaks. I then noted all the cases where Snowden was asked to reflect on his portrayal in the media of being a hero, patriot or traitor, and analyzed the manner in which Snowden responded. The interviews were viewed on numerous occasions at different stages on the process. Analysis of Snowden's contribution to the 'spheres' was therefore iterative. 


\section{Chapter 5: Findings, Analysis and Discussion}

\section{Chapter Road Map}

In order to present the findings, analysis and discussion of data as clearly as possible, the following roadmap has been provided at the outset of this chapter:

First, the data findings present the overarching, macro-level discursive spheres. Once these two spheres (labelled 'NSA leaks' and 'Edward Snowden') are mapped out, a generally summary of the interactional nature of the spheres is provided.

Second, findings and analysis are provided for each of the two spheres. The findings and analysis for the NSA leaks identify and elaborate upon the presence of a central 'storyline'. Moving to the Edward Snowden sphere, findings are then presented in which a 'Hero-Traitor' popular antagonism is evident. After a general analysis of the 'HeroTraitor' popular antagonism is provided, analysis of the 'hero bloc' is presented, followed by a discussion of this 'hero bloc.' Next, analysis of the 'traitor bloc' is presented, followed by a discussion of the 'traitor bloc.' After the two bloc have been analyzed and discussed, a discussion of the roles that 'public intellectuals' play in both the hero and traitor blocs is presented.

Third, the data findings concerning the manner in which the public at large engage the Snowden story are detailed. These are the findings pertaining to the YouTube comments. Analysis of these YouTube comments is then presented, followed by a discussion.

Fourth, and lastly, the findings, analysis and discussion of the contestation of, and resistance to the 'Hero-Traitor' popular antagonism are presented. It is here where Snowden's personal contributions to the discursive spheres and presented, analyzed and discussed. 


\section{Macro-level Findings: Mapping out the Discursive Spheres}

There are two sub spheres which combine to make up the discursive sphere of Edward Snowden's whistleblowing. One is the discourse that pertains primarily to the NSA leaks themselves, which I have labelled: NSA leaks. The other half of the sphere is the discourse that pertains primarily to Edward Snowden. This half is labelled: Edward Snowden. As might be expected, these two sub spheres are not mutually-exclusive but interconnected. That is, in the NSA leaks sphere, Snowden appears, and in the Edward Snowden sphere discourse about the NSA leaks is evident. There is - at times significant - bleeding across the two spheres. Dividing one larger, overarching discursive sphere (which is made up of two smaller ones) in the manner I have done was useful to identify the predominant 'storylines' or 'chains of equivalence' which have arisen in each. Additionally, examples have been provided which by no means totalize the spheres but illustrate how the medium of the internet plays a vital and diverse number of roles in their creation.

\section{The NSA leaks sphere}

Essentially, what constitutes this sphere is an abundance of discourse which focuses on the details of the NSA's activities as a consequence of Snowden's leaks. The amount of discourse created in this sphere is overwhelming, and any attempts to totalize its entirety would be seemingly impossible. There are, however, web pages dedicated to carrying out this very task. One notable example is the Wikipedia page: 'Global surveillance disclosures (2013- present).' Here, the NSA leaks are mapped out in meticulous detail. The following categories are placed in a contents table on the right side of the page: 'Disclosures, Systems, Agencies, People, Places, Laws, Proposed Changes, Concepts, Related Topics'. Each of these categories is constituted by specific topics, all of which are hyperlinked. Furthermore, this page, 'Global surveillance disclosures (2013- present)' falls under the general Wikipedia 'category' of 'Global surveillance', in which there are 24 pages in total. The two sub-categories which fall 
under this umbrella category include: 'Intelligence agency programmes revealed by Edward Snowden' and 'Edward Snowden'. In addition to the Wikipedia database/archive, reddit ${ }^{9}$ has a stream of links/attachments related to the NSA leaks ${ }^{10}$, where reddit users are able to post relevant information. Other reddit users are able to 'upvote' or 'downvote' each link, whereby a link to an article, video, image, etc. gains or loses relevance on the stream.

In terms of media companies and news agencies, popular English-language news websites have included pages which function as archives/databases for all of their stories related to NSA leaks. Three examples (of many) include: Russia Today, The Guardian, and The Huffington Post. Russia Today's page has the category 'trends' of which 'NSA leaks' is a sub-category; the Guardian's page has the category 'U.S. News' of which 'The NSA files' constitutes a sub-category; and The Huffington Post has the subcategory 'Nsa leaks' situated under the over-arching category 'News'. Russia Today and The Huffington Post's archives consist of all the relevant 'NSA' stories published on their webpages and which have been organized chronologically. Differing from the previous two sites, the Guardian's page 'The NSA files' includes sub-categories which are listed as the following: 'the NSA files, exclusives, debate, latest, documents, popular,' and of all which can be queried based on a selection of 'topics' provided. The first category in this list includes the elaborate interactive web document titled, 'NSA files: Decoded/What the revelations mean for you', which consists of six parts (Introduction; All the data about your data; A digital revolution, Are your details secure; Who's watching; What now?), and which is presented in a format that might be interpreted as the possible future direct of information/knowledge transference in the digital, internetbased realm. ${ }^{11}$ In addition to this webpage 'NSA files: Decoded', all of Snowden's NSA

\footnotetext{
${ }^{9}$ www.reddit.com

${ }^{10}$ http://www.reddit.com/r/NSAleaks

${ }^{11}$ This scrollable webpage contains text, charts, visualizations of data, visualizations elucidating complex processes of activities, embedded talking-head interview clips from experts in field, and embedded links to the actual NSA slide presentations leaked by Snowden. The entire page is uploaded in one stream, and can be navigated using the section links provided at the top of the page. The basic objective of this page is to expound the NSA leaks with clarity, and aided by the use of multimodality, should in turn be interpretable with relative ease. This webpage (as of March 14, 2015) has been shared over 54,000 times and 'liked' approximately 13,000 times. Novel stories seem to
} 
leaks which were published in Glenn Greenwald's, No place to Hide, can be accessed free of charge in pdf format via his website ${ }^{12}$.

Similar to aforementioned websites, also present on the internet is a page such as that published by Al Jazeera America, where an interactive hyperlinked timeline is made available under the over-arching category 'NSA leaks'. Here news stories from various sites are made available chronologically in a timeline dating from June $5^{\text {th }}, 2013$ (the start of the leaks) to September $14^{\text {th }}, 2014$. Here, one can scan through the events as they have discursively unfolded, linking into articles and videos, which themselves often link to other articles, videos, etc. Al Jazeera does not post articles from every news source but chooses the sources in which it has partnerships, and with whom (it might be argued) it shares (some) political/ideological stances. A user accessing this timeline can zoom over the events chronologically, further engaging the stories of interest by using the links to article provided.

Snowden himself, also, plays a significant role in the creation of this sphere not only because of the material and historical event of his whistleblowing, but also because he contributes discursively to expounding the NSA leaks through recorded and live-stream interviews. Digital technologies have played an essential role in the actualization potential and dispersion and transference of these discourses. On one hand, interviews such as those conducted by Glenn Greenwald or $N B C$ anchor Brian Williams are recorded, and in turn made digitally available on the internet (through YouTube or other sites). Significant to note is the fact that the interview with Williams and $N B C$ was the first interview which aired (post-recording) on television in the United States. On the other hand, digital technologies allow Snowden to appear live at various conferences or other social settings via live-stream capacities. As such, his 'Ted talk', "How we take back the internet” was conducted via a device that Snowden could control from Russia. Controlling the humanesque robot-stand, bearing a screen with live-stream footage of his face, Snowden glided across the stage, engaging with both the host and the audience. In turn, the audience could see and interact with him in real time. This talk was

\footnotetext{
lend themselves to the creation of novel presentations. The 'NSA codes' might be an example of such a phenomenon.

${ }^{12}$ www.glenngreenwald.net
} 
recorded and made digitally available online via www.ted.com as well as on YouTube. In addition to the 'Ted talk', Snowden has made live appearances at media/cultural festivals such as SXSW in 2014 and in a Toronto high school in 2015. In these examples, while a discursive enactment of Edward Snowden most certainly takes place (it's Snowden himself after all), a considerable contribution is made to the construction of the NSA leaks sphere as Snowden talks at great length about the NSA activities.

Lastly, the digital discursive sphere of NSA leaks can be evidenced and accessed by simply inserting 'NSA', 'NSA leaks', '\#NSA', or '\#NSA leaks' into internet-browser search engines (Google, Yahoo, Bing, etc.), social media sites (Facebook, Twitter, Instagram, YouTube), or particular media companies' search engines. All of the discourse that focuses primarily on the NSA leaks - inside of which almost always includes reference to Edward Snowden - makes up the digital discursive sphere, NSA leaks.

\section{The Edward Snowden Sphere}

The second sphere, the Edward Snowden sphere, contains discourse which focuses primarily on Edward Snowden, the man, the whistleblower, the leaker. Like the NSA leaks, the vast amount of discourse constituting this sphere would be impossible to totalize. Two of the most predominant discursive efforts striving to capture the essence of Snowden's life and persona are: 'The Snowden Saga: A shadowland of secrets and light", published both online and in hardcopy by Vanity Fair in May 2014, and "Edward Snowden: The Untold Story" published both online and in hardcopy by Wired in August of the same year. While both of these articles do touch on the topic of the NSA leaks and what those leaks entail, their objectives are to provide as much insight and biographical information on Edward Snowden through an extensive detailing of his personal life, his career, his motivations (as expressed by Snowden himself in interviews), his personal views on a wide-range of topics (interviews again), and his current state of life in Russia. Included in these articles are an abundance of photos of both Snowden, and, in the case of Vanity Fair, photos of the numerous other players that tie into the 'Saga'. While the internet-based Vanity Fair article follows a standard layout of text of images, the Wired article is a downward streaming narrative in seven parts, similar to that found in the 
previously-discussed "NSA files: Decoded". It contains an embedded audio file of Snowden speaking in his own words as well as hyperlinks to six other related stories. In addition to the two aforementioned articles, a Wikipedia page titled 'Edward Snowden' also exists, detailing the previously-mentioned information regarding Snowden's life.

Other sources that illustrate the manner in which the Snowden sphere is constructed include a webpage dedicated to Snowden ${ }^{13}$, which is titled, 'Free Snowden: In Support of Edward Snowden: The Courage Foundation'. Here, biographical information on Snowden is provided in the form of standard text. Also available is an FAQ providing information on Snowden, his actions, and what impact his leaks have had. The Bio. webpage $^{14}$ outlines Snowden's life and actions with some detail, as does the documentary film "CitizenFour", directed by journalist Laura Poitras, and which won the 2015 Oscar Award for best documentary. In addition, a major motion-picture, a biopic of Edward Snowden, titled "Snowden", directed by Oliver Stone, is set for release on December $25^{\text {th }}, 2015$.

As previously mentioned in the case of the NSA leaks sphere, Snowden's personallycreated discourse provides numerous examples where Snowden contributes to the creation of his public persona based on the answers he gives to the questions he has been asked, coupled with his corporeal presence: his face, his clothing, his gestures, his tone of voice, etc. Additionally, almost all sources listed here make reference to the discourse created by Snowden on various blogs and in chatrooms using pseudonyms or aliases, which have since been disclosed. All of this information contributes to the Edward Snowden sphere.

Lastly, simply inserting "Snowden”, "Snowden's life”, 'Snowden biography', 'Snowden whistleblower', '\#snowden', into search engines (Google, Yahoo, Bing, etc.), social media sites (Facebook, Twitter, Instagram, YouTube), or a particular media company's search engine results in the attainment of discourse focusing on Snowden, the man and the whistleblower.

\footnotetext{
13 www.edwardsnowden.com

14 www.biography.com
} 


\section{General Summary of the two spheres}

The two spheres, Edward Snowden and NSA leaks, combine into one overarching sphere in which the discursive enactment of Edward Snowden takes place. One sphere cannot exist without the other; they are entirely dependent on another. One cannot create discourse about Edward Snowden without making reference to his NSA leaks just as one cannot create discourse about the NSA leaks in complete isolation from the individual who brought them into existence. In observation, the vast majority of articles about the NSA leaks, or even those pertaining to internet surveillance or encryption technologies typically make reference to Edward Snowden, at least in name. Even when the NSA leaks are discussed without an explicit reference to Snowden, his whistleblowing actions reverberate in the silences.

Additionally, a discursive antagonism is evident between these two discursive spheres. As argued by MSNBC political analyst Richard Wolfe, the biographical information of Snowden 'runs counter' to the issues that 'really matter': security and governmental practices of which the functional tenets of the FISA court are of pressing importance. Wolfe states that the focus on Snowden is "undermining the debate" (Wagner, 2013) 15. Contrary to this perspective would be the notions promulgated by Rahul Sagar, who argues that understanding the motivations of a whistleblower are essential to determining whether or not the whistleblowing actions can be trusted and/or justified (Sagar, 2013).

Also important to note is that the discursive sphere of Edward Snowden does not exist in an isolated bubble in and of itself. Because discussions of Edward Snowden's whistleblowing become intertwined with all the antecedent discourse related to the topic, any discussions of Snowden the 'whistleblower' or 'leaker' stem from all previous whistleblowing discourse created on (and by) antecedent whistleblowers and whistleblowing activities. Additional topics and themes that feed into these discursive pools include: the NSA, government transparency, government secrecy, government ethics, lying and corruption, digital security, digital technology, civil disobedience, etc. Any example of discourse, whether it be public conversations or debates, academic

${ }^{15}$ http://www.msnbc.com/now-with-alex-wagner/debating-the-snowden-effect 
journals, videos, documentaries, memes, gifs, webpages, chat rooms, blogs, academic or popular books, adds to the pool of relevant discourse, a pool which Freadman (2002) refers to as the 'collective memory' of the particular social context. It is out of this 'collective memory' where particular kinds of discourse emerge. Constituted by the digital technologies of the internet, these 'pools' of discourse become easier and easier to access. Similarly, the relevant information pertaining to the pools continually becomes easier and easier to disseminate through multifarious platforms. As a consequence, the internet provides a malleable groundwork whereby a seemingly infinite number of interlocking data streams can be linked together. As the pools grow, so do the connections between them.

Lastly, constituting the discursive sphere of Edward Snowden are the discursive activities of individuals and organizations. What an historical event like the whistleblowing actions taken by Snowden creates is a realm in which individuals of the public as well as 'public intellectuals' engage in acts of articulation through which, as argued by Laclau and Mouffe, and Hajer, their identities are modified. For example, in the NSA leaks sphere, public intellectuals like William Binney and Thomas Drake's discursive efforts to disclose NSA malpractices once again gain social relevance in the wake of Snowden's whistleblowing; 'public intellectuals' of this sort are once again provided platforms and discursive potentialities in which they can act. In the Edward Snowden sphere, the same occurs. 'Public intellectuals' concerned with activism, social justice, government practices and human rights like Binney, Drake, Daniel Ellsberg, Julian Assange, Laura Poitras, Glenn Greenwald, Ewan MacAskill (and an abundance of others) may either choose to engage the topic on their own accord or find themselves pressured by others, including media institutions, to do so. The same certainly occurs with politicians and, in cases, with individuals in the general populace. Any member of a society, when taking up the whistleblowing event, possesses the opportunity to align oneself politically in one regard or another through the discursive actions they take.

\section{Findings and Analysis of the Spheres}

\section{NSA leaks Sphere}


The NSA leaks demonstrably and unequivocally constitute a fact-based discursive sphere. Because the information leaked by Snowden came directly from the NSA's internal database, and because that information has been published in unaltered, completely authentic forms, there is no central discursive antagonism with regards to its authenticity. The NSA leaks discursive sphere can therefore be seen to represent what Laclau and Mouffe labelled a democratic social antagonism in that various media companies take up the leaks in a variety of ways depending on their institutional or corporate objectives. It comes as no surprise that media companies that value the leaks discuss them at length and do so in a manner which lauds and valorizes their very existence. In contrast, media companies which do not value the leaks or rather view them as destructive or potential damaging will either discuss them in ways which undermines their presence or will not discuss them at all. It is the effort to silence their existence by not bringing them into the discursive sphere that creates, in part, the democratic social antagonism. On one hand, this antagonism exists between various methods and discursive forms of presentation, and on another, of discursive silence vs persistent discursive action. It is not the objective of this paper to discuss at length the manner in which various media companies have chosen to present the leaks. What is relevant for the examination which this investigation conducts is the emergence of a particular 'storyline' or 'chain of equivalence' in this NSA leaks discursive sphere, which is that of the 'Snowden Effect.'

The 'storyline' or 'chain of equivalence' of the 'Snowden Effect' is constituted by what Hajer (FAQ, 2015), and Laclau and Mouffe (1985) defined as having the characteristics of metonymy. Here the 'floating signifier' of 'Snowden' combines with the word 'Effect' to stand metonymically for the vast social repercussions or reverberations which his NSA disclosures have had on society at large. Jay Rosen (2013) in an article titled "The Snowden Effect: definition and examples", published on his blog, Press Think, defines the term in the following manner: "Direct and indirect gains in public knowledge from the cascade of events and further reporting that followed Edward Snowden's leaks of classified information about the surveillance state in the U.S." More specifically, Rosen (2013) notes: 
Congress and other governments begin talking in public about things they had previously kept hidden. Companies have to explain some of their dealings with the state. Journalists who were not a party to the transaction with Snowden start digging and adding background. Debates spring to life that had been necessary but missing before the leaks. (Middle Section)

Rosen's article, which is essentially an archive of other news stories, goes on to quote and hyperlink a wide-range of publications focusing on the media aspect of the 'Snowden Effect' in terms of creating discussions of security and privacy, focusing on the relationship between governments (both national and international) and citizens, as well as between governments and companies in the wake of whistleblowing. He also talks about the social pressures that various companies, as well as the government and their agencies (primarily the NSA as well as the FISA court), have faced and will face when confronted with the leaks. Rosen (2013) also highlights articles which raise polemical issues about the state of American democracy touching on discourse that demonstrates how companies implicated with the NSA's activities are actively attempting to restore their public reputations. Rosen concludes his article by providing a link to a study conducted by Dow Jones ${ }^{16}$, which, through an infographic, quantifiably shows a massive rise in 'NSA' related media stories in the wake of the Snowden disclosures.

In addition to Rosen, numerous other web agencies have taken up the 'Snowden Effect', further elaborating on its meaning. Two articles from The Economist, both titled "The Snowden effect", the first running on August $10^{\text {th }}, 2013$, and the second on January $24^{\text {th }}$, 2014, detail how Snowden's whistleblowing has, in the former, forced Obama to the confront the government's tricky and complicated breaches of public trust, and in the latter, raised issues of the laws and legal procedures present in the storing and maintaining of personal, private data (R.M., 2013; L.S., 2014). An article running on March $13^{\text {th }}, 2014$ on the website Politico, titled "The Snowden Effect: How America's spy agencies can fix their Millennials problem", details how the disclosures are causing younger Americans to lose confidence in the government's intelligence agencies

${ }^{16} \mathrm{http}: / /$ dowjones.com/pressroom/docs/DJ_NSAinfographic_v14.pdf 
(Ferraro \& Dolgin, 2014). ZDNet takes up the 'Snowden Effect' in its online article "The Snowden effect: How it's still denting business confidence in cloud security" reflecting on how Snowden's disclosures are having repercussions for commercial businesses whose services include offering safe data storage (Wolpe, 2014).

On final example - it should be noted that there are numerous others - is the article, "The Snowden Effect: 8 Things That Happened Only Because Of The NSA Leaks" published online on The Huffington Post. Here, author Matt Sledge details the '8 Things' ${ }^{17}$, showing a wide range of political and social reverberations which the leaks have caused. Important to note is the fact that Sledge (2014) uses the 'Snowden Effect' in order to argue for the direct causation between the leaks and social effects. One can certainly go through each 'thing' point by point and validate or denounce these claims. This is not the objective of the analysis at hand. The point here is to illustrate examples and uses of the 'Snowden Effect' storyline, and in this particular case to demonstrate that the author uses the 'Snowden Effect' to make a case for direct causation.

\section{Analysis of the 'Snowden effect' storyline}

Although some arguments exist that the information disclosed in Snowden's leaks merely instigated discussions concerning a need for greater oversight and evaluation of NSA practices which would have occurred regardless of Snowden's whistleblowing ${ }^{18}$, the fact that Snowden's leaks have had an effect on media coverage is undeniable. It is for this reason that the 'Snowden Effect' storyline has largely gone uncontested. The very reality that Snowden's leaks have garnered a substantial amount of media attention proves testament to this fact. If the opposite were the case, a contrary 'storyline' seeking to contest the 'Snowden Effect' would be battling with this 'storyline' in the discursive

\footnotetext{
${ }^{17}$ 1: Director of National Intelligence James Clapper had to admit he lied to Congress; 2: The House passed a bill (ostensibly) meant to stop bulk collection of phone metadata; 3: A federal judge said the NSA phone surveillance program is unconstitutional; 4: Tech companies finally got serious about privacy; 5 : Britain held its first-ever open intelligence hearing; 6: Germany opened an investigation into the tapping of Chancellor Angela Merkel's cell phone; 7: Brazil scotched a \$4 billion defense contract with Boeing; 8: President Barack Obama admitted there would be no surveillance debate without Snowden (Sledge, 2014).

${ }^{18}$ President Obama, although acknowledging the Snowden leaks started' important conversations' that the country 'needed to have'(https://www.youtube.com/watch?v=tysIV6t54L4), also suggested that 'well before' Snowden's disclosures 'thorough reviews' over NSA activities and laws were already being conducted (https://www.youtube.com/watch?v=Bxmv8aArTJk). This would seem to be an instance of discourse undermining, in degrees, the presence of the 'Snowden Effect'.
} 
sphere. Perhaps with the most scant exceptions, no such 'storylines' have been detected. It is for this reason that the 'storyline' of the 'Snowden Effect' significantly stands, at least for time being, uncontested. Taking up this 'storyline', various authors make use of the term 'Snowden effect' to latch onto the media attraction of Snowden's story and take up specific 'effects' that they believe the leaks are causing. The 'Snowden effect', therefore, provides a 'storyline' of meaning-making potentiality as well as informationtransference.

Perhaps in a number of years or decades, society at large will determine that Snowden's whistleblowing had no discernable effect. Perhaps opinion will be split on this issue and a discursive battle will emerge reflecting this antagonism. When, or if, this occurs, the discourse itself will stand as testament to the discursive reality of that time. For now, Snowden's leaks have most certainly had some effect on the digital realm of the internet.

\section{Edward Snowden Sphere}

From the moment that Snowden disclosed himself as the whistleblower behind the NSA documents, a distinct 'popular antagonism' began to form, one that grew to substantial prominence as the Snowden story unfolded. This is the 'popular antagonism' of the 'hero-traitor' or the 'patriot-traitor'. As mentioned at the outset of this paper, the 'herotraitor' antagonism does not begin with Snowden's specific whistleblowing event, but rather the whistleblowing actions that precede him. It can be recalled that Jeffrey Wigand, 'The Insider' who blew the whistle on tobacco companies was labelled both a 'hero' and 'traitor' (Johnson, 2002), and when asked by Time in 2002 whether or not the corporate whistleblowers were 'uncomfortable' with becoming 'role models' in public perception, Cynthia Copper responded, “We don't feel like we are heroes. I feel like I did my job.” Coleen Rowley answered, “...The May 21 letter from me? I am repulsed by the idea of thinking that makes me a hero or anything like that" (Time, 2002). Furthermore, it can be recalled that the whistleblowing icon Daniel Ellsberg was and is commonly-festooned with the label of 'hero', and, as previously noted, Ellsberg himself plays a significant role in perpetuating the labelling of whistleblowers as heroes.

Only three years prior to Snowden, when Chelsea Manning leaked the 'War logs', despite being lambasted by a significant faction of popular media, Daniel Ellsberg was a key 
figure who came to her defense. Not only did Ellsberg defend Manning's actions, but did so by labelling her a hero. Authors such as Anna Mulrine of the Christian Science Monitor equated Manning's actions with those taken Ellsberg, as she penned a piece titled, “Pentagon Papers vs. Wikileaks: Is Bradley Manning the new Ellsberg?” (Mulrine, 2011). Here, she writes, quoting Ellsberg,

If Bradley Manning did what he's accused of, then he's a hero of mine, the Ellsberg statement said. The government continues to persecute Manning, much as it did Ellsberg in the 1970s, he said. "I wish I could say that our government has improved its treatment of whistle-blowers in the 40 years since the Pentagon Papers." (Mulrine, 2011)

Ellsberg, two years later, also appeared in a video published on the Huffington Post (among other sites) where, holding a sign that read, "I was Bradley Manning: Pentagon Papers 1971", he states,

In the case of Bradley Manning, he's vindicated right now and he's a hero right now - he doesn't have to wait for that, and certainly in my own heart, he's a hero, and he did what he should have done, so I call him a hero for that and he did what nothing in his position, knowing what he knew, should have done. (Huffington Post, 2013)

In defending the modern whistleblower Manning in the manner that he does, Ellsberg distinctly makes use of the 'floating signifier' 'hero' in order to do so. He does the very same when Edward Snowden discloses himself as the NSA whistleblower.

Snowden disclosed his identity to the public on June 9, 2013, a disclosure which was published in four articles by the Guardian and two by the Washington Post. One article in the Guardian contained the interview with Greenwald and Snowden, where Snowden discussed his motivations at length. Almost immediately after Snowden was cast into the public light, the hero-traitor antagonism emerged. On June $9^{\text {th }}$, journalist Trevor Timm tweeted, "I was just with Dan Ellsberg as he learned about Edward Snowden. He called Snowden a hero, said he's been waiting for him for 40 years” (@trevortimm, June $9^{\text {th }}$, 2013). The same day, Buzzfeed ran a piece titled, "More People on Twitter Describe Edward Snowden As A Hero Than a Traitor" (Hayes, 2013) where it states that the "tweets calling him a hero outweighed those calling him a traitor nearly 30-1, according 
to data from Topsy." The following day, pouring into this discursive stream on Twitter, Glenn Beck tweeted, "I think I have just read about the man for which I have waited. Earmarks of a real hero. http://t.co/H63dlBdX2d” (@glennbeck, June 10 ${ }^{\text {th }}, 2013$ ). Sloan contested this view, tweeting, “@mmhastings @michaelhayes, umm, sounds like a pretty unscientific twitter study to me. The guy should be tried for what is: a traitor" (@eddlest, June 10 ${ }^{\text {th }}, 2013$ ).

At this time, Ellsberg acted quickly, writing an op-ed for The Guardian on June $10^{\text {th }}$ titled, "Edward Snowden: saving us from the United Stasi of America" (Ellsberg, 2013). Ellsberg's discourse was picked up by Jack Mirkinson of the Huffington Post, who wrote a piece titled "Daniel Ellsberg Calls Edward Snowden A 'Hero,' Says NSA Leak Was Most Important In American History" (Mirkinson, 2013). When the South China Morning Post ran the first part of its interview with Snowden, two days later, it included the following statement: "His [Snowden's] actions have been both praised and condemned globally, with some hailing him a hero while others a traitor. Some senators have accused Snowden of treason" (Lam, 2013). When the newspaper published its second part of the interview with Snowden the following day in "Edward Snowden: US government has been hacking Hong Kong and China for year", Snowden himself reflected on the already-brewing 'hero-traitor' antagonism in its nascent stages. It reads, “'I'm neither traitor nor hero. I'm an American,' he said, adding that he was proud to be an American. 'I believe in freedom of expression. I acted in good faith but it is only right that the public form its own opinion"” (Lam, 2013). In the following days, speaker of the house, John Boehner was interviewed by the Huffington Post, where he called Snowden a 'traitor' (Johnson, 2013). Some three days later, former Vice President Dick Cheney did the same (Fox News, 2013).

Contrary to notions which Foucault (1972) has posited concerning the autonomous essence of discourse, what is demonstrated here is that while certain discursive patterns or trends continue to arise in correlation with specific historical contexts, it is individuals and their discursive actions which results in the longevity and persistence of discursive trends. In this particular case it is public intellectuals like Ellsberg or Cheney who play substantial roles in creating the ongoing presence of terms such as 'hero' and 
'traitor' with regards to whistleblowing. Thus, it is a case of public intellectuals choosing to shape the discourse in the manner they have. They are not forced to call Snowden a 'hero' or a 'traitor' but actively choose to do so.

As a result of these discursive choices, within days of Snowden's blowing the whistle and mere hours after disclosing his identity to the public, the 'hero-traitor' antagonism emerged and over time grew to become the central public debate. Although this debate has lost some of its socio-discursive prominence in the most recent months, it has by no means completely disappeared. In just March of this year, an article titled "How Oliver Stone is tackling the Edward Snowden story" was published, in which the first line reads, "Depending on your point of view, Edward Snowden is either a dangerous traitor or a laudable hero" (Zeitchik, 2015). Quoted in an interview in the article, actor Zachary Quinto, who will be playing Greenwald in the Snowden bio-pic, reflected on the making of Snowden's life through film, saying,

I'm endlessly fascinated by Snowden's decision, his process, his motivation... The vast majority of accounts had it one way or another - he's either one more traitor or a righteous whistleblower. And the question is, 'Which one is it?' Or maybe it's something more complicated than that. (Zeitchik, 2015)

More than a year later, the 'hero' and 'traitor' terms continue to circulate in popular media.

\section{Analysis of the 'Hero-Traitor' Popular Antagonism}

The 'hero-traitor' antagonism forms the central 'storyline' in the discursive enactment of Edward Snowden, a storyline which is discursively constructed through 'chains of equivalence'. The construction of this antagonism is ostensibly constituted by the use of the metaphors 'hero' and 'traitor'. It is not the case that 'hero' and 'traitor' are used as synonyms, as would be evident in phrases such as: 'Snowden is like a hero' or 'Snowden resembles a traitor.' No such phrases have been found to exist. As such, by making use of the metaphors 'hero' and 'traitor', what becomes evident is the core tenet of the discursive antagonism: social beings, through discourse, confront the impossibility of fully construing their objects through their discourse. As Snowden cannot be totalized with discourse, nor can the subjects attempting to discursively enact a projection of him. 
Thus, the efforts to proclaim Snowden as a 'hero' are not only necessarily engaged antagonistically with the efforts to proclaim him a 'traitor', but are in fact contingent on the presence of the 'traitor' in order for them to be constituted as such. Discursivelyenacting Snowden in a manner through which he can become socially-conceived as a 'hero' or 'traitor' therefore requires different 'discourse coalitions' to build hegemonic 'hero' and 'traitor' blocs. These respective blocs gain social influence based on, in part, the arguments made by public intellectuals. The task becomes one of analyzing which arguments are used in each of the conflicting positions in the antagonism ('hero' and 'traitor') which, in turn, illuminates how their coalitions strive to build and maintain the hegemonic blocs.

\section{Data Findings and Analysis of the 'hero bloc'}

Below, Table 2 refers to 11 acts of discourse in which Snowden 'is a hero'. Table 3 identifies the kinds of arguments used by each of these acts of discourse. After presenting these tables, explicit examples of the arguments will be provided:

Table 1: Discourse Acts in the 'hero bloc'

\begin{tabular}{|c|c|c|c|c|c|}
\hline $\begin{array}{l}\text { Discourse } \\
\text { Act \# }\end{array}$ & "Title" & Publication & $\begin{array}{l}\text { Date Published } \\
\text { Month/day/year }\end{array}$ & $\begin{array}{l}\text { 'Public } \\
\text { Intellectual' }\end{array}$ & $\begin{array}{l}\text { Arguments } \\
\text { made }\end{array}$ \\
\hline $\mathbf{1}$ & $\begin{array}{l}\text { "Steve } \\
\text { Wozniak: } \\
\text { Snowden 'Is a } \\
\text { Hero Because } \\
\text { This Came } \\
\text { From His } \\
\text { Heart”" }\end{array}$ & The Daily Beast & $26 / 06 / 13$ & $\begin{array}{l}\text { Steve Wozniak, co- } \\
\text { founder of Apple. }\end{array}$ & $\mathrm{A}, \mathrm{B}, \mathrm{F}$ \\
\hline 2 & $\begin{array}{l}\text { "Why Edward } \\
\text { Snowden is a } \\
\text { Hero" }\end{array}$ & The New Yorker & $10 / 06 / 13$ & $\begin{array}{l}\text { John Cassidy, } \\
\text { journalist }\end{array}$ & $\mathrm{A}, \mathrm{C}, \mathrm{D}, \mathrm{E}, \mathrm{F}$ \\
\hline 3 & $\begin{array}{l}\text { "Edward } \\
\text { Snowden is a } \\
\text { hero" }\end{array}$ & $C N N$ & $10 / 06 / 13$ & $\begin{array}{l}\text { Douglass Rushkoff, } \\
\text { journalist }\end{array}$ & $\mathrm{A}, \mathrm{B}, \mathrm{D}, \mathrm{E}, \mathrm{F}$ \\
\hline 4 & $\begin{array}{l}\text { "Why Edward } \\
\text { Snowden is a } \\
\text { hero" }\end{array}$ & The Huffington Post & $11 / 06 / 13$ & $\begin{array}{l}\text { Daniel Raphael, } \\
\text { journalist }\end{array}$ & $\mathrm{C}, \mathrm{E}, \mathrm{F}$ \\
\hline 5 & $\begin{array}{l}\text { "Why Edward } \\
\text { Snowden, NSA } \\
\text { whistleblower } \\
\text { is more hero } \\
\text { than traitor: } \\
\text { Burman" }\end{array}$ & The Toronto Star & $6 / 16 / 13$ & $\begin{array}{l}\text { Tony Burman, } \\
\text { journalist }\end{array}$ & $\mathrm{A}, \mathrm{C}, \mathrm{D}, \mathrm{E}, \mathrm{F}$ \\
\hline 6 & $\begin{array}{l}\text { "Ron Paul: } \\
\text { Edward } \\
\text { Snowden is a } \\
\text { Hero" }\end{array}$ & $\begin{array}{l}\text { Fox News *video } \\
\text { (interview) }\end{array}$ & $1 / 22 / 14$ & $\begin{array}{l}\text { Ron Paul, American } \\
\text { politician } \\
\text { (Republican) }\end{array}$ & $\mathrm{C}, \mathrm{F}$ \\
\hline 7 & "Edward & Guardian *interview & $25 / 11 / 13$ & Jimmy Wales, & $\mathrm{C}, \mathrm{F}$ \\
\hline
\end{tabular}




\begin{tabular}{|c|c|c|c|c|c|}
\hline & $\begin{array}{l}\text { Snowden a } \\
\text { 'hero' for NSA } \\
\text { disclosures, } \\
\text { Wikipedia } \\
\text { founder says" }\end{array}$ & summary & & $\begin{array}{l}\text { founder of } \\
\text { Wikipedia }\end{array}$ & \\
\hline 8 & $\begin{array}{l}\text { "Oliver Stone: } \\
\text { Edward } \\
\text { Snowden is a } \\
\text { hero to me" }\end{array}$ & The Telegraph & $3 / 6 / 14$ & $\begin{array}{l}\text { Oliver Stone, major } \\
\text { motion-picture } \\
\text { director }\end{array}$ & $\mathrm{A}, \mathrm{C}, \mathrm{F}$ \\
\hline 9 & $\begin{array}{l}\text { "Jesse 'The } \\
\text { Mind' Ventura: } \\
\text { Snowden A } \\
\text { Patriot, Hero } \\
\text { (Jesse } \\
\text { Ventura's } \\
\text { Patriotic } \\
\text { Message) Off } \\
\text { the Grid - Ora" }\end{array}$ & Forbes & $6 / 01 / 14$ & $\begin{array}{l}\text { Jesse ‘The Mind' } \\
\text { Ventura (formerly } \\
\text { 'The body'), former } \\
\text { WWE wrestler and } \\
\text { governor, political } \\
\text { public figure } \\
\text { (Independent) }\end{array}$ & $\mathrm{B}, \mathrm{F}$ \\
\hline 10 & $\begin{array}{l}\text { "Why Edward } \\
\text { Snowden is a } \\
\text { hero" }\end{array}$ & The Tyee & $7 / 01 / 13$ & $\begin{array}{l}\text { John Pilger, } \\
\text { journalist }\end{array}$ & $\mathrm{E}, \mathrm{F}$ \\
\hline 11 & $\begin{array}{l}\text { "Shailene } \\
\text { Woodley } \\
\text { Praises Edward } \\
\text { Snowden as a } \\
\text { "Hero," Plays } \\
\text { His Girlfriend } \\
\text { in New Oliver } \\
\text { Stone Movie" }\end{array}$ & $\begin{array}{l}\text { Eonline *interview } \\
\text { summary }\end{array}$ & $9 / 03 / 15$ & $\begin{array}{l}\text { Shailene Woodley, } \\
\text { actress (playing } \\
\text { Snowden's } \\
\text { girlfriend in Oliver } \\
\text { Stone's Snowden } \\
\text { biopic) }\end{array}$ & $\mathrm{A}, \mathrm{B}, \mathrm{C}, \mathrm{F}$ \\
\hline
\end{tabular}

Table 2: Types of Arguments and the Discourse Acts that use them

\section{(Letter) Type of Argument}

\section{Discourse\# that includes the argument} (some cases are more explicit than others)

\begin{tabular}{lc}
\hline $\begin{array}{c}\text { (A) Legitimizing Snowden's Character \#1: } \\
\text { (basis of humanity): 'emotional', 'human'; } \\
\text { humane; 'conscience' }\end{array}$ & $1,2,3,5,8,11$ \\
$\begin{array}{c}\text { (B) Legitimizing Character \#2: made sacrifices } \\
\text { for others, took risks for others }\end{array}$ & $1,3,8,9,11$ \\
$\begin{array}{c}\text { (C) Legitimizing Character \# 3: (basis of } \\
\text { ethics): ethical decision-making; defending }\end{array}$ & $2,3,4,5,6,7,8,11$ \\
American 'constitution'; actions not for self- \\
$\quad$ benefit
\end{tabular}


Examples of Arguments:

Argument (A) - Legitimizing Snowden's Character \#1: (basis of humanity) emotional, 'human'; humane; 'conscience':

Example 1: "I think Edward Snowden is a hero because this came from his heart. And I really believe he was giving up his whole life because he just felt so deeply about honesty" (Grove, 2013).

Example 2: "He is doing it out of conscience. The higher law of his conscience dictated it" (The Telegraph, 2014).

Argument (B) - Legitimizing Character \#2: made sacrifices for others, took risks for others:

Example 1: "Edward Snowden risked his life to inform us, the American people, that the NSA was illegally spying on us, as if we were all guilty of concocting the next terrorist plot" (Rapoza, 2014).

Example 2: "'You are the epitome of the word selfless,' 'You did something knowing you wouldn't be able to come home, knowing that your country would have very mixed feelings and yet your integrity on what you believe was right or wrong or should be public knowledge was more important to you than almost your own comfortability and the life that you had lived for so long"” (Malkin, 2015).

Argument (C) - Legitimizing Character \#3: (basis of ethics): 'ethical decisionmaking'; defending American 'constitution'; actions not for self-benefit:

Example 1: “He didn’t did do it for money, or to 'aid and abet the enemy”' (Burman, 2013)

Example 2: 'Snowden spent months meticulously studying every document.' As Snowden planned to release the information he realized what the people needed to say and what would actually jeopardize national security such as U.S. military plans or any secret conversations" (Raphael, 2014).

\section{Argument (D) - Legitimizing Character \#4: Quoting Snowden as means of disclosing \& promoting legitimate motivations:}

Example 1: "'I don't want to live in a society that does these sort of things,' he told Greenwald. 'I do not want to live in a world where everything I do and say is recorded. That is not something I am willing to support or live under"' (Cassidy, 2013).

Example 2: "My sole motive is to inform the public as to that which is done in their name, and that which is done against them" (Burman, 2013).

Argument (E) - Legitimizing Whistleblowers, arguing for their valuable contributions to society: 
Example 1: "The power of truth-tellers like Bradley Manning, Julian Assange, and Edward Snowden is that they dispel a whole mythology carefully constructed by the corporate cinema, the corporate academy and the corporate media" (Pilger, 2013).

Example 2: "Whistleblowers have a right in a free society -- no a responsibility to keep the government in check" (Raphael, 2014).

\section{Argument (F) - Legitimizing the NSA leaks: the country benefited; he exposed malpractice:}

Example 1: “...he has performed a great public service that more than outweighs any breach of trust he may have committed... Snowden has brought to light important information that deserved to be in the public domain" (Cassidy, 2013).

Example 2: "He has exposed what I believe to be criminal wrongdoing, lying to Congress and certainly a shock and an affront, in America, an affront to the fourth amendment. I think that history will judge him very favourably" (Gabbit, 2013).

\section{Analysis of Arguments}

The most common arguments made in constructing Snowden as a hero fall under category (F), which posit that Snowden's actions exposed malpractice and nefarious activities in the NSA and that the country has benefited from learning about them. The second most common arguments (C) are those which legitimize his character on the basis that Snowden acted ethically. That is, that Snowden took ethically-sound actions, and that his decisions to act were done as a means of defending the American constitution on ethical grounds. These arguments also validate the ethical nature of his actions by arguing that he was acting on behalf of Americans and was not acting in a manner in which he would personally benefit. Next, approximately half of the articles defend Snowden as a whistleblower and do so by legitimizing the actions of all whistleblowers, or whistleblowers generally (E), arguing that they make valuable contributions to society and should therefore be validated and lauded. Almost half of the articles also valorize Snowden on the basis that he acted 'humanely', thus suggesting that he cares about others and humanity in general (A). Here arguments are made that foreground his caring for others, the emotional drives which cause him to act, the way in which his conscience led him to blow the whistle. Reflecting on Snowden's current state of affairs (of being trapped in Russia in asylum), nearly half of the articles portray the 
actions of Snowden as heroic in that he made sacrifices for others, or took risks for others (B). Only three of the articles quote Snowden as a means of disclosing his personal motivations (D). In doing so, these articles fully enmesh Snowden as an active individual in their discourse. That is, they have given opportunities for Snowden's own voice to emerge through their arguments.

\section{Additional Elements for Consideration}

Another important discursive element in the 'hero bloc' is the referencing of other public intellectuals, the most notable and predominant of which is Daniel Ellsberg. Six of the 11 discursive acts make explicit reference to Daniel Ellsberg. In doing so, the authors draw lines of equivalence between the 'heroic' and valuable actions taken by Ellsberg, and those by Edward Snowden. Not only do the authors make the suggestion that Snowden needs to be considered and contextualized as a whistleblower akin to that of Ellsberg, but the reference of his name leads the audience - at times directly, with hyperlinks - to consider Ellsberg's perspective on the Snowden situation. In addition, Bradley Manning is mentioned in two of the articles, George Washington's name surfaces in one, and John F. Kennedy's in another. The use of these names is relevant as they situate Snowden in the American tradition of whistleblowing specifically but more generally align him with actions taken by individuals engaged in promoting civil liberties. In short, these names are used in a manner which strives to bolster the public's perception of Snowden and to ethically justify his whistleblowing actions. They are used to strengthen the 'bloc' which argues for Snowden to be seen as a hero.

\section{Discussion of the 'hero bloc'}

The discursive acts arguing that Snowden should be perceived as a hero adhere to both conceptualization of the mythical 'hero' by Alsford (2006) as well as the 'patriot' by Viroli (1996). In arguing that Snowden's actions exposed malpractice and nefarious activities undertaken by the NSA, the NSA becomes framed as somewhat of an evil force that needed to be dealt with. In taking on this evil entity, Snowden's actions are seen as an individual "being in a world in a certain way" (Alsford, 2006) - in a way that strives towards bringing this evil entity to justice. In doing so, Snowden's actions are framed as 
doing society a benefit. They are seen as efforts to "stand up for the defense of common liberty and rights" (Viroli, 1995, p. 9-10). Because it is argued that Snowden acted ethically, his decisions to transcend the norm, in this case breaking the institutional laws to which he had ascribed, are portrayed as actions undertaken not for personal gain, but for public interest. It is argued, furthermore, that Snowden is a 'hero' because he 'sacrificed' his own well-being for the concerns of 'others'. Recalling Alsford's (2006) conceptualization of the hero, a hero does not use one's power to distance oneself from society, but rather to entrench oneself in the concerns and issues pertaining to society at large. A hero's efforts are geared towards promoting the interconnectedness of all humanity and protecting the rights of those who are not able to defend themselves.

In striving to bring a public institution's actions into the realm of social debate, it is argued that Snowden's actions are seen as efforts to bolster the public's participation in democratic practices. This is the central argument, as aforementioned, which Viroli (1995) posits, constitutes heroic, patriotic actions. Additionally, on the notion of a heroic sacrifice, while Snowden's actions significantly damage the stability of his personal wellbeing, others in society are seen as having the potential to benefit. By caring deeply for others, for the concerns of others, Snowden is argued to be a remarkably humane figure who acts with conscience. His 'human' and 'emotional' characteristics are used to further interconnect his individual self with humanity at large. Snowden, therefore, is argued to be 'hero' in that he passionately acts to empower 'others', and not merely himself.

\section{Analysis of the 'traitor bloc'}

Below, Table 4 refers to 11 acts of discourse in which Snowden 'is a traitor'. Table 5 identifies the kinds of arguments used by each of these acts of discourse. After presenting these tables, explicit examples of the arguments will be provided: 
Table 3: Discourse Acts in the 'traitor bloc'

\begin{tabular}{|c|c|c|c|c|c|}
\hline Dis \# & "Title" & Publication & $\begin{array}{l}\text { Date Published } \\
\text { Day/moth/year }\end{array}$ & $\begin{array}{l}\text { 'Public } \\
\text { Intellectual' }\end{array}$ & $\begin{array}{l}\text { Arguments } \\
\text { (Letters) }\end{array}$ \\
\hline $\mathbf{1}$ & $\begin{array}{l}\text { "Edward Snowden is } \\
\text { no hero" }\end{array}$ & $\begin{array}{l}\text { The New } \\
\text { Yorker }\end{array}$ & $10 / 06 / 13$ & $\begin{array}{l}\text { Jeffrey Toobin, } \\
\text { journalist }\end{array}$ & $\mathrm{A}, \mathrm{B}, \mathrm{C}, \mathrm{D}, \mathrm{E}, \mathrm{F}$ \\
\hline 2 & $\begin{array}{l}\text { "John Boehner: } \\
\text { Edward Snowden Is } \\
\text { A 'Traitor"” }\end{array}$ & $\begin{array}{l}\text { The } \\
\text { Huffington } \\
\text { Post *video } \\
\text { (interview } \\
\text { summary) }\end{array}$ & $11 / 06 / 13$ & $\begin{array}{l}\text { John Boehner, } \\
\text { House } \\
\text { Speaker, } \\
\text { (republican) }\end{array}$ & $\mathrm{B}, \mathrm{E}$ \\
\hline 3 & $\begin{array}{l}\text { "Yes, Edward } \\
\text { Snowden Is a } \\
\text { Traitor" }\end{array}$ & The Diplomat & $21 / 12 / 13$ & $\begin{array}{l}\text { Zachary Keck, } \\
\text { journalist }\end{array}$ & $\mathrm{A}, \mathrm{B}, \mathrm{C}, \mathrm{D}, \mathrm{E}$ \\
\hline 4 & $\begin{array}{l}\text { "Edward } \\
\text { Snowden, traitor" }\end{array}$ & $\begin{array}{l}\text { New York } \\
\text { Daily News }\end{array}$ & $1 / 06 / 14$ & $\begin{array}{l}\text { James } \\
\text { Kirchick, } \\
\text { journalist }\end{array}$ & $\mathrm{A}, \mathrm{C}, \mathrm{E}, \mathrm{F}$ \\
\hline 5 & $\begin{array}{l}\text { "Let Me Show You } \\
\text { Why Edward } \\
\text { Snowden is a Traitor } \\
\text { and Not a Patriot" }\end{array}$ & $\begin{array}{l}\text { Forward } \\
\text { Progressives }\end{array}$ & $7 / 06 / 14$ & $\begin{array}{l}\text { Allen Clifton, } \\
\text { journalist }\end{array}$ & $\mathrm{B}, \mathrm{D}, \mathrm{E}, \mathrm{F}$ \\
\hline 6 & $\begin{array}{l}\text { "Bill Gates: The } \\
\text { Rolling Stone } \\
\text { Interview" }\end{array}$ & $\begin{array}{l}\text { The Rolling } \\
\text { Stone }\end{array}$ & $14 / 03 / 14$ & $\begin{array}{l}\text { Bill Gates, CEO } \\
\text { Microsoft }\end{array}$ & $\mathrm{B}, \mathrm{D}$ \\
\hline 7 & $\begin{array}{l}\text { "Merlene Davis: } \\
\text { Snowden is a traitor, } \\
\text { not a hero" }\end{array}$ & $\begin{array}{l}\text { Lexington } \\
\text { Herald-Leader } \\
\text { (appearing on } \\
\text { Kentucky.com) }\end{array}$ & $29 / 06 / 13$ & $\begin{array}{l}\text { Merlene Davis, } \\
\text { journalist } \\
\text { ('columnist') }\end{array}$ & $\mathrm{A}, \mathrm{B}, \mathrm{D}, \mathrm{E}, \mathrm{F}$ \\
\hline 8 & $\begin{array}{l}\text { "Kerry: Snowden a } \\
\text { "Coward" and } \\
\text { "Traitor"" }\end{array}$ & $\begin{array}{l}M S N B C \\
{ }^{*} \text { embedded } \\
\text { video }\end{array}$ & $28 / 05 / 14$ & $\begin{array}{l}\text { John Kerry, } \\
\text { politician } \\
\text { (democrat) }\end{array}$ & $\mathrm{A}, \mathrm{D}, \mathrm{E}$ \\
\hline 9 & $\begin{array}{l}\text { "Cheney: "Edward } \\
\text { Snowden is a } \\
\text { Traitor"”" }\end{array}$ & $\begin{array}{l}\text { YouTube/ } \\
\text { Larry King } \\
\text { Now *video } \\
\text { interview }\end{array}$ & $14 / 11 / 13$ & $\begin{array}{l}\text { Dick Cheney, } \\
\text { former vice- } \\
\text { president to } \\
\text { George W. } \\
\text { Busch } \\
\text { (republican) } \\
\end{array}$ & $\overline{\mathrm{E}}$ \\
\hline 10 & $\begin{array}{l}\text { "Cheney defends } \\
\text { NSA programs, says } \\
\text { Snowden a 'traitor,' } \\
\text { Obama 'lacks } \\
\text { credibility'” }\end{array}$ & $\begin{array}{l}\text { Fox News } \\
\text { *video } \\
\text { interview }\end{array}$ & $16 / 06 / 13$ & $\begin{array}{l}\text { Dick Cheney, } \\
\text { former vice- } \\
\text { president to } \\
\text { George W. } \\
\text { Busch } \\
\text { (republican) }\end{array}$ & $\mathrm{B}, \mathrm{E}, \mathrm{F}$ \\
\hline 11 & $\begin{array}{l}\text { Snowden a 'traitor': } \\
\text { Andreessen }\end{array}$ & $\begin{array}{l}C N B C \text { * video } \\
\text { interview }\end{array}$ & $5 / 06 / 14$ & $\begin{array}{l}\text { Marc } \\
\text { Andreessen, } \\
\text { venture } \\
\text { capitalist } \\
\text { (silicon valley) } \\
\end{array}$ & $\mathrm{B}, \mathrm{E}$ \\
\hline
\end{tabular}


Table 4: Types of Arguments and the Discourse Acts that use them

\begin{tabular}{|c|c|}
\hline (Letter) Type of Argument & Discourse \# that includes the argument \\
\hline $\begin{array}{l}\text { (A) Delegitimizing Character \#1: As a person } \\
\text { (name-calling); framing with negative qualities } \\
\text { like 'coward' }\end{array}$ & $1,3,4,7,8$ \\
\hline $\begin{array}{l}\text { (B) Delegitimizing Character \#2: As a } \\
\text { criminal; mentioning 'crimes'; 'criminal'; 'acts } \\
\text { of treason'; 'betrayal'; he 'stole' }\end{array}$ & $1,2,3,4,5,6,7,10,11$ \\
\hline $\begin{array}{l}\text { (C) Delegitimizing Character \#3: Imposing } \\
\text { personal value system on public, democratic } \\
\text { institutions }\end{array}$ & $1,3,4$ \\
\hline $\begin{array}{l}\text { (D) Delegitimizing Character \#4: Form of } \\
\text { leaking was 'unethical'; 'irresponsible'; didn't } \\
\text { follow proper Whistleblowing codes of conduct } \\
\text { (didn't accept punishment) }\end{array}$ & $1,3,4,5,6,7,8$ \\
\hline $\begin{array}{c}\text { (E) Delegitimizing Leaks \# 1: leaks are } \\
\text { 'dangerous'; 'damaging to us/ United States', } \\
\text { puts American at 'risk'; 'hurts United States' } \\
\text { reputation’ }\end{array}$ & $1,2,3,4,5,7,8,9,10,11$ \\
\hline $\begin{array}{c}\text { (F) Delegitimizing Leaks \#2 + Fleeing to } \\
\text { adversary countries: Suggests the problems/ } \\
\text { danger of China/ Russia/ (others) }\end{array}$ & $1,4,5,7,10$ \\
\hline
\end{tabular}

Examples of Arguments:

Argument (A) - Delegitimizing Character \# 1: As a person (name-calling); framing with negative qualities like, for example 'coward':

Example 1: "Edward Snowden is a coward, he is a traitor" (Dann, 2014).

Example 2: "He is, rather, a grandiose narcissist who deserves to be in prison" (Toobin, 2013)

Argument (B) - Delegitimizing Character \#2: As a criminal; mentioning 'crimes'; 'criminal'; 'acts of treason'; 'betrayal'; he 'stole':

Example 1: "I think he has committed crimes in effect by violating agreements given the position he had" (Fox News, 2013).

Example 2: ""Just on the issue of, 'Is this a whistleblower, or is this an act of treason,' I think it directly is. And I think that most of the people who serve on [the intelligence committee] will tell you that" (Johnson, 2013).

\section{Argument (C) - Delegitimizing Character \#3: Imposing personal value system on public, democratic institutions:}

Example 1: "So he wasn't blowing the whistle on anything illegal; he was exposing something that failed to meet his own standards of propriety. The question, of course, is whether the 
government can function when all of its employees (and contractors) can take it upon themselves to sabotage the programs they don't like" (Toobin, 2013).

Example 2: "And Snowden, the know-it-all Millennial, arrogated to himself the right to determine what secrets, if any, our government should be allowed to keep" (Kirchik, 2014).

Argument (D) - Delegitimizing Character \# 4: Form of leaking was 'unethical'; 'irresponsible'; didn't follow proper Whistleblowing codes of conduct (didn't accept punishment):

Example 1: "If he wanted to raise the issues and stay in the country and engage in civil disobedience or something of that kind, or if he had been careful in terms of what he had released, then it would fit more of the model of "OK, I'm really trying to improve things." You won't find much admiration from me" (Goodell, 2014).

Example 2: "Snowden should have taken his information to an organization or politician in this country who was willing to stand with him as he blew the whistle. There are plenty of them around. He could have started with the Libertarians" (Davis, 2013).

Argument (E) - Delegitimizing Leaks \#1: leaks are ‘dangerous'; ‘damaging to us/ United States', puts American at 'risk'; 'hurts United States' reputation':

Example 1: "In fact, as others have pointed out, information from the Snowden documents has been published in a manner that seemingly seeks to do as much harm to U.S. alliances across the world as possible" (Keck, 2013).

Example 2: "I think he's done enormous damage to the country" (Larry King Now, 2013).

Argument (F) - Delegitimizing Leaks \#2 + Fleeing to adversary countries: Suggests the problems/ danger of China/ Russia/ (others):

Example 1: "But I'm very very worried that he still has additional information. That he still hasn't released yet. That the Chinese would welcome the opportunity and probably willing to provide immunity for him or sanctuary if you will in exchange for presumably what he knows or doesn't know. So, it's going to be a continuing problem. I don't think is a one-off disclosure. I think there's a real danger here" (Fox News, 2013).

Example 2: "You can't tell me Russia and China haven't taken all the information Snowden was carrying and gained a better foothold on this country's intelligence gathering as he stayed with them looking for a new home" (Davis, 2013). 


\section{Analysis of Arguments}

The most common arguments made in the 'storyline' enacting Snowden as a 'traitor' are those which argue that his leaking of classified information is 'dangerous' and 'damaging' to the United States (E). These arguments are made in all but one of the discursive acts portraying him as a traitor. Here, it is argued that the leaks inhibit America's ability to protect itself while at the same provide tools which America's enemies (or those wishing to do harm against the nation) can use to inflict damage. As such, the leaks put America at risk and are damaging. Furthermore, it is argued that damage inflicted on the United States pertains to the tarnishing of its international reputation. The most second most common arguments (B) are those which delegitimize Snowden's character on the grounds that he acted 'criminally'. Here, he is labelled a 'criminal'; his actions are considered 'crimes', a 'betrayal', and are, in cases, considered acts of 'treason'. Following closely with this line of argumentation, are claims which argue that he acted unethically (D), that he was 'irresponsible' and did not follow the typical and proper codes of conduct which should be enacted by individuals blowing the whistle in institutional contexts. Common arguments in (D) make the point that Snowden should not have fled the United States but should have faced injustice inside of the country. As a result of fleeing the country, arguments (F) are made that the fleeing has resulted in adversarial nations such as China and Russia being granted powers (insider information) which can be used against the United States. These arguments (F) work to delegitimize Snowden's actions based on the fact that his presence in China and Russia put America at risk. On a different note, in 5 of the 11 discursive acts, evident are arguments that attack Snowden's character (A). Snowden is framed as a 'narcissist' and 'coward', a framing which serves the objective of delegitimizing his character, and in turn, his actions. Lastly, arguments are made to delegitimize his character (B) by arguing that Snowden is imposing his own personal value system onto democratic practices. As such, it is argued that Snowden oversteps his authority and acts in an undemocratic manner. Because Snowden, it is argued, acts against the democratic will of the American populace, his actions should not be valorized, and he should be considered a 'traitor'. 


\section{Additional Elements for Consideration}

Unlike the 'hero bloc', which contains almost no instances of portraying Snowden with laudatory adjectives, the 'traitor bloc' displays instances of vituperative language used to condemn and criticize his character. In discourse act 1, Snowden is called, 'a grandiose narcissist'; in discourse acts 3,4 , and 8 , he is labelled 'a coward'. Discourse act 4 states that Snowden 'whines about how the people he lied to and stole from tried to prevent him from getting away with it' and argues that he has the 'worst traits of the Millennial generation: self-entitlement, moral equivocation, and no sense of loyalty to one's country.' Furthermore, this discourse describes Snowden as speaking in a 'smug tone' and labels him a 'know-it-all'. Lastly, in discourse act 7, Snowden's actions are likened to a pile of cow dung. In short, these examples of discourse strive to cripple the integrity of Snowden's character. Perhaps what can be seen as evident in these uses of language are the fervent flames of anger from which the language has arisen. Perhaps Snowden's actions have deeply affected these public intellectuals on emotional levels, and these emotions have manifested themselves in the discourse. From another perspective, perhaps these uses of language can be deemed strategic discursive maneuvers, seeking to rouse the anger pathos of those similarly affected by Snowden's actions.

Also worth noting of the discursive acts in the 'traitor bloc' are conjectural statements presented as fact. For example, discourse 1 states that 'Snowden is now at the mercy of the Chinese leaders who run Hong Kong'. Discourse act 2, writes, 'Meanwhile, Snowden seeking refuge in first China and then Russia nearly guarantees that the governments in those countries have gained a treasure trove of valuable information on NSA operations against their countries'. While there might be shards of truth jammed into these proclamations, there was not, and has never been, any factual evidence leading one to claim that leaders of those countries had any interaction with Snowden. Furthermore, without properly and thoroughly assessing the kind of information that Snowden leaked, one cannot rightfully claim that those countries (Russia and China) have gained any relevant information, let alone a 'treasure trove' of valuable goods. Additionally, discourse act 7 reads that 'NSA director Keith Alexander said that Snowden, who worked for a contractor at that agency gained access to information that was above his clearance level'. Snowden has vehemently stated that he had been given authorized 
access by the NSA officials to all of the internal information that he leaked. Lastly, this discourse act 7 reads, 'You can't tell me Russia and China haven't taken all the information Snowden was carrying and gained a better foothold on this country's intelligence gathering.' Once again, Snowden rebuts this claim, stating that he has had no contact with high-level political officials in either country, and that he gave information to the journalists: Greenwald, Gellman, Poitras, and MacAskill, and nobody else. These types of conjectural statements might strike one as instances of fearmongering, whereby Snowden becomes portrayed as a threat, or at least a threat of much greater severity than the facts would lead one to believe.

\section{Discussion of the 'traitor bloc'}

The core trait of the traitor hinges on a betrayal of one's duty or trust. When this betrayal takes place not on the individual level of say friendship or commerce, but on the national level, traitorous actions have the potential to be deemed treasonous. It is for this reason that Snowden's actions are depicted as causing serious and irrefutable damage to the United States, actions that put America's security at risk (recall that Snowden has in fact been charged under the Espionage Act). If Snowden's actions are as damaging as those in the 'traitor bloc' claim, his actions must be considered treasonous, and he, in turn, must be seen as a 'traitor'.

Furthermore, the case is made in the 'traitor bloc' that Snowden betrayed trust by breaking the law by disclosing top-secret information after having signed an affidavit vowing the contrary. The most salient arguments made in this regard are those which refer to Snowden as a 'criminal', to his actions as 'crimes', and to his gleaning of classified documents as 'stealing'. Because the law encompasses all individuals living in a particular nation, Snowden's breaching of the laws, of these very social agreements, results in arguments furthering the case that he is a traitor. It is also argued in the 'traitor bloc' that Snowden not only transcended social and institutional laws, but also the norms or codes to which the 'correct' whistleblower should adhere. As was previously stated, it is the transcending of norms, rules, or codes by an individual, which on one hand, under Nietzsche's conceptualization of the übermensch, is considered to 
be heroic. On the other hand, however, this breaching or transcending of the norm also contains the potentiality for one to be viewed as a traitor or villain.

Aside from the elements of criminality already mentioned, the transcending of laws contains the interpretative potentialities for one to be viewed as a traitor or villain in that this individual, as noted by both Alsford (2006) and Kateb (2006), can be seen as overstepping the democratically-instilled and democratically-enacted processes in order to change society in one's individual image. Although only three of the eleven acts of discourse make these arguments explicitly, the others also touch on this villainous aspect of Snowden. Imbued with the power of knowledge pertaining to classified, secretive information of which Snowden had access, Snowden, as has already been stated, was argued to have used this position of power to harm his country. As noted by Alsford (2006) a key characteristic of villain is one who 'revels' in the power to control others and to force their value system upon society at large. What occurs as a result is that the villain deepens the gulf between herself and society at large - in Snowden's case, his nation. The arguments made in the 'traitor bloc' strive to illustrate this separation of oneself from one's country by highlighting the fact that in betraying the whistleblowing code of conduct by fleeing to first China and then Russia, Snowden not only damages the United States and aids the enemy but distances himself from the country which he claims to be protecting. As such, Snowden grants himself the power to usurp democratic conventions for destruction, on one hand, and to engage in some form of world domination on the other - a form of world domination whereby his ideals override those of the general populace. Furthermore, Snowden, it is argued, abandons America's own system of governance for dealing with such cases and therefore separates himself from America not only physically but also ethically; he evades the social and legal norms through which American justice can be practiced. Essentially, it is argued that he disconnects himself from America's value system.

Lastly, the delegitimizing of Snowden's character by debasing his character, labelling him, for example as a 'narcissist', is an example of the argument stressing that Snowden's ego takes precedence over the concerns of others, that he values himself and his actions more so than his nation. It is for this reason that Snowden's leaks are argued to be unethical and irresponsible. It is only the traitorous treasonous villain who strives 
to inflict damage on one's nation by acting on unethical desires pertaining to his own will. It is the villain who deepens the gulf between himself and others, especially the ethical codes by which the others to whom he supposedly belongs live. Thus, on these discursive grounds, the' traitor bloc' constructs a 'chain of equivalence' in which Snowden becomes ascribed to the concept of a 'traitor.'

\section{Discussion of 'Public Intellectuals in both the 'Hero' and 'Traitor' Blocs}

The vast majority of discursive acts which have risen up the ranks of Google's search engine are not opinion pieces from individual journalists but rather stories about 'public intellectuals' who have taken up the Snowden story. The simple point to be made here is that 'public intellectuals' have a fair amount of socio-discursive force. That is, when they speak, or decide to weigh in on social 'issues', their discursive acts, or arguments, make news. Their acts become relatively powerful in digital spheres.

The wide range 'public intellectuals' making these arguments, in turn making up the hero and traitor coalitions, have aligned their socio-political identities with regards to Snowden through their discursive acts. Without conducting a series of interviews which each of these figures, one cannot shed further light on their reasons for doing so. What can be stated, however, is that by discursively acting in the manner they have, these 'public intellectuals', in the far or near future, might find themselves in social environments, political, personal, or otherwise, in which their discursive acts might face contestation. Contending with the proclamations declared in these earlier discursive articulations might prove to be unproblematic, especially if their opinions remain the same and if they feel as confident and committed to them as before. It might be the case, however, that their opinions have changed, in which case they will be forced to reexamine not only their earlier-held positions, but the state of their identities which had discursively acted in that manner.

It is for this reason, that Laclau and Mouffe argue (1985) that articulations should be seen as "any practice establishing a relation among elements such that their identity is modified as a result of the articulatory practice" (p. 91). Thus, it is not merely the case that Snowden's discursive entity is modified through these articulations, but so are those of the 'public intellectuals'. Intertwining (at least part of) their identities in their 
discursive articulations, the 'public intellectuals' enact Snowden not only for the public at large, but also for themselves, or perhaps for the social projections of their identities in social spheres. And while one cannot ascertain the precise reason that individuals have discursively acted in the manner they have, one should be aware that their reason(s) for doing so, most likely, cannot be reduced to a singularity. Rather, they are likely brought forth by multifarious and intermingling social, economic, political, historical, and emotional forces. Interviews with participants might help to shed light on these forces.

Having already established the manner in which Snowden has been discursively enacted in digital spheres by media institutions and 'public intellectuals', the question now becomes one of asking whether or not the public at large has taken up the Snowden debate in a similar manner.

\section{Data Findings, Analysis and Discussion in YouTube comments}

\section{Data Findings in YouTube comments: Word Frequency}

The most viewed Snowden interview on YouTube titled, "NSA whistleblower Edward Snowden: 'I don't want to live in a society that does these sort of things' initially published on The Guardian website the same day, contained, at the time of writing, 39, 373 comments (Gallagher, 2013). The compilation of these comments in a corpus demonstrates the presence of the popular antagonism of the 'hero-traitor'.

Table 5 is a condensed list of the top 40 words occurring in the comments where only the exact form of the words appears (excluding variations of the word formed with suffixes, apostrophes, hashtags, etc.). For the complete table of the top 40 words, refer to Appendix C. In reference to these tables, it needs to be stated that Nvivo removes all articles and demonstrative adjectives from the word lists. 
Table 5: Condensed table of 'Exact' words

\begin{tabular}{|ccc|}
\hline Rank & Word & \# of uses \\
\hline 1 & snowden & $\mathbf{7 0 0 1}$ \\
\hline 2 & people & $\mathbf{6 8 5 4}$ \\
\hline 3 & government & $\mathbf{6 0 7 3}$ \\
\hline 6 & nsa & $\mathbf{4 4 1 5}$ \\
\hline 17 & hero & $\mathbf{2 1 5 6}$ \\
\hline 19 & obama & $\mathbf{2 0 9 5}$ \\
\hline 33 & china & $\mathbf{1 5 6 4}$ \\
\hline 35 & traitor & $\mathbf{1 4 8 2}$ \\
\hline 36 & russia & $\mathbf{1 4 6 8}$ \\
\hline 37 & freedom & $\mathbf{1 3 8 0}$ \\
\hline 39 & fuck & $\mathbf{1 3 3 4}$ \\
\hline 144 & patriot & $\mathbf{6 8 5}$ \\
\hline
\end{tabular}

Table 6 is a list form of the top 40 words occurring in the comments where a word including all its variations is used. For example, in the table, 'snowdens' is the title word for the group where all forms of 'snowden' are included: \#snowden; snowden; 'snowden; snowden'; 'snowden'; 'snowdenized'; snowdens. In this case of 'heros' the following forms are included: \#hero; hero; 'hero; hero'; ‘hero'; hero\#; heroe; heroes; heros; 'heros'. For the complete table of the top 40 words used with variations, refer to Appendix D.

Table 6: Condensed table of 'Exact+1' words

\begin{tabular}{|ccc|}
\hline Rank & Word & \#of uses \\
\hline 1 & snowdens & 7106 \\
\hline 2 & peoples' & $\mathbf{6 9 6 7}$ \\
\hline 3 & governments & $\mathbf{6 6 1 0}$ \\
\hline 6 & nsa & $\mathbf{4 4 5 0}$ \\
\hline 18 & fucks & $\mathbf{2 5 8 0}$ \\
\hline 21 & heros & $\mathbf{2 3 3 2}$ \\
\hline 27 & obamas & $\mathbf{2 1 4 0}$ \\
\hline 37 & traitors & $\mathbf{1 7 4 1}$ \\
\hline 121 & patriots & $\mathbf{8 7 8}$ \\
\hline
\end{tabular}

What these two tables demonstrate, quite simply, is that the 'hero-traitor' popular antagonism can be evidenced in the discursive enactment of Edward Snowden (and his actions) undertaken by the public at large. While in both tables (6 and 7), 'snowden' and 'snowdens' are used the most, 7001 times and 7106 times respectively, the words 'hero' and 'traitor' also are taken up extensively in the public's discourse: 'hero' is used 2156 times, ranking $17^{\text {th }}$ on the exact-word list, and 'heros' is used 2332 times, ranking $21^{\text {st }}$ on 
the word-with-variations list. 'traitor' is used 1482 times, ranking $35^{\text {th }}$ on the exact-word list, while 'traitors' is used 1741 times, ranking $37^{\text {th }}$ on the word-with-variations list. Important to note is the fact that 'patriot'/'patriots' ranks much lower on both lists: $144^{\text {th }}$ and $121^{\text {st }}$ respectively. This demonstrates, as was mentioned earlier, that although the 'hero-traitor' antagonism has been used almost synonymous (and at times interchangeably) with the 'patriot-traitor' antagonism, the use of 'hero' is much more predominant in the discourse produced by the public at large than that of 'patriot'. Because the majority of the words on this list include commonly-used verbs such as 'need'; 'want'; 'think'; 'get'; 'make'; 'use', and words such as 'like'; 'just'; 'one'; 'man'; 'country' the presence of the words 'hero' and 'traitor' can be interpreted as 'floating signifiers' which have been taken up to construct the 'chains of equivalence' and 'storylines' pertaining to the 'hero-traitor' popular antagonism specifically with regards to Snowden's whistleblowing event.

\section{Analysis of the YouTube comments: Word Frequency}

The data demonstrates that the popular antagonism 'hero-traitor' does not pertain solely to the discourse created by popular media institutions and their respective 'public intellectuals' but also is taken up by society at large. Very generally speaking, what this demonstrates is that there is a connection between the discourse of popular media driven by 'public intellectuals' and the public at large. Although it might be argued that popular media has forced this antagonism onto the public at large, such a conclusion might struggle to gain validity as it would be difficult to prove. Perhaps a more viable interpretation would be that there is a reciprocal relationship between the discursive realm of popular media and the realm of the public at large whereby both feed into and draw from another. This argument would suggest that both discursive realms are not inherently disconnected from one another; in contrast, an intermingling of discursive forces seems to exist between the two. Claims which strive to draw strict divisions between the two realms, therefore, would seem to be ill-founded. Furthermore, because it has already been stated that the 'hero-traitor' antagonism or storyline preceded Snowden, it seems evident that both the popular media as well as the public at large draw on the already-established and communally-constructed 'hero-traitor' storyline as a source of discursive potentiality to enact Snowden and align themselves with 
contrasting political positions. That is to say, they draw from the relevant pools that constitute the 'collective memory' of these particular social contexts.

\section{Data Findings and Analysis of YouTube Comment: 'likes' and 'replies'}

In assessing the comments with more than 20 replies (11 in total), and the top-10 most liked comments ${ }^{19}$ (capped at a total of 12) in the corpus, some distinct findings are evident. (To see the full top-40 tables including text, refer to Appendix E and Appendix F.)

First, with regards to the ID's of the commenters, evident are numerous examples of pseudonyms. While there are in fact numerous examples where commenters have used 'proper names', there are no grounds to conclude that these proper names are in fact the names of the actual commenters as opposed to individuals using pseudonyms, or internet-based aliases. The presence of pseudonyms or aliases, demonstrates the aforementioned notion that in the digital discursive realm of the internet, subjects, take on multifarious identities, or, at the very least, have the potentiality to do so. Harking back to what was stated by Poster (1990), "Electronically mediated communication... invites the recipient to reconstruct his or her self in conversation with different discourses" whereby individuals (can) become "nomadic and multiple selves" (Torfing, 1999, p. 222). As subjects align their 'selves' politically and antagonistically with Snowden's whistleblowing by taking up socio-political subject positions (at times with established hegemonic blocs), they do so through digital discursive articulations in which they are not corporeally present. These subjects, therefore, have the ability to play out or enact various digital identities, which may or may not make any explicit reference to their socially-established identities in the material world offline. As such, the discursive sphere on the internet provides a realm in which one can take up a wide variety of social identities if one so chooses.

Second, with regards to the comments with at least 20 replies, a 'democratic antagonism' is evident. 8 of the 11 comments condemn Snowden and/or his actions. The

\footnotetext{
19 A 'like' is constituted by a user clicking on the 'thumbs up' icon which appears under the comment. Getting a 'like' can be understood as a comment getting 'upvoted'. This occurs because when a comment that is liked '4 times' receives a 'downvote' (a thumbs down), its total number of 'likes' becomes 3 .
} 
manner in which they do so, however, does not include (with some scant exceptions) metaphors shared by numerous users. The comment with the most replies (70) attacks Snowden using aggressive language. It reads, "That thief is a lying treasonous cunt". In other comments criticizing Snowden and his actions, he is labelled, "a fake", "a coward", "a cunt" (once again), and "not a whistleblower", and a variety of different arguments are made suggesting why neither he, nor his actions, should be lauded. As such, because 8 of the 11 comments attack Snowden in diverse manners, they are not unified in overarching 'chains of equivalence'. Therefore, the comments which created the most online discussions essentially represent the 'chains of difference' and a 'democratic antagonism'; the discursive articulations are pluralistic. This is further evident in the fact that the comment submitted by the Washington Post (replied to 33 times), merely updates, in a factual manner, the state of Snowden's affairs in terms of fleeing the country and seeking asylum. The second comment which does not attack Snowden reflects on government surveillance, stating, "I'm sure the government is making a note of all who have viewed this video." This comment was replied to 37 times. A third comment, replied to 21 times, was written in German (posted by ZDF heute), and, therefore, cannot be assessed here.

Ultimately, what created the most chains of discussion (replies) under this particular video was a wide-range of discursively diverse, though primarily antagonistically-driven, comments. This suggests that, generally speaking, creating antagonistic discourse online (in this case, specifically those attacking Snowden) creates discussions. In addition, perhaps what can also be suggested is that, although the sample size is small (and arguably too small to make any significant claims), it is not the 'hero-traitor' popular antagonism which causes people to discursively engage with one another on the comment section of YouTube videos but rather instances when one creates an antagonism by engaging the debate using unique (not previously-established) language and arguments. Perhaps it is the case that the 'hero-traitor' antagonism becomes overused and trite, losing its power to have social affect. By latching onto the popular antagonism in a relatively thoughtless and perhaps overly-accessible manner - in which one engages the debate, yet does so without creating any uniqueness through linguistic difference - it could be argued that one's individual perspective gets thoroughly 
drowned out in the most prevalent (and obvious) stream of discourse; this is to say, quite bluntly, that without individuality or uniqueness, one's comment does generate responses. Much more analysis would have to take place in order to determine if this is actually the case. Reviewing all of the replies instigated by the comment which started the discussion could lead one to ascertain whether or not the popular antagonism becomes present, and if so, for what reason(s) it does. Further complicating the matter, perhaps it is not the lead comment which created the long-chain of discussion, but rather a comment which appears at a later stage in the chain.

Regarding the top-10 most-liked comments (capped at 12), a democratic antagonism also becomes evident. 5 of the 12 comments praise Snowden and his actions, and 1 of those 5 comments not only praises Snowden but does so in addition to attacking another commenter. 3 of the 12 comments engage the Snowden situation on a 'neutral' and 'factbased' basis, discussing Snowden's situation with respect to his being in Russia, and the manner in which the government is dealing with his whistleblowing; legal issues are also touched upon. Of the remaining 4 comments, 1 reflects on government surveillance, 1 attacks Snowden, 1 criticizes the American government and calls upon individuals to take up action against it, and 1 reflects on international governance in a manner that raises questions and asks for explanations. As such, the comments which have received the most 'likes' are linguistically and argumentatively pluralistic. While the 'floating signifier' ('hero') of the of the popular antagonism does play a role in creation of 'likes', it does not seem to have value in terms of creating discussions.

Out of the 5 comments lauding Snowden, 3 make use of the 'hero' in the 'popular antagonism': The comment, "He is a hero!" received 87 'likes'; 'This guy is a true American hero. A guess you like your whole life being recorded like the Trueman [sic] Show' received 65 'likes'; and the comment, 'Hero' received 59 'likes'. While all of these comments ranked in the top-10 for 'likes', they created only one 1 reply ('Hero' was replied to once). In contrast, another comment praising Snowden, that of: "Edward Snowden is the ONLY American I respect. He woke up to the truth about his evil Country. I just hope he is telling the Russian authorities everything there is to know about the NSA and CIA etc........." received a considerable number of likes (75) and started a chain of 20 replies. Noted is the fact, that this comment not only praises 
Snowden, but antagonistically attacks the United States, and wishes harm upon it. Also relevant to note in the list of the top-10 'liked' comments is that the offensive word 'cunt' appears in the sole comment attacking Snowden. The comment: 'Yea, what a cunt, releasing all the information about the government spying on its own people. Ignorance is bliss I suppose' was 'liked' 70 times. It appears as though the word 'cunt' not only has some power to create discussions, but also to create 'likes' - at least in this specific case. Perhaps it could be argued that misogyny plays a role here, and more in-depth analysis should further light on whether or not this is a valid interpretation.

The comment which received the most 'likes' (246) reads, 'I'm sure the government is making a note of all who have viewed this video' This comment is not overtly antagonistic, but merely reflects on the potentially ubiquitous presence of government surveillance. The comment which received the second most 'likes' (92) is the aforementioned comment from the Washington Post, which was replied to 33 times. This comment is void of antagonisms and instead, as already stated, provides factual updates on the Snowden situation. What becomes evident, therefore, in assessing the comments that get 'likes' is a diverse range of comments get 'likes'; the field is essentially pluralistic. It represents a democratic antagonism.

\section{Discussion of YouTube comments}

The popular antagonism 'hero-traitor' does have a considerable degree of presence in the YouTube comments as can be seen in extensive use of the words 'hero' and 'traitor'. With regards to creating discussions (replies to comments), however, the popular antagonism appears to have a negligible presence as neither 'hero' nor 'traitor' appears in the any of comments creating 20 or more replies, the sole exception being the use of the word 'treasonous' which has already been demonstrated to be a key 'floating signifier' in the argumentative discourse pertaining to the 'traitor bloc'. Seeing as the use of the word 'hero' to laud Snowden and his actions does create a considerable number of 'likes', it can be argued that the 'hero bloc' of the popular antagonism is not only popular in Laclau and Mouffe's (1985) terms, but quite literally popular in the fact that many commenters 'like' these comments. As subjects align their socio-political selves with the subject positions in the 'hero bloc' of the popular antagonism, it can be argued that their 
political positions becomes of ones suggesting demonstrably trite or oversimplified confirmation to a popularized norm. Thus, one should question how valuable the popular antagonism is in terms of creating discussions on online spaces.

Illustrating this point, the comments which received both a high number of both 'likes' and replies: ' 246 '/37; ' 92 ' $/ 33$; ' 77 ' $/ 16$ contain two which present facts pertaining to Snowden's situation, and one which raises issues concerning government surveillance. The comment which received the most replies, and 14 'likes', was the aggressively antagonistic comment using the most caustic language. It attacks Snowden, as previously mentioned, using 4 adjectives: 'thief'; 'lying'; 'treasonous'; 'cunt'. Perhaps it comes as no surprise that the most antagonistic and offensively antagonistic comment created the most replies. Much more analysis would need to take place on the replies to this comment in order to shed light on the nature of the discussion it created.

Generally speaking, and although this argument is admittedly shrouded in conjecture, commenters who strive to create and further discussions concerning Snowden's whistleblowing on digital comment boards would be strategically wise to either avoid the popular antagonism altogether or to reinvent it, re-imbuing the antagonism's force through the use of more personalized and creative discursive expressions. In fact, postdata collection, one such comment has appeared on the YouTube video suggesting the validity of this very point.

The comment to which I am referring reads,

Edward Snowden is a true American hero. Without him none of us would know what the government creeps were doing, how they were destroying the free and open society which the founders stood for and died for. If you are from another country and think things will be better for you here let me tell you my friend that they will not, and the may be worse. We don't have enough Edward Snowdens right now, but hopefully one day we will. Until then it's just a national security police state although it appears not to be through subtle smoke and mirror efforts.

For anyone working for the government, if you believe a branch of the government or an individual is working to subvert our free and open society you must out them, even if it means living in exile. (YouTube, accessed on April 8th 2015) 
This comment, appearing approximately 3 months ago, had received, as of April $8^{\text {th }}$, 2015, 158 'likes' and 44 replies. This comment contrary to what was previously argued does take up the popular antagonism: the first line reads: "Edward Snowden is a true American hero". The key distinction between this comment, however, and the others who engage the popular antagonism and garner 'likes' but do not create discussions, is that here the author has made a lengthy and concerted effort, as his comment demonstrates, to re-invigorate the use of the term 'hero' and the 'hero' argument. The comment is not typified or trite but unique and personalized. As such, it seems that the popular antagonism can create further discussions, but only if it is creatively engaged and essentially, repurposed with novel variations. ${ }^{20}$

The question still persists, however, as to whether or not the popular antagonism is merely an unproductive distraction from the 'real issues' at hand, the social, legal, technological, governmental issues which Snowden's whistleblowing actions sought to foreground. It is this very argument, this contestation of the popular antagonism, which has been taken up by some authors on the internet, and most importantly, by Snowden himself. It is in this direction, where the analysis now turns.

\section{The Contestation of/Resistance to the Popular Antagonism}

\section{Findings, Analysis and Discussion}

From the moment in which the hero-traitor antagonism emerged, Snowden has made concerted efforts to resist it. In the $2^{\text {nd }}$ published part of the interview with the South China Morning Post, just days following his disclosure to the public, Snowden stated: "I'm neither traitor nor hero. I'm an American" (Lam, 2013). While Snowden, in this instance, was not explicitly resisting the debate itself but rather resisting the efforts to frame him on their side of the antagonism, some journalists in the media were much

\footnotetext{
20 This notion of reinvigorating typified or generic expressions in personalized, unique or creative manner in order for discursive acts to have powerful social affect was precisely the point made by discourse/genre/language theorists Mikhail Bakhtin (1986) and Anne Freadman (2002). Bakhtin (1986) writes, "Objectively neutral styles presuppose something like an identity of the addressee and the speaker, a unity of their viewpoints, but this identity and unity are purchased at the price of almost complete forfeiture of expression" (p. 98). Anne echoes this notion, writing, though in a different context, "Of course there are standard forms, and effective rhetoric depends in part - but only in part - upon knowing them. It is clear that if all we do, and all we teach our student to do, is to mimic the standard forms, then our classes will be nothing but the exercised in nonserious generic etiolations" (p.47).
} 
more explicit in their objectives to shift the debate away from Snowden and whether or not he should be seen as a hero or traitor.

A day before the second part of South China Morning Post's interview with Snowden was published, National Journal journalist Ron Fournier (2013) published an article titled, "Why I Don't Care About Edward Snowden: Hero or Traitor? The White House would love to distract us from its actions", which begins,

Is Edward Snowden a hero or a traitor? I don't care. You read right: I don't give a whit about the man who exposed sweeping U.S. online surveillance programs, nor do I worry much about his verdict in the court of public opinions. Why? Because it is the wrong question. The Snowden narrative matters mostly to White House officials trying to deflect attention from government overreach and deception, and to media executives in search of an easy storyline to serve a celebrity-obsessed audience. (First paragraph)

Fournier goes on ask numerous questions that should take focus instead of Snowden and the hero-traitor 'storyline'. He raises legal and constitutional issues concerning NSA programs, and asks for clarity concerning what is argued to be 'their effectiveness'. He argues that the issues of privacy invasion should be foregrounded as should those pertaining to civil liberties. He expresses the desire to hear more from top-level officials, and wonders where the lines of government transparency can be drawn. Ultimately, he lauds Snowden, stating that he 'forced' an important debate about the nation, and that the debate should not be about Snowden, the whistleblower, but rather the 'gnawing questions' that American society now has to deal with.

In an almost identical argumentative strain, journalist John Naughton (2013) of The Guardian, just over a month later, published an article titled, "Edward Snowden's not the story. The fate of the internet is." He writes that the "press has lost the plot over the Snowden revelations", that "the net is finished as a global network and that US firms' cloud services cannot be trusted." He laments the fact that Snowden's personal story has taken precedence over the issues which should be foregrounded, issues very similar to those mentioned in the Fournier article for the National Journal. Naughton (2013) explains how the revelations have effected governments, companies and society at large, and then highlights which issues require the most pressing attention. Almost a year 
later, further discursive efforts to quell the focus on Snowden, the whistleblower, can be found on the internet.

On such example can be found in an article written for The Huffington Post on May $29^{\text {th }}, 2014$, nearly a year after Snowden's disclosure, where journalist Davey D, explicitly laments the popular antagonism evident in the media. Titled, "We Must Move Beyond the 'Patriot' vs ‘Traitor' Debate Around Edward Snowden”, Davey D (2014) writes,

We should not get caught up in meaningless debates about whether or not Snowden is a traitor or patriot. First, there is no definitive definition for either word. They are very subjective where at the end of the day there is no "right" or "wrong." Our discussion should be about whether or not what he revealed was true and are we comfortable with that? (Introduction)

Just like the two aforementioned authors, Davey D strives to shift the public's focus away from Snowden and on to the social, political, and technological repercussions of the NSA revelations. Also, like the two aforementioned authors, Davey D raises more questions than he provides answers. Coincidently, though perhaps as a result of the kinds of discursive spheres emerging on the internet, it is around this same time period, spring 2014, when Snowden begins to conduct interviews with popular media outlets, and where his resistance to both the 'hero-traitor' framing, as well as the hero-traitor popular antagonism, becomes evident.

On March 18 ${ }^{\text {th }}$, 2014, in the 'Ted Talk' titled, "Edward Snowden: Here's how we take back the internet" (TED, 2014), the host begins the interview with Snowden by asking, "You've been called many things over the past few months. You've been called a whistleblower, a traitor, a hero, what words would you describe yourself with?" Snowden responds:

Everyone in this debate has been struggling over me and my personality and how to describe me...But this isn't the question that we should be struggling with. Who I am doesn't really matter at all...What really matters here are the issues. What really matters here is the kind of government we want. The kind of internet we want. The kind of relationship between people and societies, and that's what I'm hoping the debate will move towards, and we've seen that increasing over time. If I had to describe myself, I wouldn't use words like hero, I wouldn't use patriot, and I 
wouldn't use traitor, I'd say, I'm an American and I'm a citizen just like everyone else. (TED, 2014)

Later in the talk, the host acts the audience for a show of hands with respect to whether they believe Snowden's whistleblowing is 'hurting America' or whether it's a 'heroic act'. When Tim Berners Lee, typically-labelled 'the father of the internet', is brought onstage to talk with the Snowden's digital avatar, he is asked by the host, "Which camp are you in, traitor or hero?" Lee responds that the question would require a 'long answer' but says 'hero'. Thus, even though Snowden strives to shift the discussion away from the hero-traitor popular antagonism, the antagonism persists.

For Snowden, as his response clearly demonstrates, not only should debate focus on the 'issues that really matter' (not him, but the role that the internet can and should play in the world), but that the popular antagonism does not apply to the manner in which he perceives himself. Instead of accepting the metaphorical and mythological framing taking place in popular media, Snowden discursively situates himself first as member of his nation: "I'm an American", and secondly, as being on an equal playing-field of all individuals: "I'm a citizen just like everyone else." These statements echo what Snowden has originally stated in his first interview with The Guardian on the day of his public disclosure. There, Snowden, making reference to some individuals who blow the whistle on their governments stated:

typically people [who do this] are against the country, against the government, but I'm not. I'm no different from anybody else. I don't have special skills. I'm just another guy who sits there day to day in the office, watches what happen, and says [referring to what the NSA was doing] this is something that is not our place to decide. The public needs to decide whether these programs and politics are right or wrong [my additions]. (Gallagher, 2013)

Once again, we are reminded of the fact that Snowden, based on his own words, wants, and has always wanted, for the public at large and their potentiality to effect social change to be foregrounded over and above not only his personality but the whistleblowing actions he had taken. A few months after the 'Ted Talk', Snowden is once again faced with the popular antagonism although here his response is slightly different. 
When being interviewed with Brian Williams of $N B C$, and after being asked if he thinks he is a patriot, Snowden responds, 'I do' but immediately takes time to reflect on what it means to take up that 'signifier' by stating, "You know, I think patriot is a word that's thrown around so much that it can be devalued nowadays" (Fernandes, 2014). Snowden goes on to explain that a patriot refers to 'protecting' one's country, one's country's constitution, and fellow countrymen "from the violations of, and encroachments of adversaries" (Fernandes, 2014). Snowden explains that those adversaries are not necessarily 'foreign countries' but can also be 'bad policies', government officials and 'mistakes of government'. Perhaps what is most evident in this exchange is the discursive force of the popular antagonism; one can only avoid its presence for so long, before feeling forced to engage with it. Here, Snowden does engage the use of the word 'patriot' but does so by problematizing the term and by making efforts to unpack its meaning. Because Snowden knew that this was going to be his first televised interview on American television perhaps Snowden decided that this moment was apt to engage with the popular antagonism more directly.

Important to note, however, is that Snowden engages with the antagonism in a critical fashion, deconstructing what might be understood as typical or surface-level understandings of the term 'patriot'. As such, this interaction might demonstrate an acute understanding on Snowden's behalf of the way in which both he and his situation are being discursively taken up on the internet. An argument could be made that Snowden had shifted his perspective on addressing the hero-traitor antagonism during or before the $N B C$ interview, and if this were so, one would expect him to engage the antagonism in a similar fashion in later interviews. This seems to be the case, at least in the example of his interview with the New Yorker in October, 2014.

Here, when asked by an audience member via host Jane Mayer to reflect on the 'heroic' elements of his personae, Snowden refutes any claims to heroism, responding, as was seen earlier, by stating: "I'm an ordinary guy. I'm not a hero" (The New Yorker, 2014). He does not stop here, however. Snowden goes on, like he had in the NBC interview, to unpack not only the term 'hero' but the problematic issues of labelling people as such. He says, 
I would argue that there are no heroes. There are people who do heroic things, but when we being to label people as heroes what we're doing is we are utterizing [sic] them, we're elevating them, we're putting them on a pedestal and saying they're different. I could never do that, but the reality is that you can do that, we can all do that. We all have a line. There's a measure of incivility and inhumanity that we can tolerate and then there's one step beyond it that we cannot. All we have to do is recognize where that line is, recognize what we believe and commit ourselves not to just believing in it, but to standing for it when it comes under threat. (The New Yorker, 2014)

Something peculiar occurs here that needs to be addressed; Snowden simultaneously resists and embodies the characterization of being a 'hero'. In addressing the popular antagonism, the central 'storyline', in the manner he has, what Snowden seems to be saying is that if this powerful antagonism is going to persist (and it appears as though it will) one must think carefully about what how it is that a 'hero', a 'patriot' and in turn a 'traitor' come to be conceptualized and used. One needs to think about how these 'floating signifiers' are not only constituted but also how they are being applied to the specific context at hand. It would appear as though Snowden is concerned with these discursive projects, and an argument could certainly be made in this regard. Doing so, however, would ignore a vital point: Snowden only engages the popular antagonism when forced to do so (through the questions asked by others), and, when engaging as such, Snowden stresses the problematic nature of the 'heroic' and 'patriotic' labels with which he's been portrayed. Furthermore, Snowden's engagement with this antagonism makes up a very small percentage of his personal contributions to the discursive sphere. In each of Snowden's videos, he does speak (at times with consider length) about his life and motivations but is much more concerned with discussing the malpractices of the NSA, American governmental practices, civil-rights and liberties, and the role that the internet can and should play in securing and maintaining these very rights and liberties. The most notable example of this can be found in his interview streamed-live at SXSW in 2014 (acluvideos, 2014) where Snowden solely talks about these issues. A question arises, therefore, as to how Snowden's resistance to the popular antagonism, the herotraitor storyline, can be aptly be interpreted. 
Recalling Laclau and Mouffe's (1985) and Hajer's (2015) notions, the construction of 'chains of equivalence' or 'storylines' relies on the use of metaphors and metonyms. These 'storylines', acting as 'narratives' can take on, as demonstrably evident in the case of Snowden, mythological characteristics. Because myths are understood by Laclau (1990) as "a principle of reading a given situation" (Carpentier \& Spinoy, 2008, p.8), and by Alsford (2006) as imaginative response to existential questions in which 'prototypes' serve as models to be replicated or learned from, the use of the 'floating signifiers' 'hero', 'patriot' and 'traitor' in this case, results in the constructing of Snowden as a kind of mythological entity. Individuals doubting this claim of 'Snowden's entity being mythologized' should take careful note of the fact that like Batman, Superman, Darth Vader, and Darth Maul (among numerous others), Snowden has been made into an action figure by the company That's My Face ${ }^{21}$. (See Appendix H for screen shots of action figure). For Zizek, as cited by Torfing (1999), all 'real' objects, in this case Snowden, become mythological entities through discursive enactments which cannot, as posited by Laclau and Mouffe (1985) ever reach total closure; they cannot escape antagonisms and cannot reach a state of utter fixity. As such, although Snowden becomes a social object which social actors, through their discursive acts of 'articulation', try to lock down with concrete meanings, his essence always escapes those very efforts.

It is for this reason, that subjects aligning their socio-political positions to either the 'hero/patriot' or 'traitor' coalitions are engaged in discursive efforts that are inherently antagonistic and political. In turn, they are engaged in a hegemonic battle striving to shape social opinion based on their socio-political 'coalitions', and through which, in various degrees, their identities become modified. It seems as though Snowden is acutely aware of this discursive reality, that all efforts to enact this mythological representation of his being are acting out only a purported essence of his being on a metaphorical and mythological basis. It appears as though, based on Zizek's notions, society is engaged in acting out an ideological fantasy, which is ultimately the illusion of a totalized structured reality (Torfing, 1999). The enactment of Snowden becomes some kind of linguistic game, a game in the literal, and albeit emotionally-charged, somewhat

${ }^{21}$ www.thatsmyface.com 
trivial sense. Rendering Edward Snowden as a mythological entity begins to sever the ties that ground Edward Snowden in a corporeal, material reality. Snowden seems to be aware not only of this reality but of its somewhat misguided objectives, and as such, strives to break through or deconstruct these efforts that render his existence illusory. He does this with remarkable skill, making use of numerous discursive tactics.

First, he resists the 'hero-traitor' popular antagonism by refusing to align himself with either coalition. He does not, however, do so by making use of another mythologicallyimbued metaphor, but rather by foregrounding himself as an 'American', and more importantly as an 'ordinary' person, just like 'everyone else'. While certainly the 'American' can also be interpreted as a kind of mythological construct, it is more grounded in a discernable reality than that of the 'hero' as notions of the "American' require reference to a materially-bound geographical space regardless of how complicated or seemingly illusory that very space comes to be constructed and understood. Snowden thus shifts the focus away from the mythological and more into the realm of the material real of which he corporeally exists.

Second, when he does engage the terms of 'hero' and 'patriot', as evident in two aforementioned interviews, he carefully highlights the socially-constructed essence of the terms, forcing the public to become aware of the illusionary aspect of their discursive enactments. He is, essentially, asking people to see through, or beneath, those popular terms and to question the meaning or significance of their presence and existence. Snowden's goal here, as was previously stated, is to shift the discussion away from the popular antagonism and on to the more important 'real issues' at hand - the social and political implications of the NSA's and American government's questionable activities regarding internet surveillance. Lastly, Snowden breaks down societies' attempts to mythologize him in the very manner in which he chooses to discursively engage with society.

Although Snowden could have produced a large number of text-based articles expounding his various positions and ideas, in which, although his name would be present (as author of the text), his corporeal presence would not. Snowden does exactly the opposite. Snowden chooses to engage the discursive sphere exclusively through live- 
stream or recorded interviews (in the case of $N B C$ ), the sole exception being the open letter which he wrote to 'the Brazilian people' and a reddit AMA (Ask Me Anything) in which he participated. The reddit AMA, however, although text-based, was conducted live or in real time. Of paramount importance is that through these discursive acts it is the material-real Snowden, the corporeal Snowden that comes to presence for audiences: his voice, his smiles, his haircuts and shirts, his adjusting of his glasses, the waves of euphoric embarrassment that spread across his face when audiences shower him with choruses of applause. This 'Snowden' is a Snowden accessible in real-time, one who responds to live questions with live responses, and as such is temporally-bound. Foregrounding his corporeal presence with temporality works towards establishing Snowden's authenticity or materially-bound realness; its presence undermines the social enjoyment that occurs with structuring ideological fantasies as argued by Zizek (Torfing, 1999).

Snowden's corporeal presence is not a fully tangible corporeal presence, however. Rather, it is one that is indicative of his political and legal circumstances: trapped in Russia, Snowden has no other choice but to render his presence through the digital technologies that enable him to do so. Of upmost importance is that Snowden's embodiment of the digital technologies, permitting the presence not only of his discursive entity, but his corporeal entity, is precisely, and ultimately, an enactment of the social, political and discursive project in which he is engaged. For Snowden, the internet, and all of the technological objects and knowledge that constitute its existence, is not simply a collection of methods and means for conducting business, transferring information, and exchanging knowledge but rather a communal sphere digitally embodied by material human beings - a digital sphere in which humans politically, philosophically, intellectually and emotionally enact their identities, exploring and discovering their multiple senses of the self. Snowden's vehement defense of the internet should not, therefore, be conceptualized, on Snowden's terms, as a defense of humanity's technology, but of humanity itself. Perhaps it is these acute and powerful discursive choices that Snowden has made, which has imbued Snowden's story with the social relevance it has. 


\section{Chapter 6: Conclusions and Implications of Study}

In assessing the discursive enactment of Edward Snowden, two inherently interconnected discursive spheres have been illustrated: the NSA leaks, and Edward Snowden. In the former, a 'storyline', in Hajer's (2015) terms, is evident: 'The Snowden Effect', which is used to describe the various kinds of social 'effects' or social impact, which Snowden's whistleblowing have induced. It was argued that this storyline is a practically-uncontested 'storyline'; there is next to no perceivable discourse, or perceivable 'counter-storyline' arguing that Snowden's whistleblowing has had no effect. In the latter, the Edward Snowden sphere, it has been demonstrated that a storyline has emerged which can be interpreted as a popular antagonism in Laclau and Mouffe's (1985) terminology: the 'hero/patriot - traitor' antagonism. It has been illustrated that this antagonism has been enacted by 'coalitions' at the popular level of media companies by 'public intellectuals', and also been taken up by society at large in the comment section of a YouTube video. Although somewhat suggestive or conjectural, it was argued that the 'hero-traitor' popular antagonism was useful in terms of making an issue 'popular', that is, of getting many people to engage with an issue, or rather getting many people to engage with the topic in a certain way (with the popular antagonism), but that discursive acts of this kind might not be constructive in creating (meaningful) discussions. The acts might, instead, simply enable the popularization of socio-political positioning enacted by subjects through their articulations. Considerable more work would need to be done in this regard. A much deeper analysis would have to take place with regards to the manner in which society at large, at least in digital spheres, has taken up the 'hero-traitor' antagonism. Has society at large used the antagonism in the same manner in which popular media has? Does the antagonism function in a manner that creates further and deeper discussions? How could the antagonism be argued to function as such? What would constitute 'further' and 'deeper' discussions? Are these terms merely subjective interpretations, or can more concrete, more stabilized definitions be ascertained?

Questions also arise as to whether or not a story like Snowden's can ever gain the socio-

discursive relevance it has without the presence of a popular antagonism. Is the popular 
antagonism essential to the popularization of a societal issue, or can a social issue gain a substantial social digital presence with solely democratic antagonisms? If so, which cases, and which cases respective to which social contexts, result in either the former or the latter being the case? Larger and more diverse digital corpuses could certainly lead the way to providing some answers to these questions, but the methods of arriving at conclusions through analysis remain complex. Hopefully, this project suggests some potential methods for going forward.

In demonstrating the presence of the popular antagonism of which 'chains of equivalence' were easily discernable in the construction of 'hero' and 'traitor' coalitions, also present was a resistance to the popular antagonism of which various authors, including Snowden, were seen to be central figures. As evidenced in the discourse of these 'contesting' authors, as well as of Snowden, the popular antagonism was argued to be acting detrimentally, hindering the presence of the more important issues at hand, those pertaining to the 'Snowden Effect'. Additionally, the argument was made that Snowden can be interpreted as one with an acute sense of discursive realities (especially regarding the internet) - one who, either on his own accord, or perhaps by working with a team of public-relations experts, has been able to continually shift the focus away from the popular antagonism and on to other more 'important' discussions. Snowden's methods for doing so become emblematic; not only does he resist the mythologizing of his entity, but does so in a manner that advocates his personal views of how individuals embody the internet, why society should value the internet, and, as such, why society should be concerned with the manner in which it currently operates and is governed.

Although arguments have been made here that the popular antagonism is in some ways problematic with respect to fostering constructive discussions, it should be noted that the attention paid to Snowden, the man and the whistleblower, should not be interpreted as neither completely unnecessary nor utterly misguided. Not only was it integral for the journalists who broke the Snowden story to properly determine whether Snowden as a whistleblower could be trusted, and whether his motivations were ethically sound (Greenwald, 2014; Poitras, 2014), but it was also a pressing concern for society at large. As such, one would find it difficult to argue that the 'Snowden as human' element of the story is necessarily of secondary importance to the leaks themselves. 
Perhaps this is because the desire to make sense of Snowden's story and his motivations to blow the whistle is spurred on by the insatiable drives of human curiosity - a curiosity often piqued by the bold activities of fellow humans, such as, in this case, those of Edward Snowden. Additionally, although one cannot know the precise motivations that each individual might have for joining either the hero or traitor discursive coalitions, it cannot be denied that Snowden, to this day, still faces serious charges, still resides in Russia, in asylum. Thus, the efforts to either laud or condemn his persona and his actions are not only cases of individuals enacting their socio-political identities for personal reasons, but that those discursive efforts have the potential to sway public opinion in such a manner that, from the 'lauding' perspective, Snowden might be pardoned by the government, and might, in turn, be able one day to return home a free person, or, at the very least, to face what Snowden has expressed a desire for: a fair trial. If one wished to take a position in the popular antagonism, an argument could certainly be made that Snowden's whistleblowing actions, as discursively structured by numerous public intellectuals, society at large, and perhaps most importantly, by Snowden himself closely adhere to the notions of heroism and patriotism as conceptualized by Alsford (2006), Hook (1945) and Viroli (1995). It could be argued that Snowden's actions did not harm American society in any discernable way, that his whistleblowing practices were ethically-sound, and that both American and international society as a whole has benefited from his whistleblowing. It could be argued that Snowden acts for 'others' and strives to reinforce the inner-connectivity of all humanity. Furthermore, Snowden could be seen as an 'event-making' individual. Doing so, however, is not (or perhaps it should be stated 'no longer') the objective of this study. To argue that Snowden is either a 'hero' or 'traitor' not only goes against Snowden's wishes, wishes which this study holds in high esteem, but distracts from a central issue that needs to be explored.

In disclosing the surreptitious activities of the NSA, Snowden has argued that our societies, the world over, general speaking, need to be politically active and actively responsible for keeping our political systems in check. Societies need to continually determine and actively fight for the kinds of values, rights, liberties they deem to be not only valuable but essential to democratic societies and democratic life, regardless of how it is that one specifically interprets those terms. Moreover, Snowden argues that 
societies need to collectively determine the kind of internet they want; whether or not they want the internet to be a communally-shared space in which privacy is respected, and where the activities of the government's operational authorities are honest and transparent. For Glen Grenwald (2014), the issue of privacy, especially with regards to the internet, is of upmost importance. He writes,

Privacy is essential to human freedom and happiness for reasons that are rarely discussed but instinctively understood by most people, as evidenced by the length to which they go to protect their own... Only when we believe that nobody else is watching us do we feel free - safe - to truly experiment, to test boundaries, to explore new ways of thinking and being, to explore what it means to be ourselves. What made the internet so appealing was precisely that it afforded the ability to speak and act anonymously, which is so vital to individual exploration. (p. 173 - 174)

While Greenwald (2014), as well as Snowden (New Yorker, 2014) argue that surveillance can only not be effective but also that it plays a necessary and important role in local, national and global security and governance when conducted ethically, and through democratically, transparent processes, both Greenwald and Snowden also note that society should be extremely cautious when surveillance takes on the role of monitoring and tracking all citizens, in all societies, without their knowledge that such surveillance is taking place. Not only does Snowden consider these practices 'unconstitutional', but he also argues that they preclude the very potential that the internet possesses as a means for individuals to live out their personal, emotional and intellectual lives in the manner they so choose. Greenwald, taking up this notion from a more politically-driven perspective, argues that surveillance practices of this kind, greatly prevent acts of social dissent or civil disobedience from being enacted in the manner they should in democratic societies. He writes,

Those who pose no challenge are rarely targeted by oppressive measures, and from their perspective, they can then convince themselves that oppression does not really exist. But the true measure of a society's freedom is how it treats its dissidents and other marginalized groups, not how it treats its good loyalists...We shouldn't want a society where the message is conveyed that you will be left alone only if you mimic the accommodating behavior and conventional wisdom of an establishment columnist. (Greenwald, 2014, p. 196) 
As such, argues Greenwald, denying a populace the potential to contest the authorities' enactments of power, whether those enactments are justified or not, is greatly detrimental to the collective ethos that supposedly free and democratic societies should, at the very least, strive, to foster. It should be obvious that not everyone in every society, democratic or otherwise, would share this perspective.

Ultimately, the issues revolve around, as aforementioned, collectively-determining the roles that government should play, and the amount of power it should be granted with regards to those roles. With multifarious perspectives concerning these issues, especially with regards to the role that government should play in permitting or encouraging blatant dissent, what does become evident is that Snowden's whistleblowing actions, and in turn, his discursive actions, are forcing sectors of American society as well as perhaps societies in other parts of the world to re-examine their notions of dissent and civil disobedience. From Thoreau to Ghandi to Rosa Parks, from Nelson Mandela to Martin Luther King, to protestors in the Arab Spring or at G8 summits, or protestors such as Indigenous Canadians fighting for land-claims, self-autonomy and government accountability, what Snowden's case demonstrates is that social dissent and civil disobedience have taken, and will continue to take, new forms as they seek to battle power structures over issues both new and old. Those who might claim that Snowden has somehow benefited from his whistleblowing actions are certainly correct in one regard: Snowden's actions, and more specifically, how he has engaged the sociodiscursive spheres in order to justify his actions and make a cause for his claims, has strengthened his social position as a 'public intellectual'. Snowden's voice continues to reverberate.

His discursive acts, which at times strive to contest a mythological rendering of his entity, have been very effective at bringing the issues he so passionately wants society to be concerned and engaged with into the social spotlight, at least for now. If he is ever to be pardoned, it could be argued that the discursive realities created by Snowden and others played a substantial role in bringing about this outcome. This is because the creation of discursive realities significantly affects the creation of realities themselves. As noted by Wittgenstein (2009), and an abundance of others, language does not 
describe the external world, it performs actions in the external worlds, it constitutes lived, and living, realities.

And so, questions arise, which only the future and in turn future studies will help us answer: Will other whistleblowers make use of Snowden's discursive actions and strategies? Will they also prove effective? Will future whistleblowers be labelled as 'heroes' or 'traitors', or will the discursive spheres shift, taking on new storylines and new antagonisms? If so, what might these new terms be, and what will they tell us about changing social values and ever-changing social discursive strategies? How might different cultures in different locations take up the stories? How will the new terms, and perhaps the new forms of civil disobedience come to be discursively enacted not only in American society, but in diverse societies the world over? What kind of roles will technology play in these discursive enactments and socio-political power struggles?

How will we come to make use of their potentialities to shape the kinds of societies we want? How can we, in turn, make sense of these activities?

We can only wait. But not for long, and certainly not idly. The potential to seize, to act, to engage is always before us. 


\section{References}

acluvideos. (2014, March 10). Edward Snowden and ACLU at SXSW (non-optimized audio version). YouTube. Retrieved from https://www.youtube.com/watch?v=CPrDqoaHHSY

Alsford, M. (2006). Heroes and villains. Waco, TX: Baylor University Press.

Androutsopoulos, J. (2008). Potentials and limitations of discourse-centred online ethnography.Language@ internet,5(8).

Arendt, H. (1972). Crisis of the republic. New York: Harcourt Brace.

Bakhtin, M. (1986). Speech genres and other late essays. Austin, TX: University of Texas Press.

Bamford, J. (2014, August). Edward Snowden: The untold story. Wired. Retrieved from http://www.wired.com/2014/o8/edward-snowden/

Belvedere, M. (2014, June 5). Snowden a 'traitor’: Andressen. CNBC. Retrieved from http://www.cnbc.com/id/101733893\#

Biography. (2015). Daniel Ellsberg Biography. Biography.com. Retrieved from http://www.biography.com/people/daniel-ellsberg-17176398

Branum, J. \& Charteris-Black, J. (2015). The Edward Snowden affair: A corpus study of the British press. Discourse \& Communication, 9(2), 199-220.

Breckenridge, J. (2012). Choosing a methodological path: Reflections on the constructivist turn. Grounded Theory Review, 11(1).

Burman, T. (2013, June 15). Why Edward Snowden, NSA whistleblower is more hero than traitor: Burman. The Toronto Star. Retrieved from 
http://www.thestar.com/news/world/2013/06/15/why edward snowden nsa whistle blower is more hero than traitor burman.html

Burrough, B., Andrews, S., \& Ellison, S. (2014, May). The Snowden saga. Vanity Fair, 645, 152$166,196-203$.

Carlton, E. (1998). Treason: Meanings and motives. Brookfield, VT: Ashgate.

Carpentier, N.,\& Spinoy, E. (2008). Introduction: From the political to the cultural. In N. Carpentier \& E. Spinoy (Eds.), Discourse Theory and Cultural Analysis. Cresskill, NJ: Hampton Press.

Cassidy, J. (2013, June 10). Why Edward Snowden is a hero. The New Yorker. Retrieved from http://www.newyorker.com/news/john-cassidy/why-edward-snowden-is-a-hero

Clifton, A. (2014, June 7). Let me show you why Edward Snowden is a traitor and not a patriot. Forward Progressives. Retrieved from http://www.forwardprogressives.com/let-meshow-why-edward-snowden-traitor-not-patriot/

Currie, S.C. (2013). How to save the world: The ideologies of four ENGOs and their discursive constructions of climate change (Unpublished doctoral dissertation). Carleton University, Ottawa.

Davis, M. (2013, June 29). Merlene Davis: Snowden is a traitor, not a hero. Lexington HeraldLeader. Retrieved from http://www.kentucky.com/2013/06/29/2697779/merlenedavis-snowden-is-a-traitor.html

D, D. (2014, May 29). We must move beyond the 'patriot' vs. 'traitor' debate around Edward Snowden. The Huffington Post._Retrieved from http://www.huffingtonpost.com/davey-d/snowden-interview b 5412891.html 
Dann, C. (2014, May 28). Kerry: Snowden a "coward” and "traitor”. MSNBC. Retrieved from http://www.nbcnews.com/politics/first-read/kerry-snowden-coward-traitor-n116366

Dinakar, K., Reichart, R., \& Lieberman, H. (2011). Modeling the detection of Textual Cyberbullying. In The Social Mobile Web.

Democracy Now! (2013, June 10). Inside the NSA's domestic surveillance apparatus: Whistleblower William Binney speaks out [video file]. Democracy Now!. Retrieved from http://www.democracynow.org/blog/2013/6/10/inside the nsas domestic surveillan ce apparatus whistleblower william binney speaks out

Dörnyei, Z. (2007). Research methods in applied linguistics. Oxford: Oxford University Press.

Ellsberg, D. (2013, June 10). Edward Snowden: saving us from the United Stasi of America. The Guardian. Retrieved from http://www.theguardian.com/commentisfree/2013/jun/10/edward-snowden-united$\underline{\text { stasi-america }}$

Fairclough, N. (2000). New Labour, new language? London: Psychology Press.

Fairclough, N. L. (2005). Blair's contribution to elaborating a new 'doctrine of international community'. Journal of Language and Politics, 4(1), 41-63.

Fernandes, D. (2014, May 29). Edward Snowden NBC news (full interview) May 28, 2014. Daily Motion. Retrieved from http://www.dailymotion.com/video/x1xfc4b edward-snowden$\underline{\text { nbc-news-full-interview-may-28-2014 news }}$

Ferraro, F.M., \& Dolgin, D. (2014, March 13). The Snowden effect: How America's spy agencies can fix their millennial problems. Politico. Retrieved from http://www.politico.com/magazine/story/2014/03/the-snowden-effect104642.html\#.VSwNQpOrHfe 
Foucault, M. (1972). The archaeology of knowledge. (A.M. Sheridan Smith, Trans.). New York: Vintage Books.

Fox News. (2014, January 22). Ron Paul: Edward Snowden is a Hero. Fox News. Retrieved from https://www.youtube.com/watch?v=AV7yobI1m40

Fox News. (2013, June 16). Cheney defends NSA programs, says Snowden, 'a traitor, Obama ‘lacks credibility'. Fox News. Retrieved from

http://www.foxnews.com/politics/2013/06/16/cheney-defends-us-surveillance-

programs-says-snowden-traitor-obama-lacks/

Fournier, R. (2013, June 12). Why I don't care about Edward Snowden: Hero or traitor? The White House would love to distract us from its actions. National Journal. Retrieved from http://www.nationaljournal.com/politics/why-i-don-t-care-about-edward-

$\underline{\text { snowden-20130612 }}$

Freadman, A. (2002). Uptake. In R. Coe., L. Lingard. \& T. Teslendko (Eds.). The rhetoric and ideology of genre: Strategies for stability and change. (pp. 39-53). Cresskill, NJ: Hampton Press Inc.

Freake, R., Gentil, G., \& Sheyholislami, J. (2011). A bilingual corpus-assisted discourse study of the construction of nationhood and belonging in Quebec. Discourse \& Society, 22(1), 2147.

Gabbatt, A. (2013, November 25). Edward Snowden a 'hero' for NSA disclosures, Wikipedia founder says. The Guardian. Retrieved from http://www.theguardian.com/world/2013/nov/25/edward-snowden-nsa-wikipediafounder 
Gallagher, K.M. (2013, June 9). NSA whistleblower Edward Snowden: ‘I don’t want to live in a society that does these sorts of things'. YouTube. Retrieved from https://www.youtube.com/watch?v=5yB3ngfu-rM

Goodell, J. (2014, March 13). Bill Gates: The Rolling Stone Interview. Rolling Stone. Retrieved from http://www.rollingstone.com/culture/news/bill-gates-the-rolling-stone-interview20140313?page $=2$

Gramsci, A. (2000). The Gramsci Reader: Selected writings 1916-1935. D. Forgas (Ed.). New York: New York University Press.

Greenwald, G. (2014). No place to hide: Edward Snowden, the NSA, and the U.S. surveillance state. New York: McClelland \& Stewart

Grove, L. (2013, June 26). Steve Wozniak: Snowden 'is a hero because this came from his heart'. The Daily Beast. Retrieved from http://www.thedailybeast.com/articles/2013/06/26/steve-wozniak-snowden-is-ahero-because-this-came-from-his-heart.html

Hajer, M. (2015). FAQ. Maarten Hajer Personal Website. Retrieved from http://www.maartenhajer.nl/wordpress/

Hayes, M. (2013, June 9). More people on Twitter describe Edward Snowden as hero than a traitor. BuzzFeed. Retrieved from http://www.buzzfeed.com/mikehayes/more-people-think-edward-snowden-is-a-herothan-a-traitor\#.qfeeLww5a1

Harper, D. (2014). Traitor. In Online Etymology Dictionary. Retrieved from $\underline{\text { http://etymonline.com/index.php?term=traitor\&allowed in frame }=0}$ 
Hersh, M.A. (2002). Whistleblowers - Heroes or traitors?: Individual and collective responsibility for ethical behaviour. Annual Review in Control, 26, 243-262.

Hoffman, T. (1997). Treasons and loyalties. Queen's Quarterly, 104, 30-45.

Howarth, D. (2000). Discourse. Philadelphia, PA: Open University Press.

Huckin, T. (2002). Textual silence and the discourse of homelessness. Discourse \& Society, 13(3), 347-372.

Huffington Post. (2012, December 4). Daniel Ellsberg, Pentagon Papers Whistleblower: Bradley Manning is a Hero [video file]. The Huffington Post. Retrieved from http://www.huffingtonpost.com/2012/12/04/bradley-manning-daniel-ellsbergpentagon-papers n 2240016.html

Hughey, M. W. \& Daniels, J. (2013). Racist comments at online news sites: a methodological dilemma for discourse analysis. Media, Culture \& Society, 35(3), 332-347.

Johnson, J (1988). Mixing humans and nonhumans together: The sociology of a door-closer. Social Problems, 35(3), 298-310

Johnson, L. (2013, June 11). John Boehner: Edward Snowden is a 'traitor'. The Huffington Post. Retrieved from http://www.huffingtonpost.com/2013/06/11/john-boehner-edwardsnowden n $3420635 \cdot \mathrm{html}$

Johnson, R.A. (2002). Whistleblowing: When it works - and why. Boulder, Co: Lynne Rienner.

Kateb, G. (2006)._Patriotism and other mistakes. New Haven, NJ: Yale University Press

Keck, Z. (2013, December 21). Yes, Edward Snowden is a traitor. The Diplomat. Retrieved from http://thediplomat.com/2013/12/yes-edward-snowden-is-a-traitor/ 
Kirchick, J. (2014, June 1). Edward Snowden, traitor. New York Daily News. Retrieved from http://www.nydailynews.com/opinion/edward-snowden-traitor-article-1.1811878

Kuhn, T.S. (1962). The structure of scientific revolutions. Chicago: Chicago University Press.

L.M. (2014, January 24). The Snowden effect. The Economist. Retrieved from http://www.economist.com/blogs/babbage/2014/o1/internet-governance

Laclau, E., \& Mouffe, C.(1985). Hegemony and socialist strategy: Towards a radical democratic politics. New York: Verso.

Lam, L. (2013, June 12). Whistleblower Edward Snowden tells SCMP: 'Let Hong Kong people decide my fate'. South China Morning Post. Retrieved from http://www.scmp.com/news/hong-kong/article/1259422/edward-snowden-let-hongkong-people-decide-my-fate

Lam, L. (2013, June 13). Exclusive: Whistle blower Edward Snowden talks to South China Morning Post. South China Morning Post. Retrieved from http://www.scmp.com/news/hong-kong/article/1259335/exclusive-whistle-bloweredward-snowden-talks-south-china-morning

Larry King Now. (2013, November 14). Cheney "Edward Snowden is a traitor". Larry King Now - Ora TV. Retrieved from https://www.youtube.com/watch?v=p5oNV4P9mg8

Latour, B. (2005). Resembling the Social. Oxford: Oxford University Press

Law, J. (2009). Actor Network Theory and Material Semiotics. In B.S. Turner (Ed.), The New Blackwell Companion to Social Theory. Hoboken, NJ: Blackwell Publishing

Malkin, M. (2015, March 9). Shailene Woodley praises Edward Snowden as "hero", plays his girlfriend in the new Oliver Stone movie. Eonline. Retrieved from 
http://ca.eonline.com/news/633254/shailene-woodley-praises-edward-snowden-as-ahero-plays-his-girlfriend-in-new-oliver-stone-movie

Miceli, M., \& Near. J (1992). Blowing the whistle: The organizational and legal implications for companies and employees. New York: Lexington Books.

Mirkinson, J. (2013, June 10). Daniel Ellsberg Calls Edward Snowden A 'Hero,' Says NSA Leak Was Most Important In American History”. The Huffington Post. Retrieved from http://www.huffingtonpost.com/2013/o6/10/edward-snowden-daniel-ellsbergwhistleblower-history n $3413545 \cdot$ html

Mulrine, A. (2011). Pentagon Papers vs. Wikileaks: Is Bradley Manning the new Daniel Ellsberg?. The Christian Science Monitor. Retrieved from http://www.csmonitor.com/USA/Military/2011/0613/Pentagon-Papers-vs.-WikiLeaksIs-Bradley-Manning-the-new-Ellsberg

Naughton, J. (2013, July 28). Edward Snowden is not the story. The fate of the internet is. The Guardian. Retrieved from http://www.theguardian.com/technology/2013/jul/28/edward-snowden-death-ofinternet

Nietzsche, N. (1967). Thus Spake Zarathustra. (T. Common, Trans.). New York: The Heritage Press (Original work published 1883-1885)

Oddo, J. (2011). War legitimation discourse: Representing 'Us' and 'Them' in four US presidential addresses. Discourse \& Society, 22(3), 287-314.

OWS. (2015). The Espionage Act and the limitations of the first amendment. OWS. Retrieved from http://ows.edb.utexas.edu/site/espionage-act-and-limitations-first$\underline{\text { ammendment/espionage-act }}$ 
Pantana Sr., P.M. (2007). America: A purpose driven nation. The Woodlands, TX: Xulon Press.

Partington, A. (2008). The armchair and the machine: Corpus-assisted discourse research. Corpora for University Language Teachers, 74 (95).

Pilger, J. (2013, July 1). Why Edward Snowden is a hero. The Tyee. Retrieved from http://thetyee.ca/Mediacheck/2013/07/01/Why-Edward-Snowden-Is-a-Hero/

Poitras, L. (Producer), \& Poitras, L. (Director). (2014). Citizenfour [motion picture]. United States: Praxis Films.

Qin, J. (2015). Hero on Twitter, traitor on news: How social media and legacy news frame Snowden. The International Journal or Press/Politics, 2o(2), 166-184.

Quine, W.V.O. (1961). Word and Object. Cambridge, MA: MIT.

Raphael, D. (2013, November 7). Why Edward Snowden is a hero. The Huffington Post. Retrieved from http://www.huffingtonpost.com/daniel-raphael/why-edward-snowdenis-a-h b $4227605 \cdot h t m l$

Rapoza, K. (2014, January 7). Jesse ‘The Mind’ Ventura: Snowden, a patriot, hero. Forbes. Retrieved from http://www.forbes.com/sites/kenrapoza/2014/01/07/jesse-the-mindventura-snowden-a-patriot-hero/

Ridenhour. (2011). 2011 prize for truth-telling speeches. Ridenhour.org. Retrieved from http://www.ridenhour.org/prizes truth-telling 2011.html

Ripley. A., \& Sieger. M. (2002-2003, December 30-January 6). Persons of the year: The special agent, Time, 34-40.

Rosen, J. (2013, July 5). The Snowden Effect: definition and examples. Press Think. Retrieved from http://pressthink.org/2013/07/the-snowden-effect-definition-and-examples/ 
Rushkoff, D. (2013, June 10). Edward Snowden is a hero. CNN. Retrieved from http://www.cnn.com/2013/o6/10/opinion/rushkoff-snowden-hero/

R.M. (2013, August 10). The Snowden effect. The Economist. Retrieved from http://www.economist.com/blogs/democracyinamerica/2013/08/american$\underline{\text { surveillance }}$

R.M. (2011, May 18). The prosecution of Thomas Drake. The Economist. Retrieved from http://www.economist.com/blogs/democracyinamerica/2011/05/prosecution thomas

$\underline{\text { drake }}$

Sagar, R. (2013). Secrets and leaks. Princeton, NJ: Princeton University Press.

Sheyholislami, J. (2010). Identity, language, and new media: the Kurdish case. Language policy, 9(4), 289-312.

Sheyholislami, J. (2012). Linguistic Minorities on the Internet. In Kirk St. Amant \& Kelsey

Sigrid (Eds.), Computer-Mediated Communication across Cultures: International Interactions in Online Environments (pp. 235-250). IGI Global publication.

Shantz, J., \& Tomblin, J. (2014). Cyber Disobedience. Alresford, UK: Zero Books.

Siersdorfer, S., Chelaru, S., Nejdl, W., \& San Pedro, J. (2010). How useful are your comments?: analyzing and predicting YouTube comments and comment ratings. In Proceedings of the 19th international conference on world wide web, 891-900.

Sledge, M. (2014, July 5). The Snowden effect: 8 things that happened only because of the NSA leaks. The Huffington Post. Retrieved from http://www.huffingtonpost.com/2014/06/05/edward-snowden-nsa-

effect n 5447431.html 
Smart, G. (2011). Argumentation across web-based organizational discourses: The case of climate change." In C.N. Candlin \& S. Sarangi (Eds.), Handbook of Communication in Organisations and Professions: HAL 3, (363- 386). Berlin: Walter de Gruyter.

Stainton, R.J. (1996). Philosophical perspectives on language. Peterborough, ON: Broadview.

TED. (2014, March 18). Edward Snowden: Here's how we take back the internet. YouTube. Retrieved from https://www.youtube.com/watch?v=yVwAodrjZMY

Teo, H., \& Caspersz, D. (2011). Dissenting discourse: Exploring alternatives to the whistleblowing/silence dichotomy. Journal of Business Ethics, 104, 237-249.

The New Yorker. (2014, October 11). The virtual interview: Edward Snowden - The New Yorker festival. YouTube. Retrieved from https://www.youtube.com/watch?v=fidq3jow8bc

The Simple The Truth2/BBC four. (2015). Daniel Ellsberg exposes the US government (Pentagon Papers Documentary) Part 1-9.avi. YouTube/BBCfour. Retrieved from https://www.youtube.com/watch?v= zPdXOZ5okE

The Telegraph. (2014, June 3). Oliver Stone: Edward Snowden is a hero to me. The Telegraph. Retrieved from http://www.telegraph.co.uk/news/worldnews/wikileaks/10872149/Oliver-StoneEdward-Snowden-is-a-hero-to-me.html

Time. (2002-2003, December 30-January 6). Persons of the year: The interview, Time, 58-60. Toobin, J. (2013, June 10). Edward Snowden is no hero. The New Yorker. Retrieved from http://www.newyorker.com/news/daily-comment/edward-snowden-is-no-hero

Torfing, J. (1999). New theories of discourse: Laclau, Mouffe and Zizek. Malden, MA: WileyBlackwell. 
Varoli, M. (1995). For love of country: An essay on patriotism and nationalism. Oxford: Clarendon Press.

Walther, J. B., DeAndrea, D., Kim, J., \& Anthony, J. C. (2010). The influence of online comments on perceptions of antimarijuana public service announcements on YouTube. Human Communication Research, 36,(4), 469-492.

Wagner, A. (2013, July 8). Now with Alex Wagner. In Debating 'The Snowden Effect'. Retrieved from http://www.msnbc.com/now-with-alex-wagner/debating-the-snowden-effect

Wise, D. (2011, August). Leaks and the law: The story of Thomas Drake. The Smithsonian. Retrieved from http://www.smithsonianmag.com/history/leaks-and-the-law-the-storyof-thomas-drake-14796786/?no-ist

Wittgenstein, L. (2009). Philosophical investigations. (G.E.M. Anscombe, P.M.S. Hacker \& J. Schulte, Trans.). Malden, MA: Wiley-Blackwell. (Original work published 1953)

Wolpe, T. (2014, September 8). The Snowden effect: How it's still denting business in cloud security. ZDNet. Retrieved from http://www.zdnet.com/article/the-snowden-effecthow-its-still-denting-business-confidence-in-cloud-security/

Wu, A., W.K. Ma, W., \& W. L. Chan, W. (2015). “Whistleblower or Leaker?” Examining the portrayal and characterization of Edward Snowden in USA, UK, and HK posts. In W. W.K. Ma, A. H.K. Yuen, J. Park, W. W.F. Lau, L. Deng (Eds.). New Media, Knowledge Practices and Multiliteracies (53-66). Singapore: Springer.

Zeitchik, S. (2015, March 21). How Oliver Stone is tackling the Edward Snowden story. South China Morning Post. Retrieved from http://www.scmp.com/lifestyle/artsculture/article/1742700/how-oliver-stone-tackling-edward-snowden-story 


\section{Appendices}

\section{Appendix A: Nvivo Screen Shots}

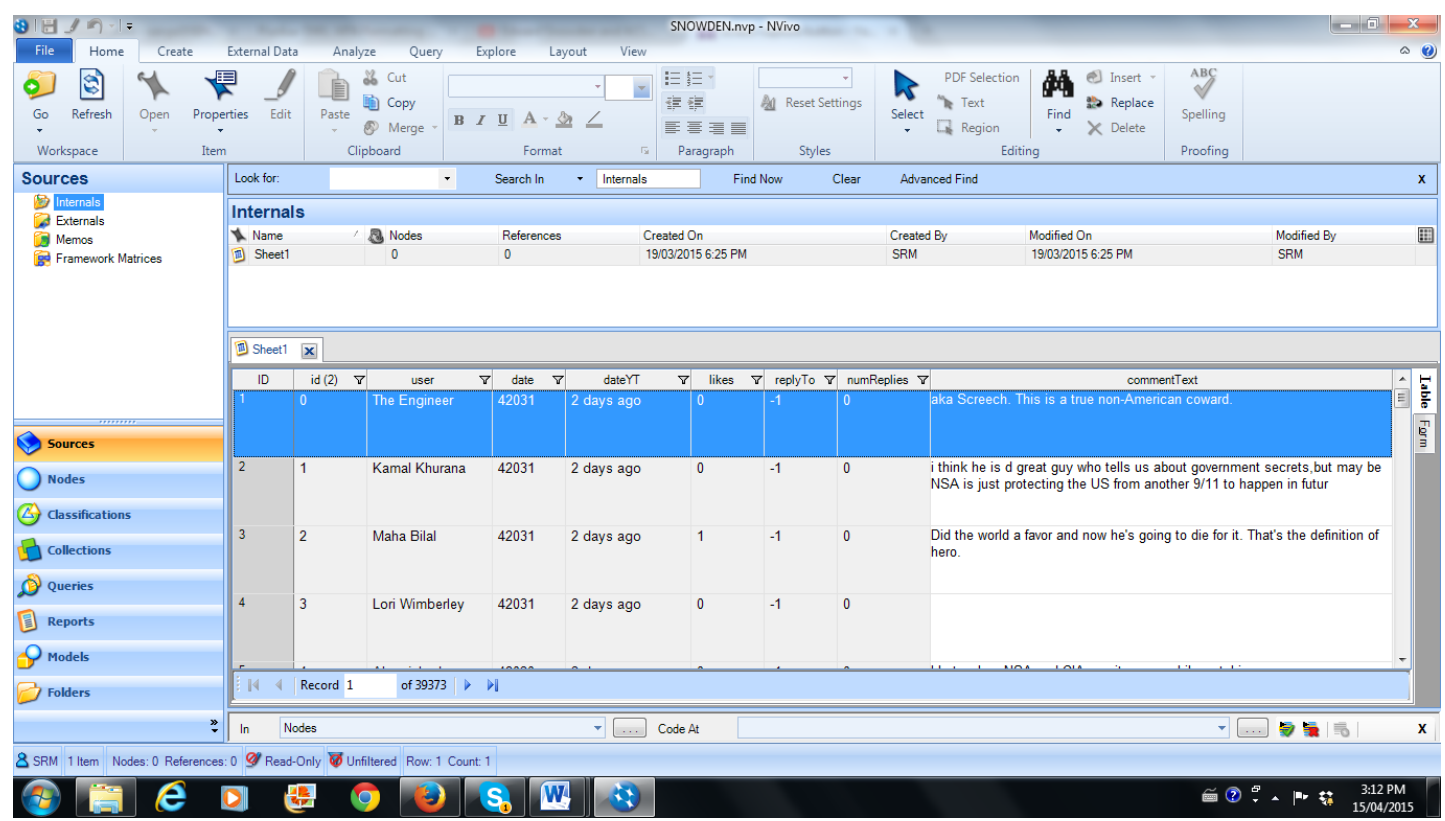

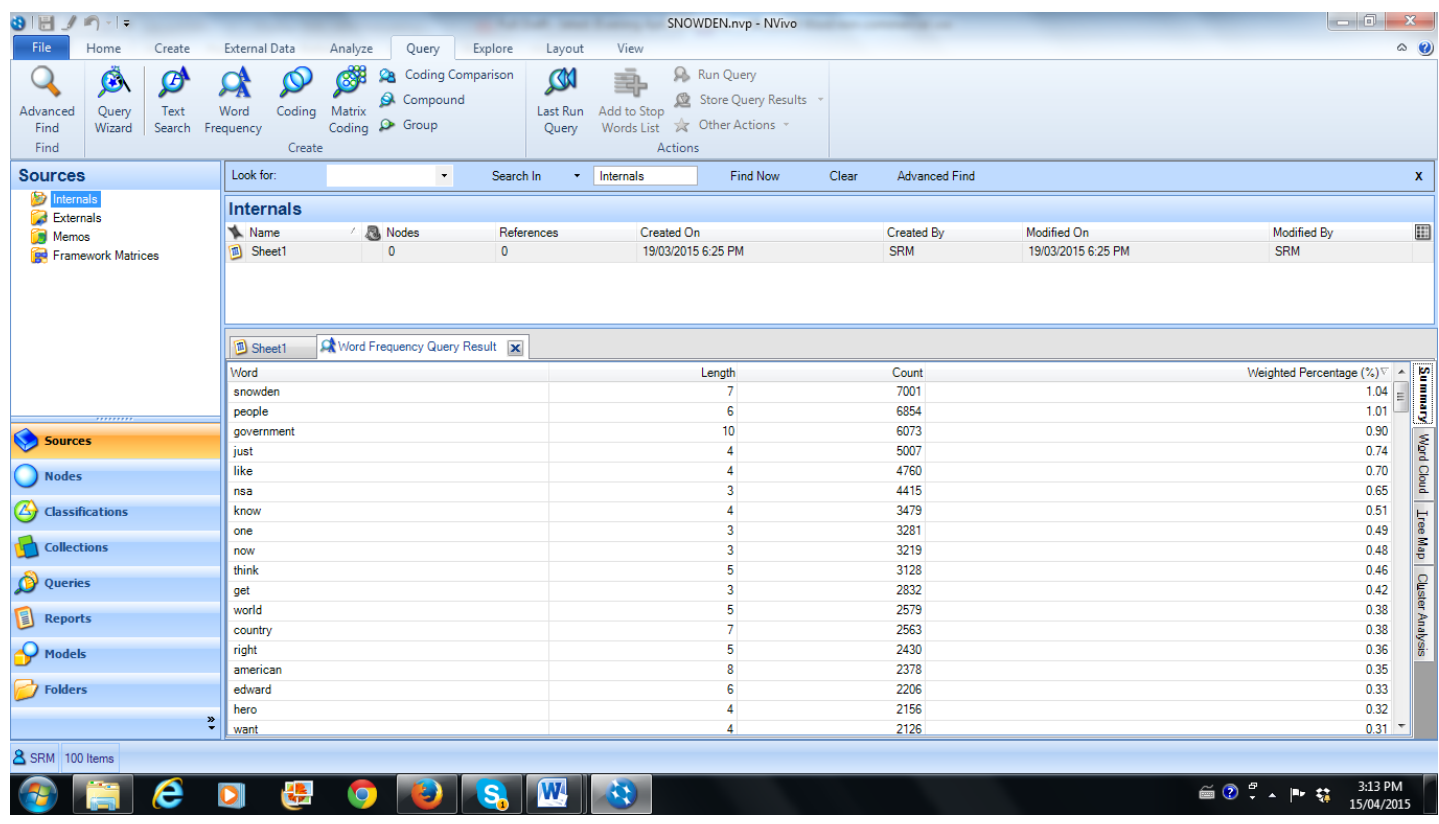




\section{Appendix B: Table of Snowden-Interview videos}

\begin{tabular}{|c|c|c|c|}
\hline $\begin{array}{l}\text { Title of } \\
\text { Video }\end{array}$ & $\begin{array}{l}\text { Date } \\
\text { Published }\end{array}$ & $\begin{array}{l}\text { \# of } \\
\text { Views } \\
\text { (approx.) }\end{array}$ & URL \\
\hline $\begin{array}{l}\text { Edward } \\
\text { Snowden NBC } \\
\text { News (full } \\
\text { interview) }\end{array}$ & $\begin{array}{l}\text { May } 28^{\text {th }} \\
2014\end{array}$ & 6,300 & $\begin{array}{l}\text { http://www.dailymotion.com/video/x1xfc4b edward- } \\
\text { snowden-nbc-news-full-interview-may-28-2014 news }\end{array}$ \\
\hline $\begin{array}{l}\text { NSA } \\
\text { Whistleblower } \\
\text { Edward } \\
\text { Snowden: 'I } \\
\text { don't want to } \\
\text { live in a world } \\
\text { that does these } \\
\text { sort of things' }\end{array}$ & June $9^{\text {th }}, 2013$ & $3,000,000$ & https://www.youtube.com/watch?v=5yB3ngfu-rM \\
\hline $\begin{array}{l}\text { Edward } \\
\text { Snowden: } \\
\text { Here's how we } \\
\text { take back the } \\
\text { internet }\end{array}$ & $\begin{array}{l}\text { March } 18^{\text {th }}, \\
2014\end{array}$ & $\begin{array}{l}\text { 1, 100,ooo } \\
\text { (YouTube) } \\
2,900,000 \\
\text { (Ted) }\end{array}$ & https://www.youtube.com/watch?v=yVwAodrjZMY \\
\hline $\begin{array}{l}\text { The Virtual } \\
\text { Interview: } \\
\text { Edward } \\
\text { Snowden - The } \\
\text { New Yorker } \\
\text { Festival }\end{array}$ & $\begin{array}{l}\text { October 11, } \\
2014\end{array}$ & 320,000 & https://www.youtube.com/watch?v=fidq3jow8bc \\
\hline $\begin{array}{l}\text { Edward } \\
\text { Snowden and } \\
\text { ACLU at SXSW } \\
\text { (non-optimized } \\
\text { audio version) }\end{array}$ & $\begin{array}{l}\text { March, } 10^{\text {th }}, \\
2014\end{array}$ & 240,000 & https://www.youtube.com/watch?v=CPrDqoaHHSY \\
\hline
\end{tabular}


Appendix C: Top-40 word frequency table + 'patriot' using 'Exact' setting on Nvivo.

\begin{tabular}{|c|c|c|}
\hline Rank & Word & \# of hits \\
\hline 1 & snowden & 7001 \\
\hline 2 & people & 6854 \\
\hline 3 & government & 6073 \\
\hline 4 & just & 5007 \\
\hline 5 & like & 4760 \\
\hline 6 & nsa & 4415 \\
\hline 7 & know & 3479 \\
\hline 8 & one & 3281 \\
\hline 9 & now & 3219 \\
\hline 10 & think & 3128 \\
\hline 11 & get & 2832 \\
\hline 12 & world & 2579 \\
\hline 13 & country & 2563 \\
\hline 14 & right & 2430 \\
\hline 15 & american & 2378 \\
\hline 16 & edward & 2206 \\
\hline 17 & hero & 2156 \\
\hline 18 & want & 2126 \\
\hline 19 & obama & 2095 \\
\hline 20 & even & 2092 \\
\hline 21 & good & 1936 \\
\hline 22 & see & 1933 \\
\hline 23 & time & 1932 \\
\hline 24 & america & 1855 \\
\hline 25 & well & 1801 \\
\hline 26 & man & 1790 \\
\hline 27 & information & 1769 \\
\hline 28 & make & 1706 \\
\hline 29 & need & 1704 \\
\hline 30 & really & 1647 \\
\hline 31 & going & 1632 \\
\hline 32 & guy & 1620 \\
\hline 33 & china & 1564 \\
\hline 34 & way & 1542 \\
\hline 35 & traitor & 1482 \\
\hline 36 & russia & 1468 \\
\hline 37 & freedom & 1380 \\
\hline 38 & life & 1355 \\
\hline 39 & fuck & 1334 \\
\hline 40 & nothing & 1317 \\
\hline 144 & patriot & 685 \\
\hline
\end{tabular}


Appendix D: Top-40 word frequency table + 'patriot' using 'Exact+ 1' setting on Nvivo.

\begin{tabular}{|c|c|c|}
\hline Rank & Word & \#of hits \\
\hline 1 & snowdens & 7106 \\
\hline 2 & peoples' & 6967 \\
\hline 3 & governments & 6610 \\
\hline 4 & liking & 5098 \\
\hline 5 & justly & 5012 \\
\hline 6 & nsa & 4450 \\
\hline 7 & knows & 4072 \\
\hline 8 & americans & 3702 \\
\hline 9 & rights & 3683 \\
\hline 10 & getting & 3611 \\
\hline 11 & thinks & 3571 \\
\hline 12 & ones & 3561 \\
\hline 13 & countrys & 3554 \\
\hline 14 & now & 3221 \\
\hline 15 & want & 2988 \\
\hline 16 & making & 2704 \\
\hline 17 & worlds & 2623 \\
\hline 18 & fucks & 2580 \\
\hline 19 & thing & 2470 \\
\hline 20 & needs & 2370 \\
\hline 21 & heros & 2332 \\
\hline 22 & spying & 2327 \\
\hline 23 & timing & 2275 \\
\hline 24 & edwards & 2239 \\
\hline 25 & mans & 2166 \\
\hline 26 & using & 2141 \\
\hline 27 & obamas & 2140 \\
\hline 28 & even & 2109 \\
\hline 29 & guys & 2108 \\
\hline 30 & seeing & 2101 \\
\hline 31 & informs & 2031 \\
\hline 32 & goods & 1980 \\
\hline 33 & americas & 1897 \\
\hline 34 & living & 1893 \\
\hline 35 & wells & 1812 \\
\hline 36 & calls & 1807 \\
\hline 37 & traitors & 1741 \\
\hline 38 & taking & 1706 \\
\hline 39 & ways & 1705 \\
\hline 40 & looks & 1667 \\
\hline 121 & patriot & 878 \\
\hline
\end{tabular}




\section{Appendix E: top-10 YouTube comments ranked by the most-replies (capped at 11).}

\begin{tabular}{|c|c|c|c|c|}
\hline Rank & ID & $\begin{array}{l}\text { \# of } \\
\text { replies }\end{array}$ & Likes & Text \\
\hline \multirow[t]{2}{*}{$\mathbf{1}$} & $\begin{array}{l}\text { Institutional } \\
\text { Pseudonym }\end{array}$ & 70 & 14 & That thief is a lying treasonous cunt. \\
\hline & $\begin{array}{l}\text { Personal } \\
\text { Pseudonym }\end{array}$ & $\mathbf{3 8}$ & 6 & $\begin{array}{l}\text { Dear Mr. Snowden, I'm only reminding you of the } \\
\text { ramifications of your actions despite how much } \\
\text { the Government has erred. Intelligence, be it } \\
\text { gathered underhanded or not, was what helped } \\
\text { create this country and defend the our notion of } \\
\text { Freedom, Liberty and Privacy. Let me remind you } \\
\text { that it was this "evil institution and society" that } \\
\text { bought for you freedom, liberty, and privacy. } \\
\text { While this "society" certainly has committed ills, } \\
\text { you don't have the right to pass down judgment. } \\
\text { The fact of the matter is your actions do not make } \\
\text { this society a better place because society does not } \\
\text { go according to one man's beliefs. Besides, } \\
\text { Freedom and Privacy come at a cost. We cannot } \\
\text { have absolute Freedom and absolute Privacy } \\
\text { because that would cause anarchy. }\end{array}$ \\
\hline 2 & Proper Name & 37 & 246 & $\begin{array}{l}\text { I'm sure the government is making a note of all } \\
\text { who have viewed this video. }\end{array}$ \\
\hline 3 & Proper Name & 36 & 7 & $\begin{array}{l}\text { Snowden is a fake. Who gets up and just leaves } \\
\text { their job and family then gets media support when } \\
\text { the } \$ \text { controlling the media also controls the } \\
\text { military??? Nobody. Thats who. Fools, Snowden is } \\
\text { covering their ass and distracting you from the real } \\
\text { story. Come interview me, any takers wanna lose } \\
\text { their career? Thats what will happen to anyone } \\
\text { that airs my story on any network, i guarantee it }\end{array}$ \\
\hline 4 & Proper Name & 35 & 9 & $\begin{array}{l}\text { Edward Snowden has basically went from this big } \\
\text { heroic whistleblower who reveled the NSA's } \\
\text { limitless ends of how they are invading your } \\
\text { privacy, to this whiny , pouty asshole who is } \\
\text { starved for attention. He's pretty much worn out } \\
\text { his welcome in every country he's tried to make an } \\
\text { asylum deal with, including Russia who has told } \\
\text { him to knock off the act until they get a chance to } \\
\text { deal with the US directly over him. If he truly } \\
\text { believes in his "mission", then quit running like a } \\
\text { coward. Release ALL your information publicly } \\
\text { now, then face your fate like a man. I'd at least } \\
\text { have more respect for him then, right now? He's } \\
\text { just a coward running scared and releasing really } \\
\text { NO information. Seems to be more talk than } \\
\text { action }\end{array}$ \\
\hline 5 & $\begin{array}{l}\text { Recognizable } \\
\text { Institution: } \\
\text { (Washington Post) }\end{array}$ & 33 & 92 & $\begin{array}{l}\text { Hong Kong seen as unlikely refuge for NSA leaker } \\
\text { Update: Out of all the places Edward Snowden } \\
\text { could have chosen to hide, he selected this city, } \\
\text { with its towering buildings, glittering nightscape } \\
\text { and reputation for protecting free speech. } \\
\text { http://wapo.st/17Cl4SI But some in Hong Kong }\end{array}$ \\
\hline
\end{tabular}




\begin{tabular}{|c|c|c|c|c|}
\hline & & & & $\begin{array}{l}\text { aren't sure what the man who has admitted } \\
\text { leaking information about a top-secret U.S. } \\
\text { surveillance program is doing in this semi- } \\
\text { autonomous jurisdiction, which has a strong } \\
\text { extradition treaty with the United States. }\end{array}$ \\
\hline 6 & Proper Name & 29 & 5 & $\begin{array}{l}\text { What a cunt. One day the United States is going to } \\
\text { get him back (can easily be done by making deals } \\
\text { with Russia) and he's going to wish he was never } \\
\text { born when he reaches U.S. soil again. }\end{array}$ \\
\hline 6 & $\begin{array}{l}\text { Pseudonym with } \\
\text { cultural reference }\end{array}$ & 29 & 0 & $\begin{array}{l}\text { We all know what the NSA is, but Snowden didn't } \\
\text { do himself or his supporters any favours. In the } \\
\text { case of Australia (to name one of many countries } \\
\text { affected), he released info on Australia spying on } \\
\text { Indonesia during the start of a new government } \\
\text { causing not only that country damage but also the } \\
\text { government. I fail to see the justification from his } \\
\text { comments in this video of the actions he has taken. }\end{array}$ \\
\hline 7 & Proper Name & $\mathbf{2 8}$ & 3 & $\begin{array}{l}\text { This guy is doing there right thing in the wrong } \\
\text { way. I'm just worried at how many U.S. soldier's } \\
\text { lives he's putting at risk }\end{array}$ \\
\hline 8 & $\begin{array}{l}\text { Recognizable } \\
\text { Institution } \\
\text { (German): (ZDF } \\
\text { heute) }\end{array}$ & 21 & 19 & $\begin{array}{l}\text { "Ich will in so einer Welt nicht leben" Daten- } \\
\text { Spionage-Skandal: Unter dem Namen PRISM hat } \\
\text { die USA ein Programm gefahren, dass den } \\
\text { Geheimdiensten ermöglicht, nahezu sämtliche } \\
\text { Daten der Nutzer von Social Media, Email, Skype } \\
\text { und Co abzugreifen. In diesem Video-Interview } \\
\text { meldet sich der "Whistleblower" (engl.: } \\
\text { Geheimnisverräter) zu Wort. }\end{array}$ \\
\hline 8 & Proper Name & 21 & 2 & $\begin{array}{l}\text { Snowden is not a 'whistleblower'-- the term refers } \\
\text { to exposing fraud or corruption. Snowden } \\
\text { betrayed state secrets, and every state keeps } \\
\text { secrets in order to function. The secrets revealed } \\
\text { by Snowden do not support the paranoid } \\
\text { conspiracy theories they have been used to justify. }\end{array}$ \\
\hline
\end{tabular}




\section{Appendix F: top-10 YouTube comments ranked by number of 'likes' (capped at 12).}

\begin{tabular}{|c|c|c|c|c|}
\hline Rank & ID & \# of likes & $\begin{array}{l}\text { \#of } \\
\text { replies }\end{array}$ & Text \\
\hline \multirow[t]{2}{*}{$\mathbf{1}$} & Personal Name & 246 & 37 & $\begin{array}{l}\text { I'm sure the government is making a note of all } \\
\text { who have viewed this video }\end{array}$ \\
\hline & $\begin{array}{l}\text { Recognizable } \\
\text { Institution } \\
\text { (Washington Post) }\end{array}$ & 92 & 33 & $\begin{array}{l}\text { Hong Kong seen as unlikely refuge for NSA } \\
\text { leaker Update: Out of all the places Edward } \\
\text { Snowden could have chosen to hide, he selected } \\
\text { this city, with its towering buildings, glittering } \\
\text { nightscape and reputation for protecting free } \\
\text { speech. http://wapo.st/17Cl4SI But some in } \\
\text { Hong Kong aren't sure what the man who has } \\
\text { admitted leaking information about a top-secret } \\
\text { U.S. surveillance program is doing in this semi- } \\
\text { autonomous jurisdiction, which has a strong } \\
\text { extradition treaty with the United States. }\end{array}$ \\
\hline 2 & $\begin{array}{l}\text { (Lettering in } \\
\text { Mandarin) }\end{array}$ & 87 & o & He is a hero! $* *$ \\
\hline 3 & Personal Name & 77 & 16 & $\begin{array}{l}\text { Edward Snowden. A former CIA technician who } \\
\text { worked for the NSA and says that he gave up "a } \\
\text { very comfortable life" that included a salary of } \\
\text { roughly } \$ 200, \text { ooo, a girlfriend with whom he } \\
\text { shared a home in Hawaii, a stable career, and a } \\
\text { family he loves. "I'm willing to sacrifice all of that } \\
\text { because I can't in good conscience allow the US } \\
\text { government to destroy privacy, internet freedom } \\
\text { and basic liberties for people around the world } \\
\text { with this massive surveillance machine they're } \\
\text { secretly building." He fled to Hong Kong as he is } \\
\text { aware the US government will come after him } \\
\text { and he expects more safety in the Chinese } \\
\text { enclave than on American soil. Hong Kong has } \\
\text { autonomy over extradition so it won't be the } \\
\text { Chinese government who will decide on the } \\
\text { process, although there will no doubt be a } \\
\text { diplomatic argument. China is ultimately in } \\
\text { charge of Hong Kong's foreign relations so it will } \\
\text { be a complex process. His hopes are on asylum in } \\
\text { Iceland, but his chances to even arrive there in } \\
\text { freedom seem slim. Ultimately I expect Hong } \\
\text { Kong to extradite him to the US where he will } \\
\text { follow Bradley Manning and disappear from the } \\
\text { face of the earth. High cost of high principles. } \\
\text { \#NSA }\end{array}$ \\
\hline T-4 & Personal Pseudonym & 75 & 20 & $\begin{array}{l}\text { Edward Snowden is the ONLY American I } \\
\text { respect. He woke up to the truth about his evil } \\
\text { Country. I just hope he is telling the Russian } \\
\text { authorities everything there is to know about the } \\
\text { NSA and CIA etc......... }\end{array}$ \\
\hline T-4 & $\begin{array}{l}\text { Cryptic Numerical } \\
\text { Pseudonym }\end{array}$ & 75 & $\mathrm{O}$ & $\begin{array}{l}\text { Yea, what a cunt, releasing all the information } \\
\text { about the government spying on its own people. } \\
\text { Ignorance is bliss I suppose ** }\end{array}$ \\
\hline 5 & $\begin{array}{l}\text { Pseudonym with } \\
\text { cultural reference }\end{array}$ & 69 & 8 & $\begin{array}{l}\text { more people need to speak out, fuck this corrupt } \\
\text { government }\end{array}$ \\
\hline 6 & Personal Name & 65 & $\mathrm{O}$ & $\begin{array}{l}\text { This guy is a true American hero. A guess you } \\
\text { like your whole life being recorded like the }\end{array}$ \\
\hline
\end{tabular}




\begin{tabular}{|c|c|c|c|c|}
\hline & & & & Trueman Show. ${ }^{* *}$ \\
\hline T-7 & $\begin{array}{l}\text { Pseudonym with } \\
\text { cultural reference }\end{array}$ & 62 & 10 & $\begin{array}{l}\text { Obama to Putin: "Your violating Ukraine!" Putin } \\
\text { to Obama: "Your violating Libya" Obama to } \\
\text { Putin: "I was keeping Americans safe" Putin to } \\
\text { Obama: "I was keeping Russians safe" EXPLAIN } \\
\text { THIS SHIT TO ME! }\end{array}$ \\
\hline T-7 & $\begin{array}{l}\text { Pseudonym with } \\
\text { cultural reference }\end{array}$ & 62 & 5 & $\begin{array}{l}\text { Dear viewers, keep in mind that the government } \\
\text { is calling for Snowden to return to the US to have } \\
\text { his day in court. What you may not know is, since } \\
\text { he is being charged under the Espionage Act he } \\
\text { will not be tried by a jury of his peers. Since } \\
\text { evidence presented in trial will be classified, the } \\
\text { transcript of his trial will be classified and not } \\
\text { accessible to the public. This all but guarantees a } \\
\text { guilty verdict therefore he would be wise to stay } \\
\text { out of the country until a president pardons him. }\end{array}$ \\
\hline 8 & Personal Name & 59 & 1 & Hero \\
\hline 9 & $\begin{array}{l}\text { Personal Name with } \\
\text { numeric attachment }\end{array}$ & 57 & 0 & $\begin{array}{l}\text { Really? You want to hang a guy that exposed the } \\
\text { wrongdoings of a government against its people? } \\
\text { You're a douche. }{ }^{* *}\end{array}$ \\
\hline
\end{tabular}




\section{Appendix G: Stage by Stage Coding Practice}

\section{Full Text}

June 10, 2013

\section{Edward Snowden Is No Hero}

\section{By Jeffrey Toobin}

Edward Snowden, a twenty-nine-year-old former C.I.A. employee and current government contractor, has leaked news of National Security Agency programs that collect vast amounts of information about the telephone calls made by millions of Americans, as well as e-mails and other files of foreign targets and their American connections. For this, some, including my colleague John Cassidy, are hailing him as a hero and a whistle-blower. He is neither. He is, rather, a grandiose narcissist who deserves to be in prison.

Snowden provided information to the Washington Post and the Guardian, which also posted $\underline{\mathrm{a}}$ video interview with him. In it, he describes himself as appalled by the government he served:

The N.S.A. has built an infrastructure that allows it to intercept almost everything. With this capability, the vast majority of human communications are automatically ingested without targeting. If I wanted to see your e-mails or your wife's phone, all I have to do is use intercepts. I can get your e-mails, passwords, phone records, credit cards.

I don't want to live in a society that does these sort of things... I do not want to live in a world where everything I do and say is recorded. That is not something I am willing to support or live under.

What, one wonders, did Snowden think the N.S.A. did? Any marginally attentive citizen, much less N.S.A. employee or contractor, knows that the entire mission of the agency is to intercept electronic communications. Perhaps he thought that the N.S.A. operated only outside the United States; in that case, he hadn't been paying very close attention. In any event, Snowden decided that he does not "want to live in a society" that intercepts private communications. His latterday conversion is dubious.

And what of his decision to leak the documents? Doing so was, as he more or less acknowledges, a crime. Any government employee or contractor is warned repeatedly that the unauthorized disclosure of classified information is a crime. But Snowden, apparently, was answering to a higher calling. "When you see everything you realize that some of these things are abusive," he said. "The awareness of wrongdoing builds up. There was not one morning when I woke up. It was a natural process." These were legally authorized programs; in the case of Verizon Business's phone records, Snowden certainly knew this, because he leaked the very court order that approved the continuation of the project. So he wasn't blowing the whistle on anything illegal; he was exposing something that failed to meet his own standards of propriety. The question, of course, is whether the government can function when all of its employees (and 
contractors) can take it upon themselves to sabotage the programs they don't like. That's what Snowden has done.

What makes leak cases difficult is that some leaking-some interaction between reporters and sources who have access to classified information-is normal, even indispensable, in a society with a free press. It's not easy to draw the line between those kinds of healthy encounters and the wholesale, reckless dumping of classified information by the likes of Snowden or Bradley Manning. Indeed, Snowden was so irresponsible in what he gave the Guardian and the Post that even these institutions thought some of it should not be disseminated to the public. The Post decided to publish only four of the forty-one slides that Snowden provided. Its exercise of judgment suggests the absence of Snowden's.

Snowden fled to Hong Kong when he knew publication of his leaks was imminent. In his interview, he said he went there because "they have a spirited commitment to free speech and the right of political dissent." This may be true, in some limited way, but the overriding fact is that Hong Kong is part of China, which is, as Snowden knows, a stalwart adversary of the United States in intelligence matters. (Evan Osnos has more on that.) Snowden is now at the mercy of the Chinese leaders who run Hong Kong. As a result, all of Snowden's secrets may wind up in the hands of the Chinese government-which has no commitment at all to free speech or the right to political dissent. And that makes Snowden a hero?

The American government, and its democracy, are flawed institutions. But our system offers legal options to disgruntled government employees and contractors. They can take advantage of federal whistle-blower laws; they can bring their complaints to Congress; they can try to protest within the institutions where they work. But Snowden did none of this. Instead, in an act that speaks more to his ego than his conscience, he threw the secrets he knew up in the air-and trusted, somehow, that good would come of it. We all now have to hope that he's right. 


\section{Coding Stage 1: Identifying arguments in bold}

June 10, 2013

\section{Edward Snowden Is No Hero}

\section{By Jeffrey Toobin}

Edward Snowden, a twenty-nine-year-old former C.I.A. employee and current government contractor, has leaked news of National Security Agency programs that collect vast amounts of information about the telephone calls made by millions of Americans, as well as e-mails and other files of foreign targets and their American connections. For this, some, including my colleague John Cassidy, are hailing him as a hero and a whistle-blower. He is neither. He is, rather, a grandiose narcissist who deserves to be in prison.

Snowden provided information to the Washington Post and the Guardian, which also posted $\underline{\text { a }}$ video interview with him. In it, he describes himself as appalled by the government he served:

The N.S.A. has built an infrastructure that allows it to intercept almost everything. With this capability, the vast majority of human communications are automatically ingested without targeting. If I wanted to see your e-mails or your wife's phone, all I have to do is use intercepts. I can get your e-mails, passwords, phone records, credit cards.

I don't want to live in a society that does these sort of things... I do not want to live in a world where everything I do and say is recorded. That is not something I am willing to support or live under.

\section{What, one wonders, did Snowden think the N.S.A. did?}

Any marginally attentive citizen, much less N.S.A. employee or contractor, knows that the entire mission of the agency is to intercept electronic communications. Perhaps he thought that the N.S.A. operated only outside the United States; in that case, he hadn't been paying very close attention. In any event, Snowden decided that he does not "want to live in a society" that intercepts private communications. His latter-day conversion is dubious.

And what of his decision to leak the documents? Doing so was, as he more or less acknowledges,

a crime. Any government employee or contractor is warned repeatedly that the unauthorized disclosure of classified information is a crime. But Snowden, apparently, was answering to a higher calling. "When you see everything you realize that some of these things are abusive," he said. "The awareness of wrongdoing builds up. There was not one morning when I woke up. It was a natural process." These were legally authorized programs; in the case of Verizon Business's phone records, Snowden certainly knew this, because he leaked the very court order that approved the 
continuation of the project. So he wasn't blowing the whistle on anything illegal; he was exposing something that failed to meet his own standards of propriety. The question, of course, is whether the government can function when all of its employees (and contractors) can take it upon themselves to sabotage the programs they don't like. That's what Snowden has done.

What makes leak cases difficult is that some leaking-some interaction between reporters and sources who have access to classified information-is normal, even indispensable, in a society with a free press. It's not easy to draw the line between those kinds of healthy encounters and the wholesale, reckless dumping of classified information by the likes of Snowden or Bradley Manning. Indeed, Snowden was so irresponsible in what he gave the Guardian and the Post that even these institutions thought some of it should not be disseminated to the public. The Post decided to publish only four of the fortyone slides that Snowden provided. Its exercise of judgment suggests the absence of Snowden's.

Snowden fled to Hong Kong when he knew publication of his leaks was imminent. In his interview, he said he went there because "they have a spirited commitment to free speech and the right of political dissent." This may be true, in some limited way, but the overriding fact is that Hong Kong is part of China, which is, as Snowden knows, a stalwart adversary of the United States in intelligence matters. (Evan Osnos has more on that.) Snowden is now at the mercy of the Chinese leaders who run Hong Kong. As a result, all of Snowden's secrets may wind up in the hands of the Chinese government-which has no commitment at all to free speech or the right to political dissent. And that makes Snowden a hero? 
The American government, and its democracy, are flawed institutions. But our system offers legal options to disgruntled government employees and contractors. They can take advantage of federal whistle-blower laws; they can bring their complaints to Congress; they can try to protest within the institutions where they work. But Snowden did none of this. Instead, in an act that speaks more to his ego than his

conscience, he threw the secrets he knew up in the air-and trusted, somehow, that good would come of it. We all now have to hope that he's right. 


\section{Coding Stage 2: Labelling arguments}

June 10, 2013

\section{Edward Snowden Is No Hero}

\section{By Jeffrey Toobin}

Edward Snowden, a twenty-nine-year-old former C.I.A. employee and current government contractor, has leaked news of National Security Agency programs that collect vast amounts of information about the telephone calls made by millions of Americans, as well as e-mails and other files of foreign targets and their American connections. For this, some, including my colleague John Cassidy, are hailing him as a hero and a whistle-blower. He is neither. He is, rather, a grandiose narcissist who deserves to be in prison. (delegit character namecalling)

Snowden provided information to the Washington Post and the Guardian, which also posted $\underline{\text { a }}$ video interview with him. In it, he describes himself as appalled by the government he served:

The N.S.A. has built an infrastructure that allows it to intercept almost everything. With this capability, the vast majority of human communications are automatically ingested without targeting. If I wanted to see your e-mails or your wife's phone, all I have to do is use intercepts. I can get your e-mails, passwords, phone records, credit cards.

I don't want to live in a society that does these sort of things... I do not want to live in a world where everything I do and say is recorded. That is not something I am willing to support or live under.

What, one wonders, did Snowden think the N.S.A. did? (delegit character - naïve) Any marginally attentive citizen, much less N.S.A. employee or contractor, knows that the entire mission of the agency is to intercept electronic communications. Perhaps he thought that the N.S.A. operated only outside the United States; in that case, he hadn't been paying very close attention. In any event, Snowden decided that he does not "want to live in a society" that intercepts private communications. His latter-day conversion is dubious. (delegit character questioning motivations, intent)

And what of his decision to leak the documents? Doing so was, as he more or less acknowledges, a crime. (delegit character - labelling a criminal) Any government employee or contractor is warned repeatedly that the unauthorized disclosure of classified information is a crime. (criminal) But Snowden, apparently, was answering to a higher calling. "When you see everything you realize that some of these things are abusive," he said. "The awareness of wrongdoing builds up. There was not one morning when I woke up. It was a natural process." These were legally authorized programs; in the case of Verizon Business's phone records, Snowden certainly knew this, because he leaked the very court order that approved the continuation of the project. So he wasn't blowing the whistle on anything illegal; he was 
exposing something that failed to meet his own standards of propriety. The question, of course, is whether the government can function when all of its employees (and contractors) can take it upon themselves to sabotage the programs they don't like. That's what Snowden has done.

\section{(delegit actions - overriding the system with his own values)}

What makes leak cases difficult is that some leaking-some interaction between reporters and sources who have access to classified information-is normal, even indispensable, in a society with a free press. It's not easy to draw the line between those kinds of healthy encounters and the wholesale, reckless dumping of classified information by the likes of Snowden or Bradley Manning. Indeed, Snowden was so irresponsible in what he gave the Guardian and the Post that even these institutions thought some of it should not be disseminated to the public. The Post decided to publish only four of the forty-one slides that Snowden provided. Its exercise of judgment suggests the absence of Snowden's. (deligit actions - acting irresponsibly, unethically / delegit character - no judgement)

Snowden fled to Hong Kong when he knew publication of his leaks was imminent. In his interview, he said he went there because "they have a spirited commitment to free speech and the right of political dissent.” This may be true, in some limited way, but the overriding fact is that Hong Kong is part of China, which is, as Snowden knows, a stalwart adversary of the United States in intelligence matters. (linking to China - enemy) (Evan Osnos has more on that.) Snowden is now at the mercy of the Chinese leaders who run Hong Kong. (conjecture) As a result, all of Snowden's secrets may wind up in the hands of the Chinese government-which has no commitment at all to free speech or the right to political dissent. And that makes Snowden a hero? (somewhat conjectural / danger of China) 
Coding Stage 3: Separating arguments from text to compare with others

ARTICLE 1 - Toobin /New Yorker/ June 10, 2013

grandiose narcissist who deserves to be in prison. (delegit character - namecalling) What, one wonders, did Snowden think the N.S.A. did? (delegit character - naïve) In any event, Snowden decided that he does not "want to live in a society" that intercepts private communications. His latter-day conversion is dubious. (delegit character - questioning motivations, intent) a crime. (delegit character - labelling a criminal) a crime. (criminal) But Snowden, apparently, was answering to a higher calling.(questioning motives/ character) ". So he wasn't blowing the whistle on anything illegal; he was exposing something that failed to meet his own standards of propriety. The question, of course, is whether the government can function when all of its employees (and contractors) can take it upon themselves to sabotage the programs they don't like. That's what Snowden has done. (delegit actions - overriding the system with his own values) wholesale, reckless dumping of classified information by the likes of Snowden or Bradley Manning. Indeed, Snowden was so irresponsible in what he gave the Guardian and the Post that even these institutions thought some of it should not be disseminated to the public. The Post decided to publish only four of the forty-one slides that Snowden provided. Its exercise of judgment suggests the absence of Snowden's. (deligit actions - acting irresponsibly, unethically / delegit character no judgement) This may be true, in some limited way, but the overriding fact is that Hong Kong is part of China, which is, as Snowden knows, a stalwart adversary of the United States in intelligence matters. (linking to China - enemy) As a result, all of Snowden's secrets may wind up in the hands of the Chinese government-which has no commitment at all to free speech or the right to political dissent. And that makes Snowden a hero? (somewhat conjectural / danger of China) 


\section{Appendix H: Screenshots of Edward Snowden action figure}
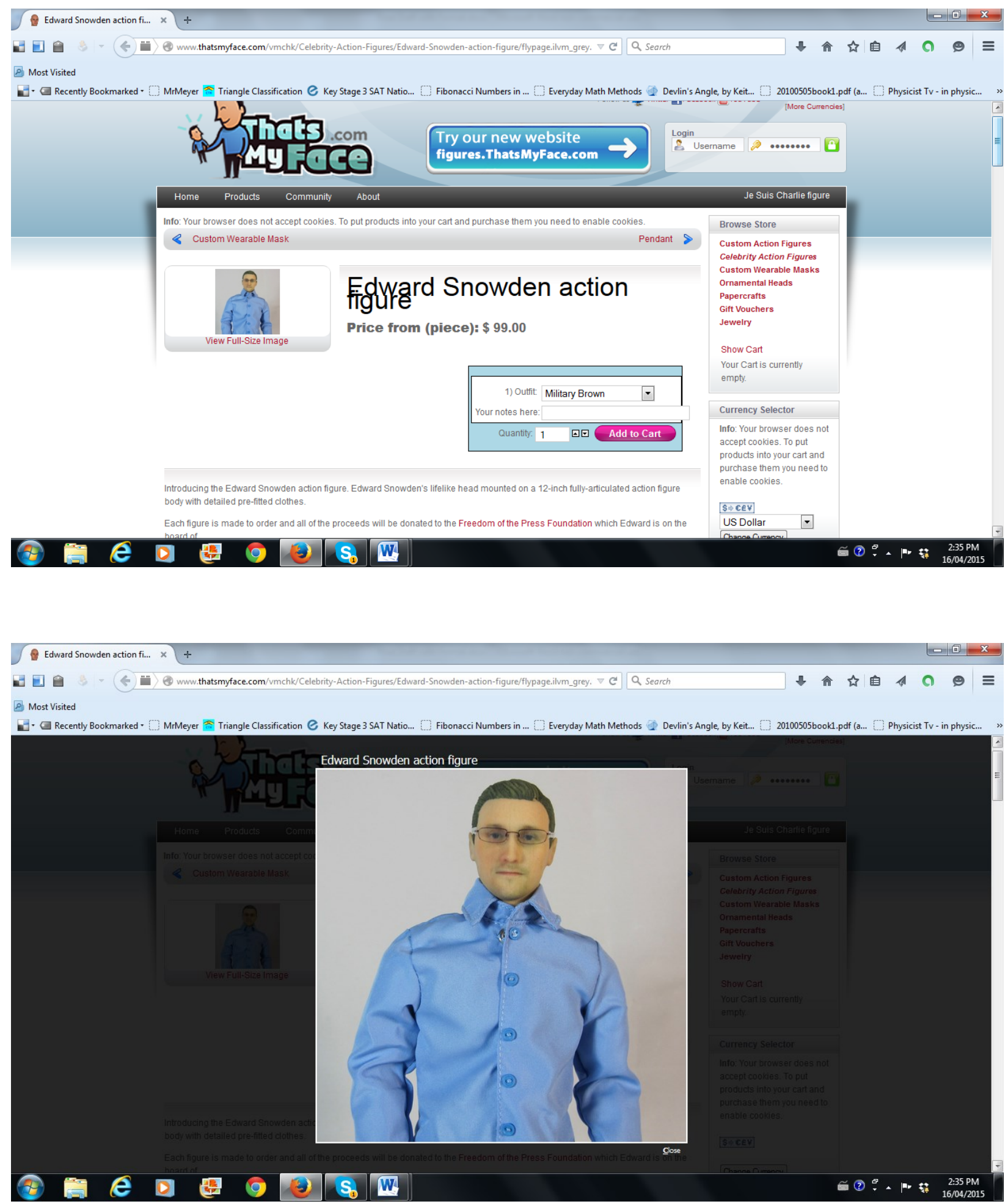